\title{
Effects of face velocity, cross-draft velocity and interventions on the performance of a benchtop enclosing hood
}

\author{
Xinjian He \\ West Virginia University
}

Follow this and additional works at: https://researchrepository.wvu.edu/etd

\section{Recommended Citation}

$\mathrm{He}$, Xinjian, "Effects of face velocity, cross-draft velocity and interventions on the performance of a benchtop enclosing hood" (2010). Graduate Theses, Dissertations, and Problem Reports. 2150.

https://researchrepository.wvu.edu/etd/2150

This Thesis is protected by copyright and/or related rights. It has been brought to you by the The Research Repository @ WVU with permission from the rights-holder(s). You are free to use this Thesis in any way that is permitted by the copyright and related rights legislation that applies to your use. For other uses you must obtain permission from the rights-holder(s) directly, unless additional rights are indicated by a Creative Commons license in the record and/ or on the work itself. This Thesis has been accepted for inclusion in WVU Graduate Theses, Dissertations, and Problem Reports collection by an authorized administrator of The Research Repository @ WVU. For more information, please contact researchrepository@mail.wvu.edu. 


\title{
Effects of Face Velocity, Cross-Draft Velocity and Interventions on the Performance of $A$ Benchtop Enclosing Hood
}

\author{
By \\ Xinjian He \\ Thesis submitted to \\ The College of Engineering and Mineral Resources \\ at West Virginia University \\ In partial fulfillment of the requirements for the degree of \\ Master of Science \\ In \\ Industrial Hygiene and Safety
}

Steven E. Guffey, Ph.D., Chair

Warren R. Myers, Ph.D.

Wafik H. Iskander, Ph.D.

Department of Industrial and Management Systems Engineering

Morgantown, West Virginia

2010

Keywords: Tracer gas study, Ventilation, Manikin, Exposure assessment 


\section{Abstract}

\section{"Effects of Face Velocity, Cross-Draft Velocity and Interventions on the Performance of A Benchtop Enclosing Hood"}

\section{Xinjian He}

In industry, benchtop enclosing hoods are critical in protecting workers from airborne contaminants, but there is little research published about industrial enclosing hoods. Almost all hood research has been done on laboratory fume hoods.

A tracer gas method was used to study the performance of a single benchtop enclosing hood tested inside a $9 \mathrm{ft}$ high, $12 \mathrm{ft}$ wide and $40 \mathrm{ft}$ long wind tunnel. Freon134a concentrations were measured on an anthropometrically scaled, heated, breathing manikin holding a source between its hands while standing at the enclosing hood's face. Samples were taken at the nose $\left(C_{\text {nose }}\right)$, mouth $\left(C_{\text {mouth }}\right)$, inlet of the wind tunnel $\left(C_{\text {ambient }}\right)$, downstream of the wind tunnel $\left(C_{\text {downstream }}\right)$ and the exhaust duct $\left(C_{d u c t}\right)$. Each location was sampled at 0.15 LPM for 20 minutes.

The work was divided into two studies, each having a complete factorial design and two replicates of each treatment combination. Study-I tested the effects of hood face velocity at five levels $(111,140,170,200$ and $229 \mathrm{fpm})$ and wind tunnel cross-draft velocity at five levels $(14,26,36,46$ and $57 \mathrm{fpm})$ on the plain enclosing hood performance. Study-II determined the effects of different interventions added to the face of the same enclosing hood.

The results showed that hood face velocity, wind tunnel cross-draft velocity and different interventions had significant effects on the concentrations at $C_{\text {nose }}$ and $C_{\text {mouth }}$. Flanges, cowls, and most other interventions failed to consistently reduce exposures and often exacerbated them. However, the customized sash reduced exposures to nearly zero. It is also found that higher face velocity and cross-draft velocity were associated with lower $C_{\text {nose }}$ and $C_{\text {mouth }}$. 


\section{Acknowledgements}

This project has been supported by the Industrial and Management Systems Engineering Department (IMSE) and the National Institute for Occupational Safety and Health (NIOSH).

I would like to express my deepest gratitude to my academic and research advisor, Dr. Steven Guffey, who has given me tremendous help during my stay at WVU. His expert guidance and constant support helped me to conduct and complete this work.

I am indebted to Dr. Warren Myers for his encouragement and generous support. I would also like to thank Dr. Wafik Iskander for his continued support and for serving on my committee.

I especial want to thank Dr. William Dodrill and Braxton V. Lewis. Their valuable assistance and expert experience helped me a lot and working with them was enjoyable. Many thanks to all the people I have come to know in West Virginia, whose friendship and companionship I will always treasure.

Finally, I want to extend my profound appreciation to my beloved parents and younger sister for their love in my life. 


\section{Abbreviations}

WT

Wind tunnel

$V_{\text {face }}$

Enclosing hood face velocity

$V_{\text {cross }}$

Wind tunnel cross-draft velocity

$C_{\text {ambient, } L}$

Concentration at left entrance location of WT

$C_{\text {ambient, } R}$

Concentration at right entrance location of WT

$C_{\text {downstream }}$

Concentration at downstream of inside WT

$C_{\text {nose }}$

Concentration at manikin nose location

$C_{\text {mouth }}$

Concentration at manikin mouth location

$C_{\text {duct }}$

Concentration at exhaust duct location

LPM Liter per minute

fpm

feet per minute

ppm

parts per million

$\eta_{\text {pro }}$

Hood protection efficiency

$\eta_{\text {cap }}$

Hood capture efficiency 


\section{Table of Contents}

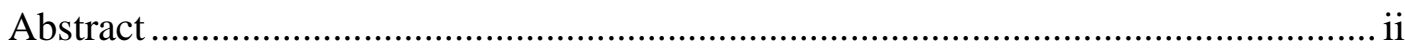

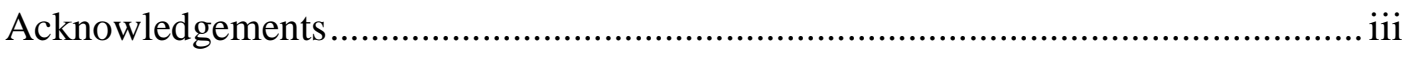

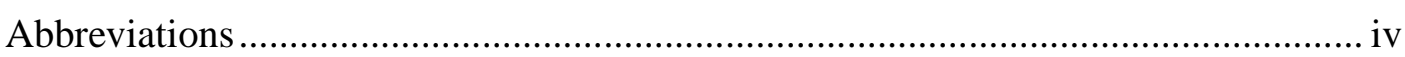

List of Figures ................................................................................................. vii

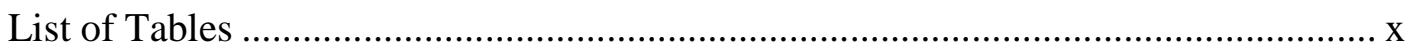

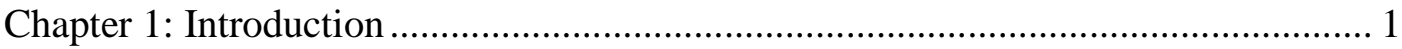

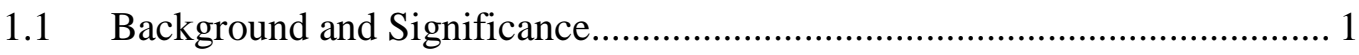

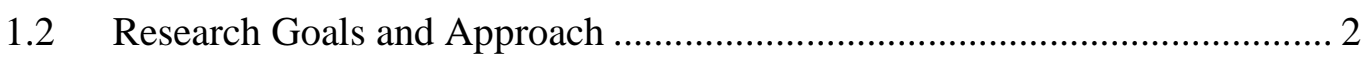

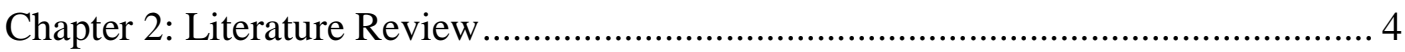

2.1 Effects of Hood Face Velocity $\left(V_{\text {face }}\right)$....................................................... 4

2.2 Effects of Cross-Draft Velocity $\left(\mathrm{V}_{\text {cross }}\right)$.................................................... 5

2.3 Benchtop Enclosing Hoods: Interventions ................................................... 6

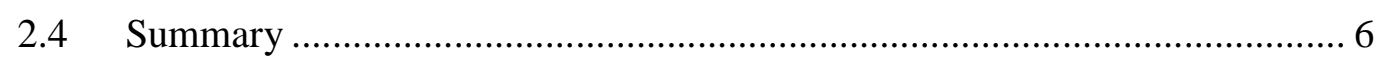

Chapter 3: Research Design and Methods ……...................................................... 7

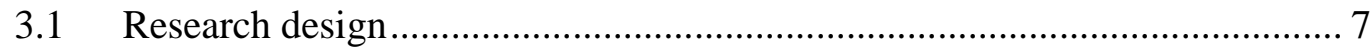

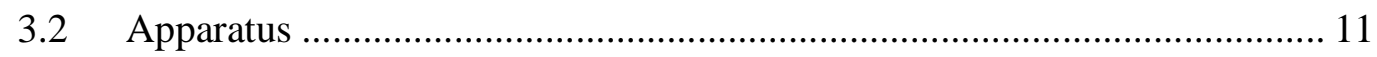

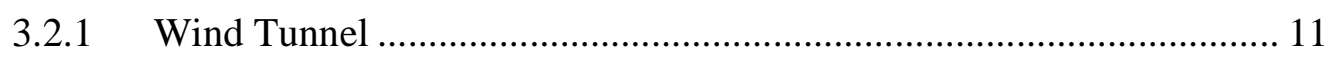

3.2.2 Experimental Enclosing Hood .............................................................. 11

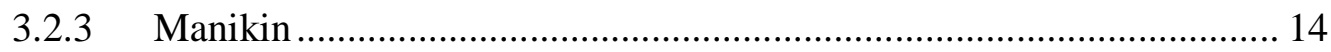

3.2.4 Temperature, Humidity and Barometric Measurements...................... 16

3.2.5 Tracer Gas Release System.................................................................. 16

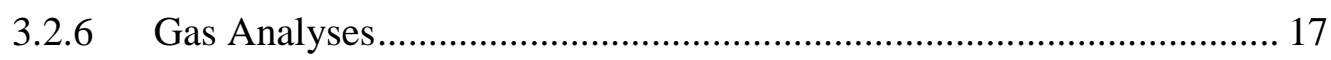

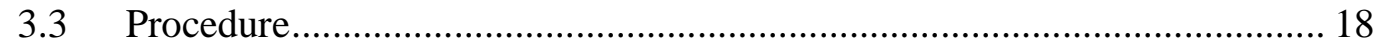

3.3.1 Sampling System Preparation Prior To Experiment Runs.................... 18

3.3.2 Tracer Gas Release System............................................................. 19

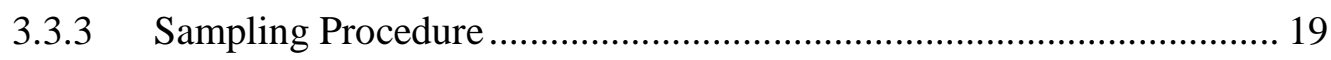

3.3.4 Analysis of Sampling Bags ................................................................ 20

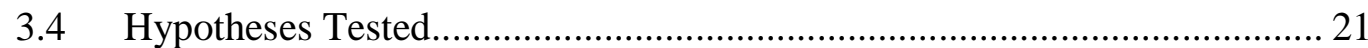

Chapter 4: Results of Study I - Effects of $V_{\text {cross }}$ and $V_{\text {face }}$ on Concentrations for the Plain Hood

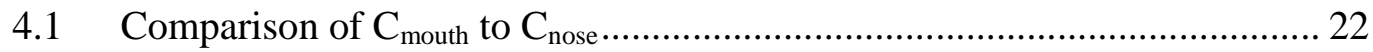


4.2 Effects of Hood Face Velocity $\left(V_{\text {face }}\right)$ on Concentration at Mouth $\left(C_{\text {mouth }}\right) . .23$

4.3 Effects of Wind Tunnel Cross-Draft $\left(V_{\text {cross }}\right)$ on Concentration at Mouth $\left(C_{\text {mouth }}\right)$......

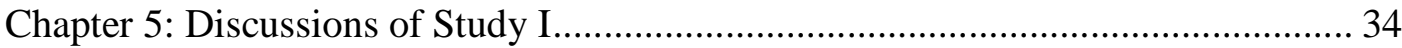

5.1 Effects of Independent Variables on Mouth Concentration......................... 34

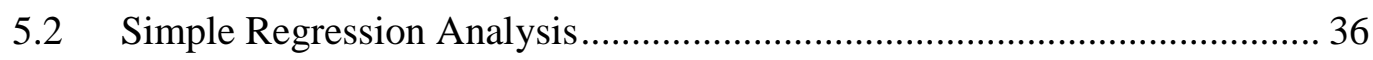

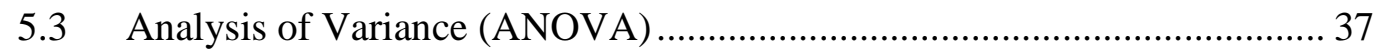

Chapter 6: Results of Study II-Flange, Cowl and Sash Tests ................................ 38

6.1 Comparison of Effects of Different Interventions on Concentration at Mouth

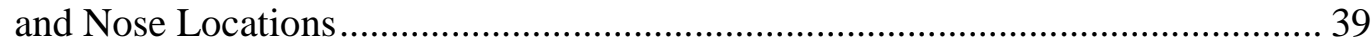

6.2 Results of $C_{\text {mouth }}$ for each Intervention ..................................................... 40

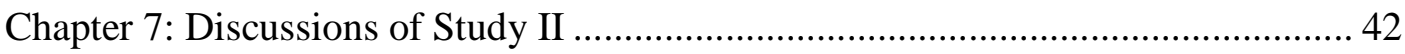

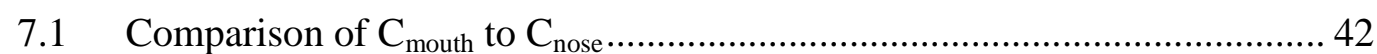

7.2 Effects of Intervention Variables on Mouth and Nose Concentration ......... 42

7.3 Analysis of Variance (ANOVA) ................................................................ 44

Chapter 8: Conclusions and Recommendations ....................................................... 46

8.1 Conclusions for Plain Enclosing Hood Study ............................................ 46

8.2 Conclusions for the Interventions Study ................................................. 47

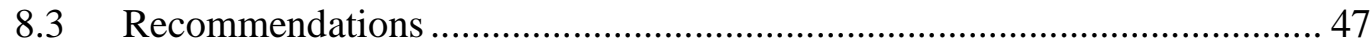

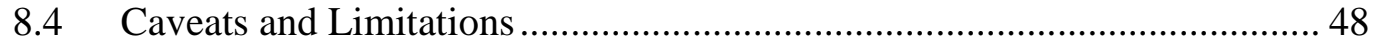

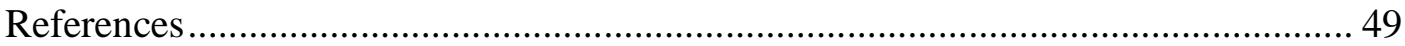

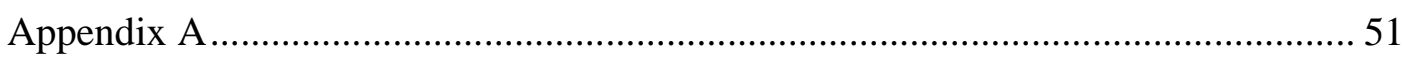

Gasmet ${ }^{\circledR}$ Fourier Transform Infrared (FT-IR) Gas Analyzer ............................... 51

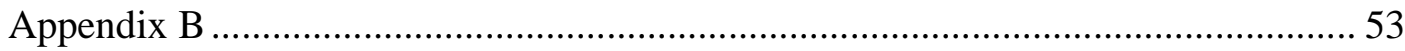

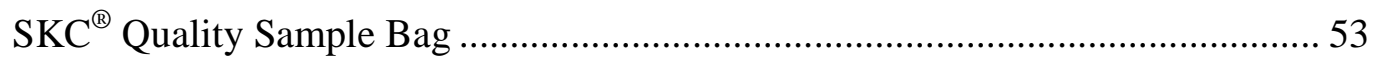

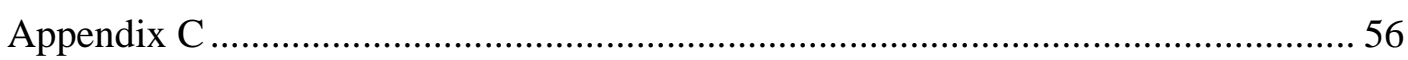

$\mathrm{SKC}^{\circledR}$ Low Flow Sample Pump 222 Series ........................................................ 56

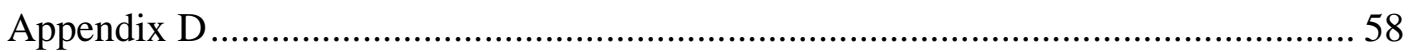

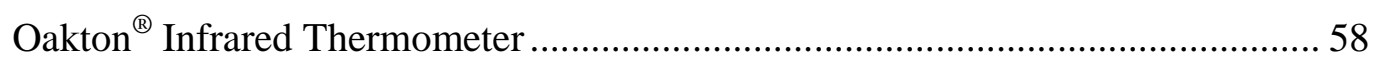

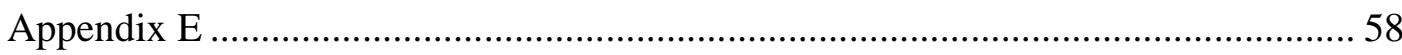

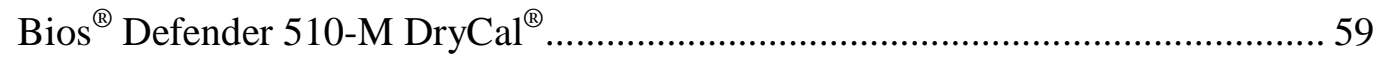

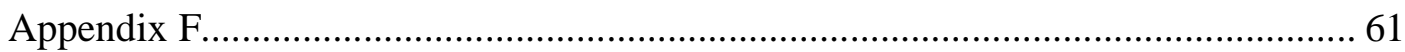

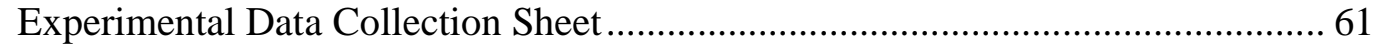

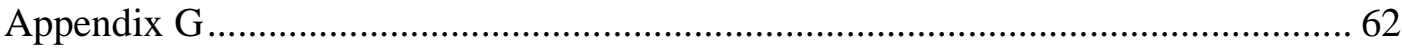

Experimental Data Collection Software - Heavent ${ }^{\circledR}$ Measurement ....................... 62 


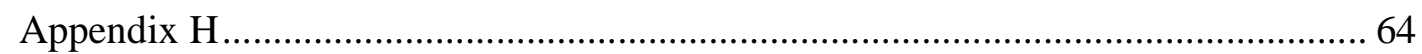

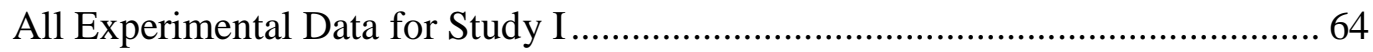

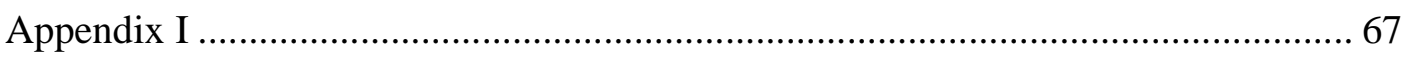

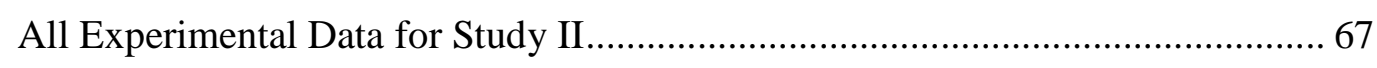




\section{List of Figures}

Figure 1.1: Benchtop Enclosing Hood

1

Figure 1.2: Bench-Top Hood with A Manikin In The "Working" Position At The Hood

Face.

Figure 3. 1: The overall view of the Wind Tunnel................................................7

Figure 3. 2: Test manikin standing in front of the enclosing with a "working"

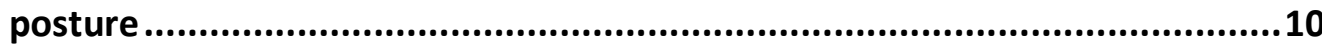

Figure 3. 3: The experimental enclosing hood and its location in a wind tunnel ....12

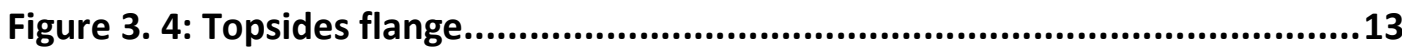

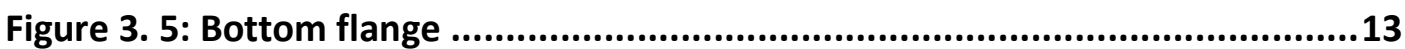

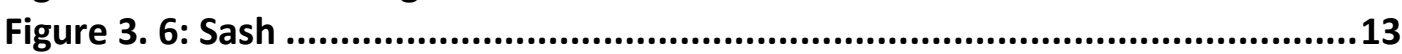

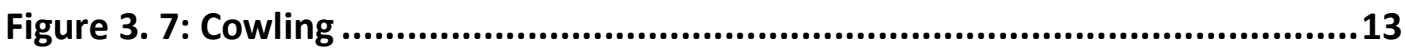

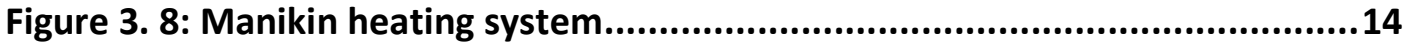

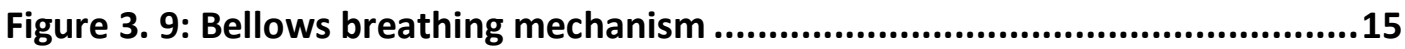

Figure 3. 10: Tracer gas release system part I ...................................................16

Figure 3. 11: Tracer gas release system part II ..............................................17

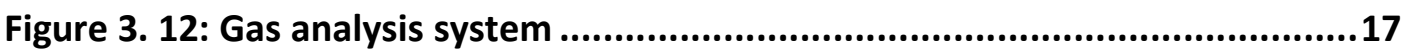

Figure 4.1.1: Cmouth Versus Cnose ..............................................................22

Figure 4.2.1- a: Mouth concentration versus hood face velocity for plain hood

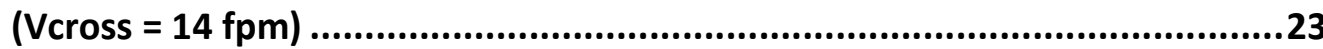

Figure 4.2.1- b: $\log$ Cmouth versus hood face velocity for plain hood (Vcross $=14$ fpm)

Figure 4.2.2- a: Mouth concentration versus hood face velocity for plain hood (Vcross $=26 \mathrm{fpm})$

Figure 4.2.2- b: log Cmouth versus hood face velocity for plain hood (Vcross = 26 fpm)

Figure 4.2.3- a: Mouth concentration versus hood face velocity for plain hood (Vcross $=36 \mathrm{fpm})$. .25

Figure 4.2.3- b: $\log$ Cmouth versus hood face velocity for plain hood (Vcross $=36$ fpm)

Figure 4.2.4- a: Mouth concentration versus hood face velocity for plain hood (Vcross $=\mathbf{4 6} \mathrm{fpm})$

Figure 4.2.4- b: log Cmouth versus hood face velocity for plain hood (Vcross $=46$ fpm)

Figure 4.2.5- a: Mouth concentration versus hood face velocity for plain hood (Vcross $=57 \mathrm{fpm})$

Figure 4.2.5- b: log Cmouth versus hood face velocity for plain hood (Vcross $=57$ fpm) 
Figure 4.3- a: Mouth concentration versus wind tunnel cross-draft velocity for plain

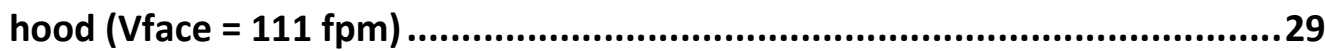

Figure 4.3- b: log Cmouth versus wind tunnel cross-draft velocity for plain hood (Vface $=111 \mathrm{fpm})$ .29

Figure 4.3- c: Mouth concentration versus wind tunnel cross-draft velocity for plain hood (Vface $=140 \mathrm{fpm})$ 30

Figure 4.3- $d$ : log Cmouth versus wind tunnel cross-draft velocity for plain hood $($ Vface $=140 \mathrm{fpm})$. .30

Figure 4.3- e: Mouth concentration versus wind tunnel cross-draft velocity for plain hood (Vface $=170 \mathrm{fpm}$ )

Figure 4.3- $\mathrm{f}$ : log Cmouth versus wind tunnel cross-draft velocity for plain hood (Vface $=170 \mathrm{fpm})$.

Figure 4.3- $\mathrm{g}$ : Mouth concentration versus wind tunnel cross-draft velocity for plain hood (Vface $=\mathbf{2 0 0} \mathrm{fpm})$

Figure 4.3- $h$ : log Cmouth versus wind tunnel cross-draft velocity for plain hood (Vface $=200 \mathrm{fpm})$

Figure 4.3- i: Mouth concentration versus wind tunnel cross-draft velocity for plain hood (Vface $=229 \mathrm{fpm})$

Figure 4.3- j: log Cmouth versus wind tunnel cross-draft velocity for plain hood (Vface $=229 \mathrm{fpm})$.

Figure 5. 1: Hood face velocity versus mouth concentration for plain hood regardless of the levels of wind tunnel cross-draft velocity. 34

Figure 5. 2: Hood face velocity versus log Cmouth for plain hood regardless of the levels of wind tunnel cross-draft velocity

Figure 5. 3: Wind tunnel cross-draft velocity versus moth concentration for plain hood regardless of the levels of hood face velocity.

Figure 5. 4: Wind tunnel cross-draft velocity versus log Cmouth for plain hood regardless of the levels of hood face velocity

Figure 6.2. 1: Cmouth versus four different interventions (Vface=111 fpm; Vcross $=14,46 \mathrm{fpm}$ )

Figure 6.2. 2: Cmouth versus four different interventions (Vface=170 fpm; Vcross $=14,46 \mathrm{fpm}$ )

Figure 6.2. 3: Cmouth versus four different interventions (Vface=229 fpm; Vcross $=14,46 \mathrm{fpm}$ )

Figure 7. 1: Cmouth Versus Cnose ..................................................................42

Figure 7.2.1: Effects of interventions on Cmouth regardless of Vface and Vcross ..43

Figure 7.2.2: Effects of interventions on Cnose regardless of Vface and Vcross .....43 


\section{List of Tables}

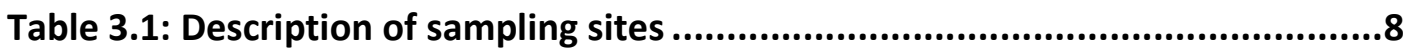

Table 3.2: Levels for independent variables for study $\mathrm{I}$........................................9

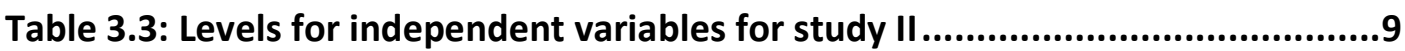

Table 3.4: Description of interventions ........................................................12

Table5.2. 1: Simple Regression Analysis Results for log Cmouth with Hood Face

Velocity (Vface) .............................................................................................36

Table5.2. 2: Simple Regression Analysis Results for log Cmouth with Cross-draft

Velocity (Vcross) ..........................................................................................36

Table 5.3. 1: The ANOVA table for Cmouth on the plain hood .............................37

Table 6. 1: Levels for independent variables for study II ......................................38

Table 6. 2: Results of Cmouth and Cnose by giving different interventions ...........39

Table 7.3. 1 The ANOVA table for log Cmouth on intervention tests .....................44

Table 7.3. 2: The ANOVA table for log Cnose on intervention tests......................44 


\section{Chapter 1: Introduction}

In industry, benchtop enclosing hoods are critical for protecting workers from airborne contaminants. Generally, these hoods are boxes with a plenum in the back leading to a tapered takeoff, (see Figure 1.1). The performance of an enclosing hood represents its ability to capture, contain, and remove the airborne contaminants generated inside the hood. In this study, performance was determined from tracer gas concentrations at a manikin's mouth and nose.

\subsection{Background and Significance}

Benchtop enclosing hoods are widely used to control airborne contaminants in industrial processes, since they can effectively reduce worker exposure if the hood performs well.

Many factors affect the performance of enclosing hoods (Brent A. Altemose, 1998). Some are dependent on work practices, such as arm movements of the user, and the source characteristics. Physical characteristics, such as the shape of the hood
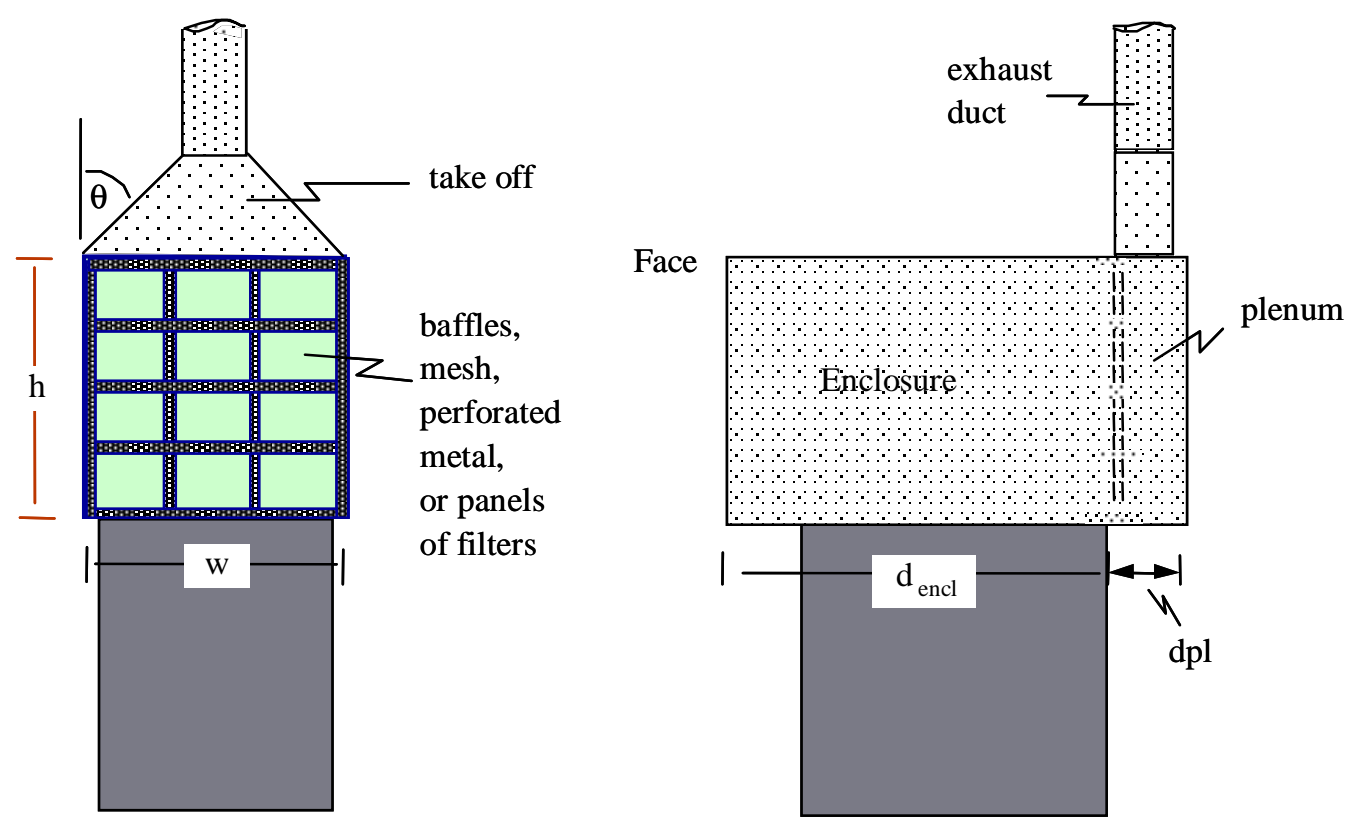

Figure 1.1: Benchtop Enclosing Hood 
opening and baffle locations, also can affect the effectiveness of the hood. Furthermore, the location of a hood can expose it to disruptive cross drafts across the face, especially if it is near air supply diffusers, doorways, windows, or aisles. Finally, operating parameters, such as exhaust flow rate and face velocity, have long been thought to be very important to hood performance (Kwangseog Ahn et al.., 2008).

However, opinions have been supported by very little published research on the effectiveness of the simple enclosing hoods that are used so commonly in industry (Guffey, 1994). Almost all hood research has been conducted on laboratory fume hoods. Due to the differences in airflow patterns induced by the sash of laboratory fume hoods, results from lab hood studies could be very misleading if applied to plain enclosing hoods.

Given the complete lack of published surveys of hood performance and lack of predictive models of their performance, practitioners have little solid guidance in designing small enclosing hoods.

\subsection{Research Goals and Approach}

This research investigated factors affecting the performance of one benchtop enclosing hood. The following factors are involved in this research:

$>$ Hood face velocity $\left(\mathrm{V}_{\text {face }}\right)$

$>$ Wind tunnel cross-draft velocity ( $\left.\mathrm{V}_{\text {cross }}\right)$

$>$ Interventions, including: collar flange, bottom flange, cowling and a custom sash.

Since enclosing hoods are intended to minimize exposure of individuals working at the hood, testing should measure exposure. Accordingly, tracer gas tests were used on this study, with a heated, breathing manikin standing at the face of the enclosing hood (see Figure 1.2). The objectives of this research effort include the following:

1. Determine the effects of face velocity combined with wind tunnel crossdraft velocity for a plain, benchtop enclosing hood on $C_{\text {nose }}$ and $C_{\text {mouth }}$. 
2. Determine hood performance for the same hood with either a flange, cowl, or sash added.
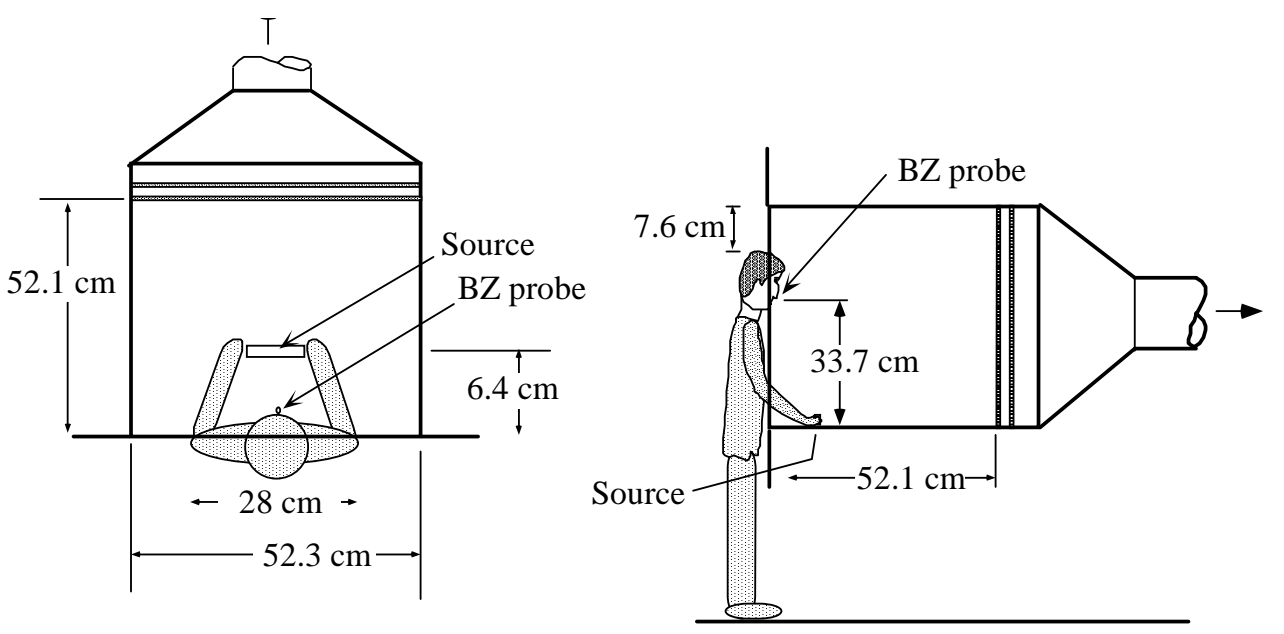

Figure 1.2: Bench-Top Hood with A Manikin In The "Working" Position At The Hood Face

To achieve these goals, a full sized mannequin was used while it was in a "working" posture standing at the face of the hood (see Figure 1.2). The mannequin was heated and "breathed". A tracer gas, Freon-134a mixed with helium, was released from a 9 in. circular pan placed at the front of the enclosing hood. The mannequin and hood were placed so that the hood was perpendicular to the flow of air through the wind tunnel. Samples were taken at the nose $\left(C_{\text {nose }}\right)$, mouth $\left(C_{\text {mouth }}\right)$, outside the wind tunnel $\left(C_{\text {ambient }}\right)$, downstream of the wind tunnel $\left(C_{\text {downstream }}\right)$, and from the exhaust duct $\left(C_{d u c t}\right)$. Samples were analyzed by a Gasmet Fourier transform infrared (FT-IR) gas analyzer to determine concentrations. By comparing the results of all tests, the effects of different factors on the effectiveness of the enclosing hood were determined. 


\section{Chapter 2: Literature Review}

Forty-three studies found in the literature reported on experimental investigations of the effects of various factors on lab hood performance. Each used either a tracer gas or aerosols as the contaminant source (Ahn et al., 2008). Only one study involved a plain benchtop enclosing hood (Guffey and Barnea, 1994). Clearly, there is a need for additional studies of plain enclosing hood effectiveness.

\subsection{Effects of Hood Face Velocity $\left(V_{\text {face }}\right)$}

Historically, evaluating hood performance has focused on measuring face velocity and its distribution across the face. Many papers and organizations have recommended acceptable ranges for average face velocity and its spatial distribution across a laboratory fume hood. ${ }^{(2-5,15)}$ Much evidence supports the commonly recommended range of 80 to $120 \mathrm{ft} / \mathrm{min}$ inflow velocity into laboratory hoods.

For all enclosing hoods the operational assumption is that the inward movement of air must overcome competing air currents induced by cross-drafts, diffusers, traffic, operator motions, etc. For very large hoods, the 2010 ACGIH Industrial Ventilation (IVM) recommends 75-125 ft/min, depending on the perceived strength of competing motions. For "small" hoods, the recommended range is $100-150 \mathrm{ft} / \mathrm{min}$. It is also assumed that the performance of a hood is best when the hood face velocity is uniform (ACGIH, 2010).

Altemose (1998) found that face velocity $\left(\mathrm{V}_{\text {face }}\right)$ and its variability are important in determining whether a laboratory hood will leak. They also found that the temporal variation of face velocity was more strongly related to tracer gas test results than spatial variation. However, in that research, the complex interaction of cross drafts with face velocity and their relationship to hood performance were described as not well understood and warranting further study. 
Guffey and Barnea (1994), in a study of the effectiveness of a plain benchtop enclosing hood, found that hood face velocity was the dominant factor affecting exposure at the breathing zone of a manikin standing at the face of the hood. At face velocities above $0.51 \mathrm{~m} / \mathrm{sec}(100 \mathrm{ft} / \mathrm{min})$, exposures were low for all cases. Increasing face velocities always decreased concentrations, even at the highest face velocities. They also concluded that exposures generally were substantially higher when the manikin's head and arms intruded into the hood than when they did not, especially when velocities were low.

\subsection{Effects of Cross-Draft Velocity $\left(V_{\text {cross }}\right)$}

Existing standards for laboratory fume hoods focus on the face velocity. The influence of room air currents is as important as face velocity in capturing contaminants when a manikin is standing at the hood face. Further, face velocity standards are not very meaningful for auxiliary air hoods ${ }^{(5)}$. Cross-drafts caused by external airflows, pumping doors, or by walking past a hood, are believed to affect the performance of lab hoods (Rota, 2000). However no guidance is available as to what level of cross-draft is acceptable (DiBerardinis, 2003). The effects of cross-drafts on the performance of lab hood can be dramatic and complex. One suggestion is that the cross-draft velocity should be less than $25 \%$ of the hood face velocity (i.e., $<25 \mathrm{ft} / \mathrm{min}$ ) (Caplan, 1982).

Two studies reported that high cross-draft velocities reduced the performance of a laboratory fume hood (Caplan, 1982; Altemose, 1998). Recommendations for acceptable

cross draft velocities vary from one-fifth to two-thirds of the average face velocity. ${ }^{(6,17,23)}$

Rake (1978) found that as the crossflow velocity exceeded $100 \mathrm{fpm}$, the ability of a biological safety cabinet to protect either experiments or investigators decreased logarithmically with increasing crossdraft speed. She also indicated that because $100 \mathrm{fpm}$ is an airspeed easily achieved by some air conditioning and heating vents (open windows and doorways may crate velocities far in excess of $200 \mathrm{fpm}$ ), the proper placement of a biological safety cabinet within the laboratory (i.e., away from such disruptive air currents) is essential to satisfactory cabinet performance. 


\subsection{Benchtop Enclosing Hoods: Interventions}

There is also wide agreement that airfoil sills are important to lab hood performance (Ljungvist, 1991). Only one published article reported results from an experimental study of effectiveness of a benchtop enclosing hood (Guffey, 1994). That study reported that the presence of a manikin dramatically increased concentrations at the hood face. It also reported that attaching flanges and tapered entries to the plain hood increased the exposures. However that research was conducted in the absence of crossdrafts and the manikin was neither heated nor breathing.

Furthermore, that result may have occurred because: 1) the tapered inlets pushed the worker partially out of the hood, and moved the source closer to the hood face, and (2) the flange and tapers were in direct contact with the manikin's thighs, effectively blocking upward flow between its belly and the hood.

\subsection{Summary}

In short, the nearly complete lack of published studies of plain enclosing hood performance makes guidance to practitioners a matter of perceived plausibility rather than empirical science. This thesis focuses on the effects of face velocity, cross-drafts, and different interventions on the performance of a small plain enclosing hood. The author hopes that this study will provide information useful to practitioners and lead them to more effective hood designs and more certain selection of hood airflows. 


\section{Chapter 3: Research Design and Methods}

\subsection{Research design}

The experiments were carried out in a wind tunnel that is $40 \mathrm{ft}$ long, $9 \mathrm{ft}$ high and $12 \mathrm{ft}$ wide. A tracer gas (Freon 134a) was released at a fixed rate from a fixed position in the hood and monitored in the breathing zone of a mannequin "working" at the face of the hood. The wind tunnel is shown as Figure 3.1.

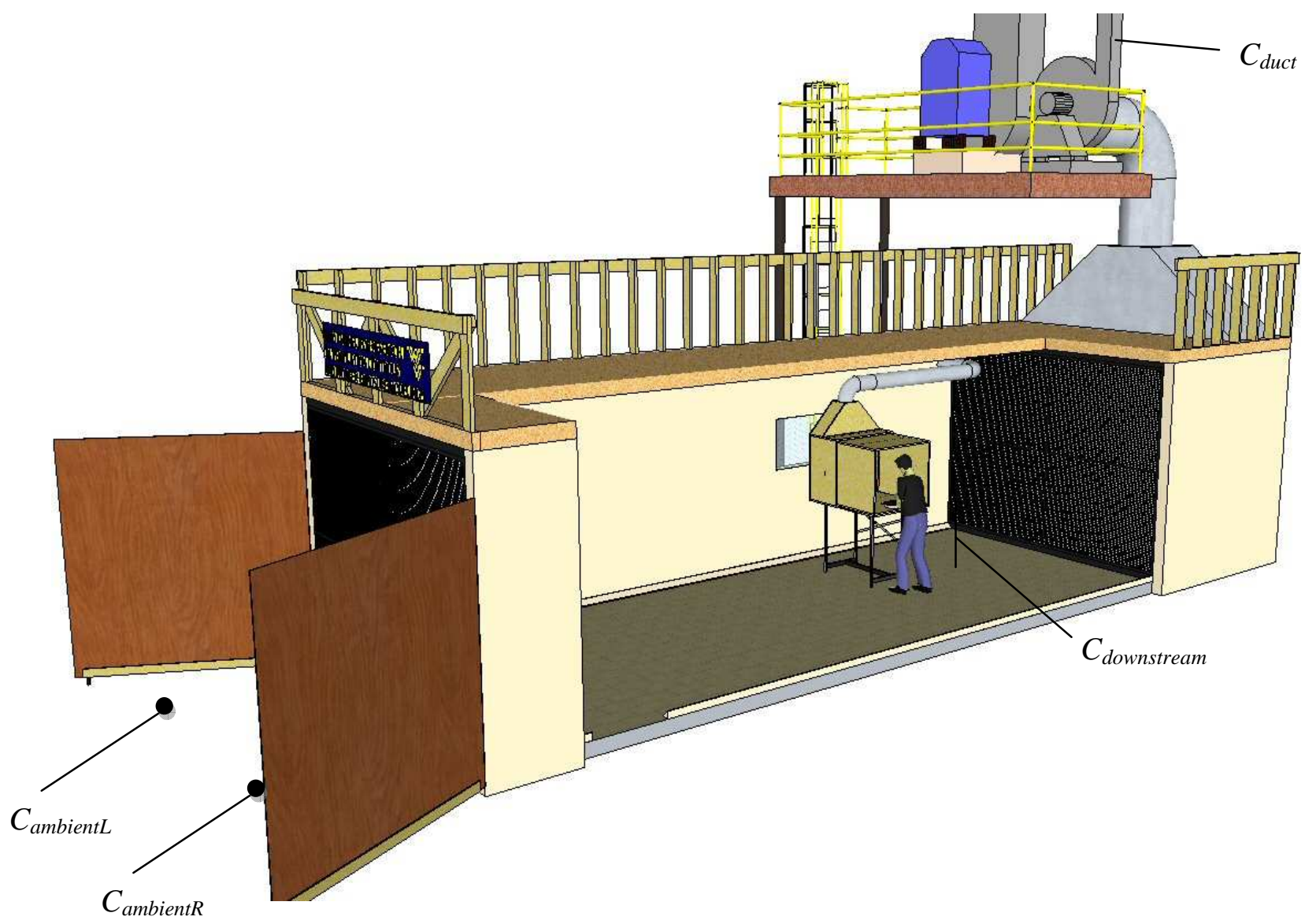

Figure 3. 1: The overall view of the Wind Tunnel 
Samples were taken at the nose $\left(C_{\text {nose }}\right)$, mouth $\left(C_{\text {mouth }}\right)$, outside the wind tunnel $\left(C_{\text {ambient }}\right)$, downstream of the wind tunnel $\left(C_{\text {downstream }}\right)$, and from the exhaust duct $\left(C_{\text {duct }}\right)$. The sampling locations for the study are shown in Table 3.1.

Each sample was collected for 20 minutes and all locations were sampled concurrently by drawing sampled air into plastic bags (see Appendices B \& C). Sampling volumes were 3 liters each. After sample collection, each sample was analyzed by a Gasmet Fourier transform infrared (FT-IR) gas analyzer (see Appendix A) to determine its concentration.

The dependent variables for this study were concentrations measured simultaneously at five designated different locations as shown (see Table 3.1).

Table 3.1: Description of sampling sites (see Fig. 3.1)

\begin{tabular}{c|c|c}
\hline \multicolumn{1}{c|}{ Description } & Location & Abrev. \\
\hline $0.5 \mathrm{~cm}$ laterally from nasal orifice & Nose & $\mathrm{C}_{\text {nose }}$ \\
\hline $\begin{array}{c}\text { At the mouth } 3 \mathrm{~cm} \text { from the right of the lip } \\
\text { At } 2 \mathrm{~m} \text { in front of the outlet of the wind tunnel, between } \\
\text { the hood face and wind tunnel outlet }\end{array}$ & Mouth & $\mathrm{C}_{\text {mouth }}$ \\
\hline $\begin{array}{c}\text { At } 2 \mathrm{~m} \text { downstream of the exhaust duct fan } \\
2 \mathrm{~m} \text { at the wind tunnel inlet }\end{array}$ & Duct & $\mathrm{C}_{\text {downstream }}$ \\
\hline \hline
\end{tabular}

The independent variables were enclosing hood face modifications, as well as several pre-determined levels of hood face velocity $\left(V_{\text {face }}\right)$ and wind tunnel cross-draft velocity $\left(V_{\text {cross }}\right)$.

This study consisted of two parts: Study I and Study II.

- Study I tested the plain hood's performance without any intervention. Two factors were investigated: hood face velocities and wind tunnel cross-draft velocities. Test conditions included every combination of five predetermined hood velocities: 111, 140, 170, 200 and $229 \mathrm{ft} / \mathrm{min}$, and five 
cross-draft velocities: 14, 26, 36, 46 and $57 \mathrm{ft} / \mathrm{min}$. Roughly 45 minutes were required for each test $(30 \mathrm{~min}$. for sampling, and $15 \mathrm{~min}$. for FT-IR sampling analysis). Each condition test was done twice (see Table 3.2). The total number of tests was 50 .

- Study II was done to determine the effects of flanges, cowling, and sashes added to a plain enclosing hood. The test methods were the same as Study I. Test conditions included every combination of the three hood velocities (111, 170 and $229 \mathrm{ft} / \mathrm{min}$ ), two cross-draft velocities (14 and $46 \mathrm{ft} / \mathrm{min}$ ), and five intervention conditions (no intervention, collar flange, bottom flange, cowling, and sash). Fifty minutes was required for each test (35 min. for sampling, and $15 \mathrm{~min}$. for FT-IR sampling analysis). Each condition test was repeated once. (see Table 3.3)

Table 3.2: Levels for independent variables for study I

\begin{tabular}{c|c}
\hline \hline Independent Variables & Levels \\
\hline Hood face velocity $(f t / \mathrm{min}), \mathrm{V}_{\text {face }}$ & $111,140,170,200,229$ \\
\hline Cross-draft velocity $(\mathrm{ft} / \mathrm{min}), \mathrm{V}_{\text {cross }}$ & $14,26,36,46,57$ \\
\hline \hline
\end{tabular}

Table 3.3: Levels for independent variables for study II

\begin{tabular}{c|c}
\hline \hline Independent Variables & Levels \\
\hline Hood face velocity $(f t / m i n), \mathrm{V}_{\text {face }}$ & $111,170,229$ \\
\hline Cross-draft velocity $(f t / m i n), \mathrm{V}_{\text {cross }}$ & 14,46 \\
\hline \multirow{2}{*}{ Intervention } & Collar flange \\
\cline { 2 - 2 } & Bottom flange \\
\cline { 2 - 2 } & Cowling \\
\cline { 2 - 2 } & Sash \\
\cline { 2 - 2 } & Plain Hood (No Intervention) \\
\hline \hline
\end{tabular}


There were two replicates for each combination of independent variables. The significance of the independent variables and their interactions for each study was analyzed using the Data Desk (Data Description, Cornell, NY) statistical package.

The fixed conditions for this study included the use of one anthropometrically proportioned manikin wearing summer clothes (see Figure 3.2). The manikin was stationary and was posed in a fixed "working" posture for all tests. During each test, the manikin's hands were placed on each side of the tracer gas source (a 9 inch pie-pan) in a manner intended to simulate a "working" posture at the hood face.

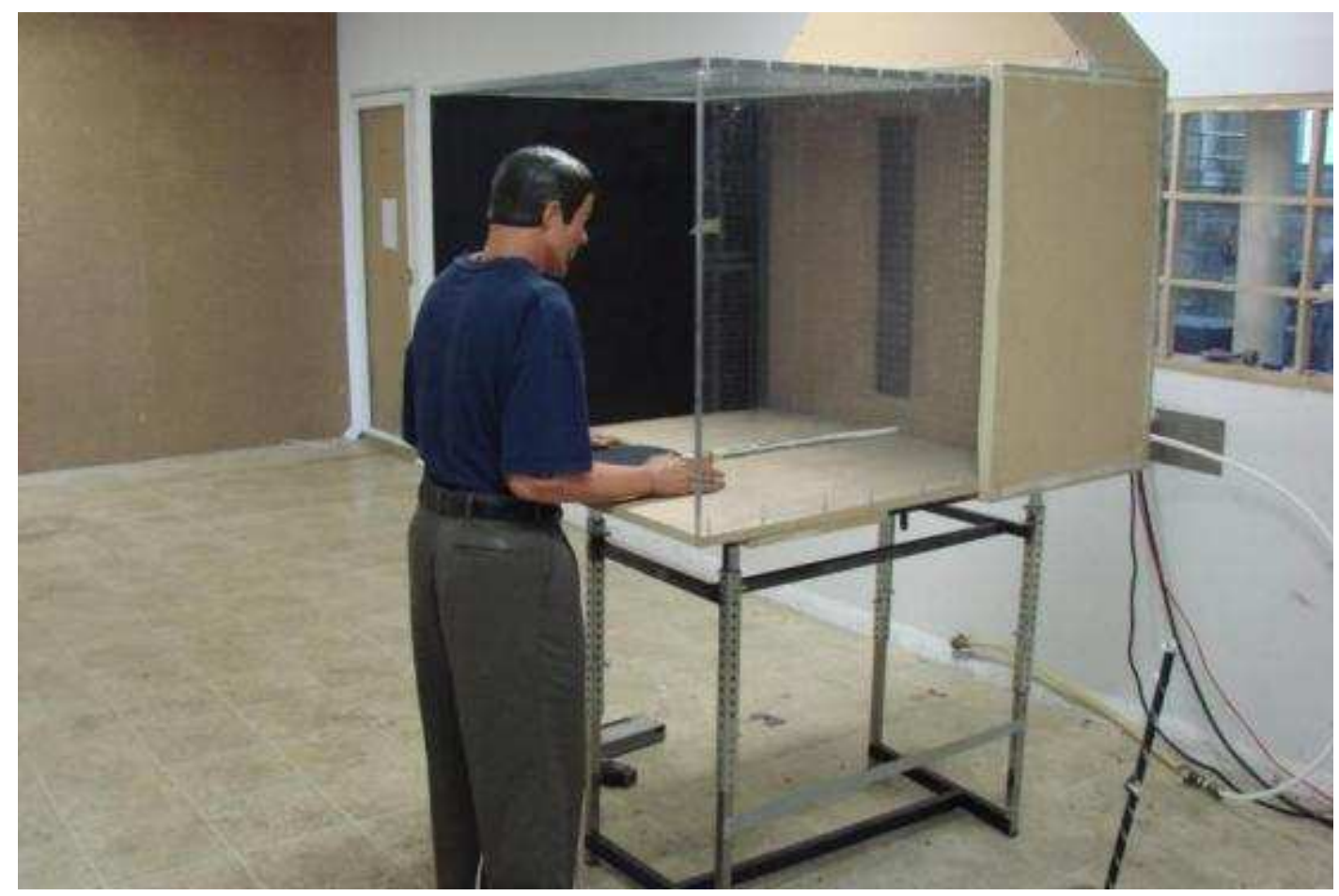

Figure 3. 2: Test manikin standing in front of the enclosing with a "working" posture 


\subsection{Apparatus}

\subsubsection{Wind Tunnel}

The study was done in the Ventilation Laboratory in the Mineral Resources Building (MRB) at CEMR, West Virginia University. The dimensions of the wind tunnel are $40 \mathrm{ft}$ long, $9 \mathrm{ft}$ high and $12 \mathrm{ft}$ wide. The uniformity of velocities in the wind tunnel is improved by the upstream and downstream HEPA filters. Constant Temperature Anemometry (CTA) measurements taken at 6" intervals vertically and 12" intervals horizontally showed a coefficient of variation of $10 \%$. The turbulent intensity was generally around $10 \%$. It was $3-5 \%$ in the middle where the manikin stands. The wind tunnel fan is controlled by a variable frequency drive, allowing a range of wind tunnel velocities of 10 to $155 \mathrm{ft} / \mathrm{min}$.

The combined cross-section of the full-sized enclosing hood and the manikin was less than $15 \%$ of the wind tunnel cross-section. To reduce thermal buoyancy effects due to different temperatures at floor and ceiling, the concrete floor of the building was covered with $0.75^{\prime \prime}$ styrene foam insulating sheets, which was overlaid with 1 " plywood sheets and a linoleum floor covering. Infrared thermometry showed temperatures in the air and at the walls, ceiling and floor to be within $2^{\circ} \mathrm{C}$ winter and summer.

\subsubsection{Experimental Enclosing Hood}

The enclosing hood has a transparent plastic glass side and top to allow inside observation (see Figure 3.2). The hood dimensions are 36 inch wide and 30 inch high. To enhance spatial velocity uniformity, a perforated sheet face with $95 \%$ opacity was installed in the back of the hood. The takeoff is tapered 45 degrees in a typical square to round transition. The enclosing hood was located such that the subject is near the center of the width of the wind tunnel (see Figure 3.3). 


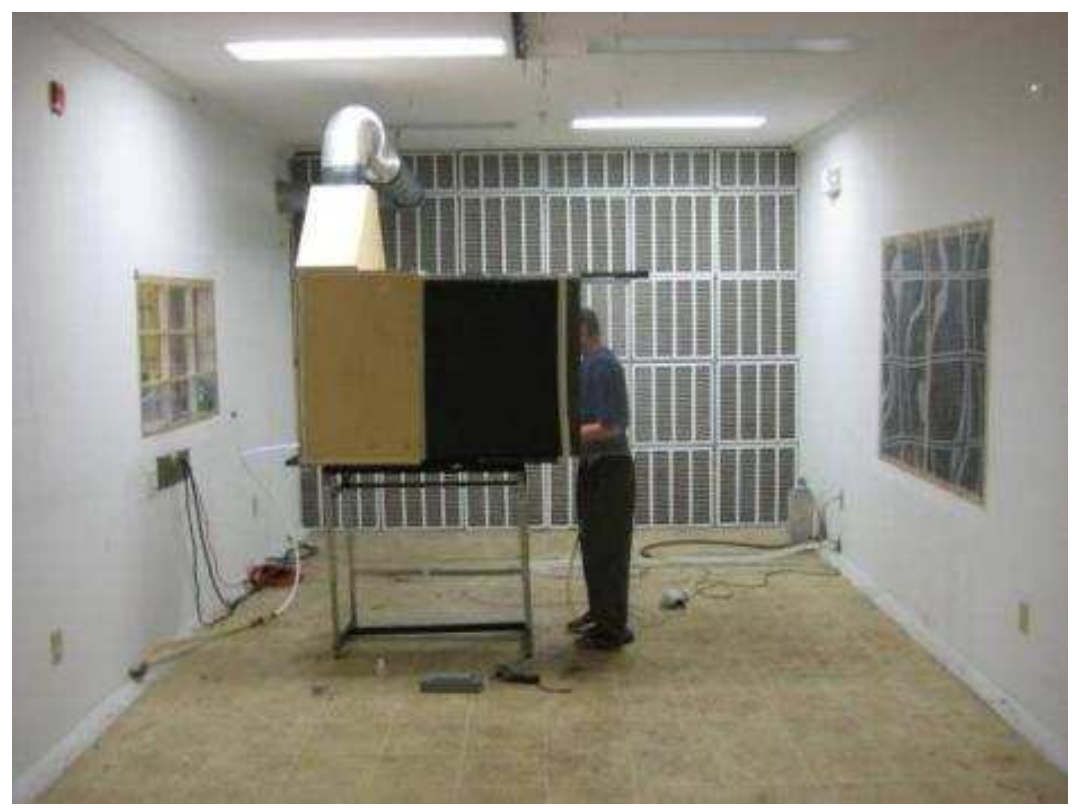

Figure 3. 3: The experimental enclosing hood and its location in a wind tunnel

For testing the effects of interventions on the plain hood's performance, the following modifications were made at the hood inlet (see Table 3.4):

Table 3.4: Description of interventions

\begin{tabular}{l|c}
\hline \hline \multicolumn{1}{c|}{ Description } & Interventions \\
\hline $\begin{array}{l}\text { Attached a 12 inch, 90 degree flange to the sides and top to } \\
\text { the hood (see Figure 3.4) }\end{array}$ & Collar flange \\
\hline $\begin{array}{l}\text { Attached a 12 inch, 90 degree flange to the bottom of the } \\
\text { hood (see Figure 3.5) }\end{array}$ & Bottom flange \\
\hline $\begin{array}{l}\text { Attached a cowling, which is 12 inch straight extension of } \\
\text { the two sides and top (see Figure 3.6) }\end{array}$ & Cowling \\
\hline \begin{tabular}{l} 
Installed a custom sash inside of the hood (see Figure 3.7) \\
\hline
\end{tabular}
\end{tabular}




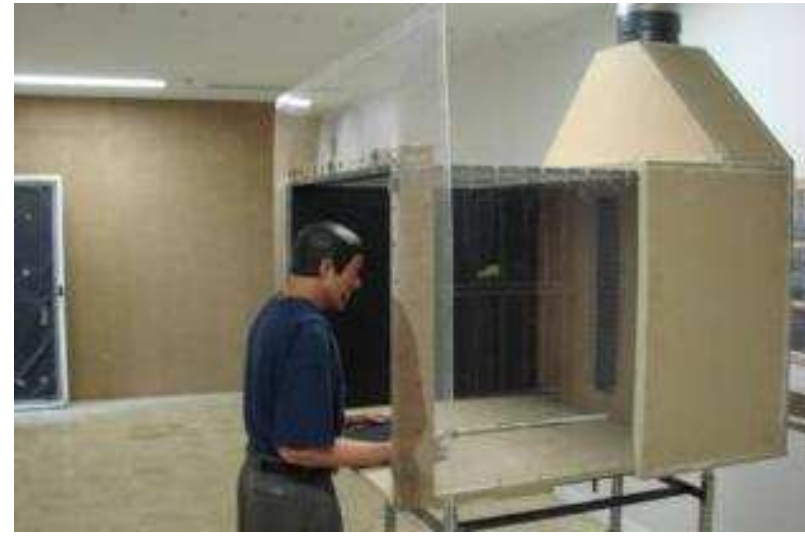

Figure 3. 4: Collar flange

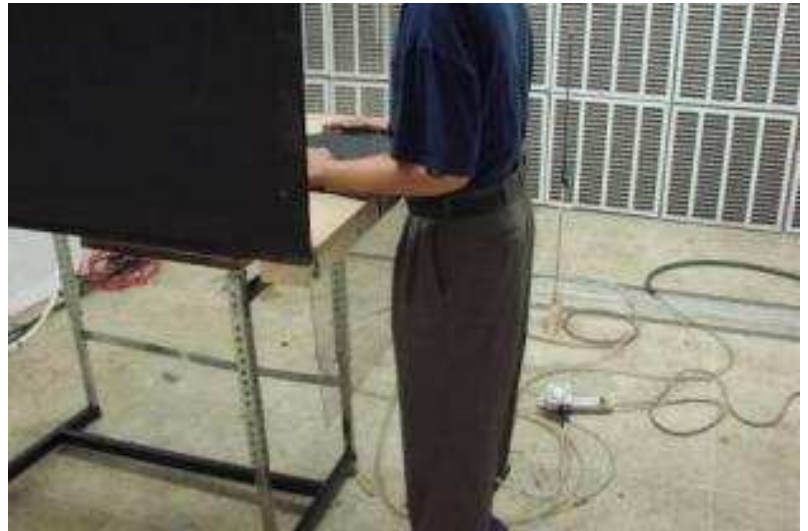

Figure 3. 5: Bottom flange

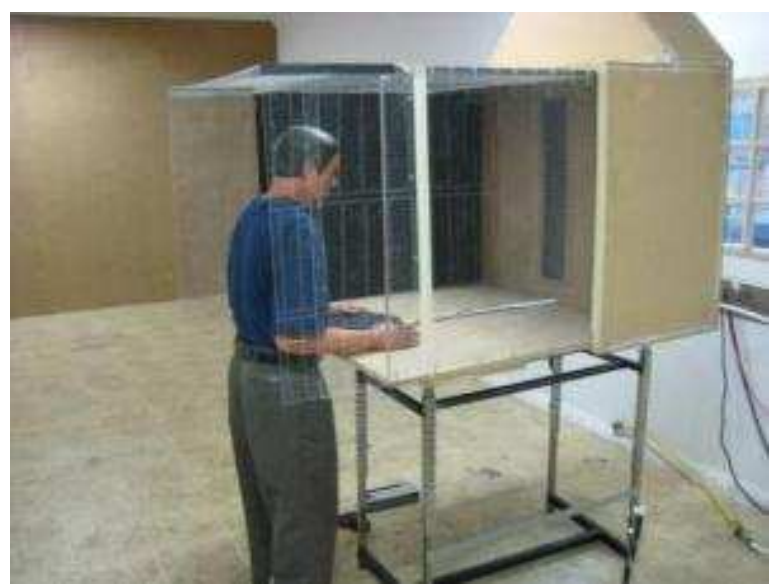

Figure 3. 7: Cowling

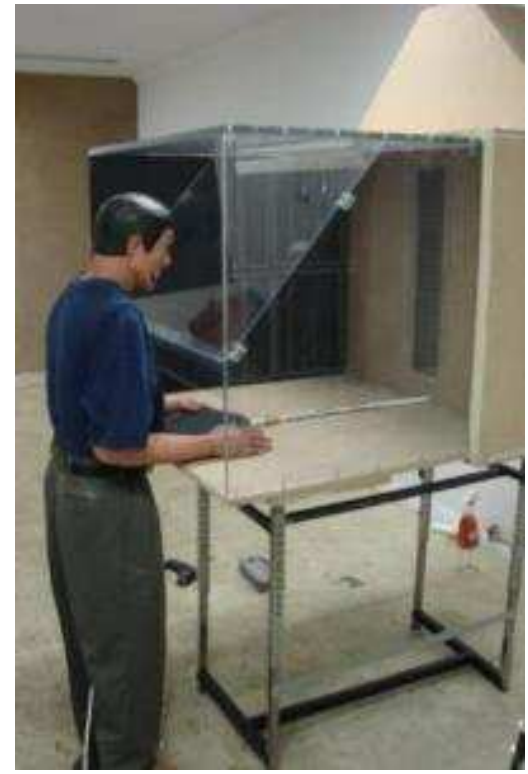

Figure 3. 6: Sash 


\subsubsection{Manikin}

The test manikin is a $66^{\prime \prime}$ high, anthropometrically-scaled (including facial features and short hair) male with hollow cavities in the head, torso, legs and arms. It has a rubber skin that feels reasonably like real skin. The manikin has joints in shoulders, hips and knees. This enables it to stand, sit and to pose in lifelike postures. Measuring 66 inches in height, the manikin dimensions match with $50^{\text {th }}$ percentile for women and $5^{\text {th }}$ percentile for men.

Heating the manikin head and torso to simulate the body heat of humans was done by placing strings of 1.5 watt lights within the torso and the head, for a total of 90 watts of power (see Figure 3.8). This produced the manikin's face temperatures $\left(24-28{ }^{\circ} \mathrm{C}\right)$ and back temperatures $\left(34-38{ }^{\circ} \mathrm{C}\right)$.

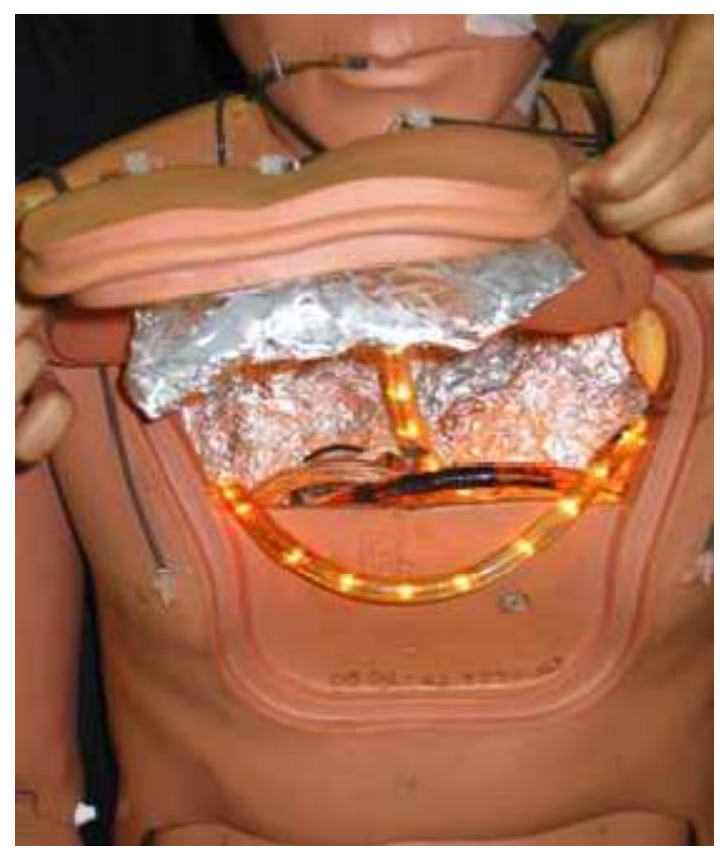

Figure 3. 8: Manikin heating system

The manikin was clothed with loose-fitting pants and a summer-weight shortsleeved shirt. Breathing by the manikin was simulated by using a bellows device (see Figure 3.9). Air was drawn in and expelled the same air through the nasal openings, 
which was connected to $1^{\prime \prime}$ diameter Teflon tubing. This air was heated to $98^{\circ} \mathrm{F}$ as it passing through the torso. A motorized bellows outside the wind tunnel provided a sinusoidal pattern at roughly $0.4-0.5$ Liter per breath and $30-39$ breathes per minute.

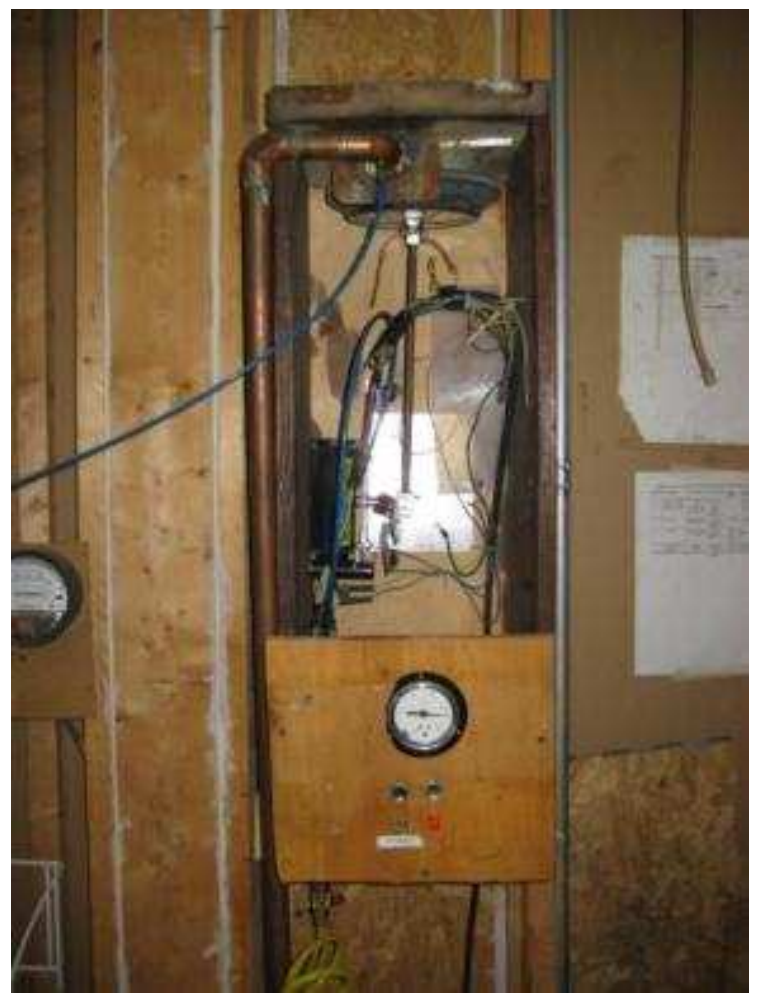

Figure 3. 9: Bellows breathing mechanism 


\subsubsection{Temperature, Humidity and Barometric Measurements}

Temperatures of surfaces were measured with an infrared thermometer (Oakton, model number EW-35629, see Appendix D). Multiple points were measured on the manikin's cheek and torso, along with multiple points on the wind tunnel walls, ceiling, and floor. Air temperatures were measured with a calibrated dry bulb thermometer. Humidity was determined from a standard sling psychrometer, and barometric pressure was measured with a standard laboratory mercury barometer.

\subsubsection{Tracer Gas Release System}

A tracer gas was utilized in this study to determine the performance of the enclosing hood. Freon-134a was mixed with helium in a roughly neutrally buoyant mixture. Tracer gas was released through a 9" pie-pan into the enclosing hood front face. The pie-pan was covered by a plastic glass with 99 uniformly spaced drilled holes, each 0.05 in. in diameter. The system is shown as Figures $3.10-3.11$.

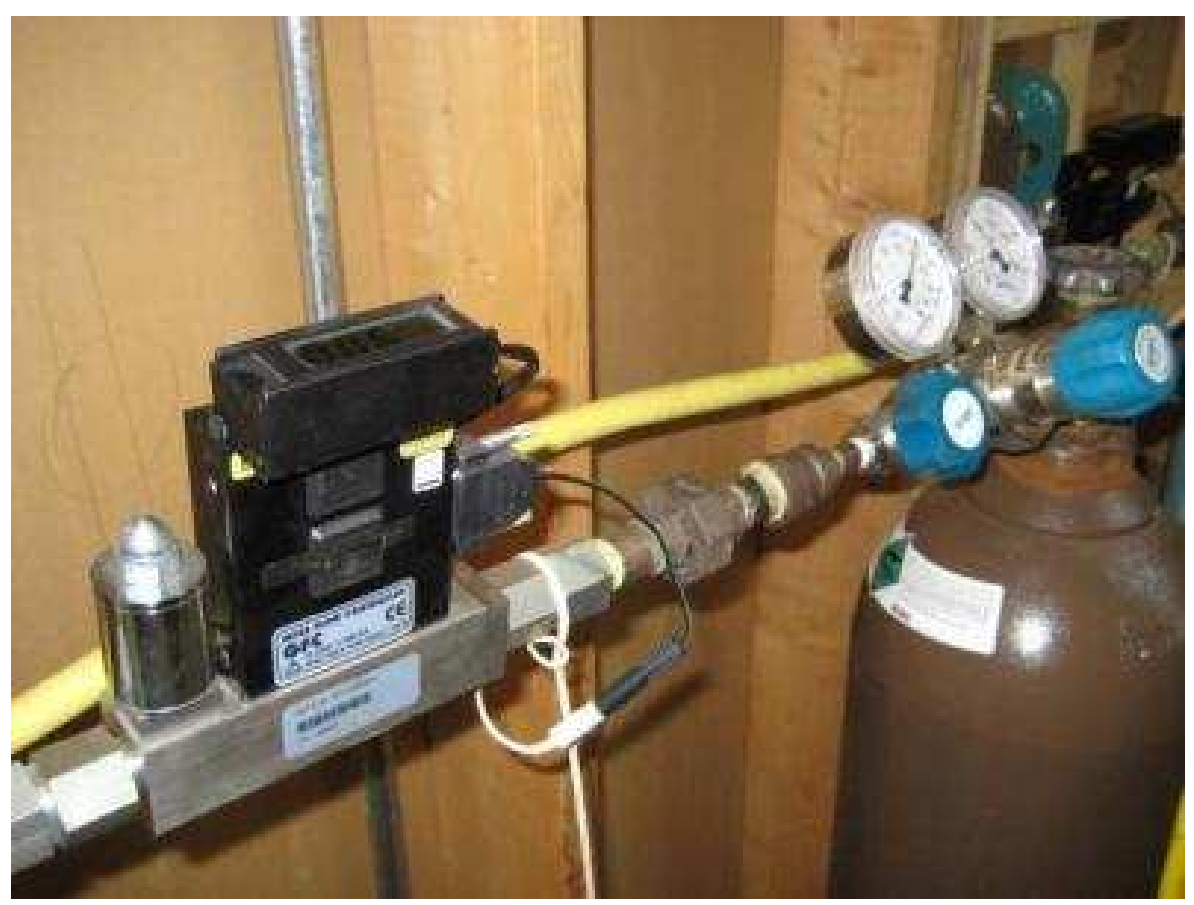

Figure 3. 10: Tracer gas release system part I 


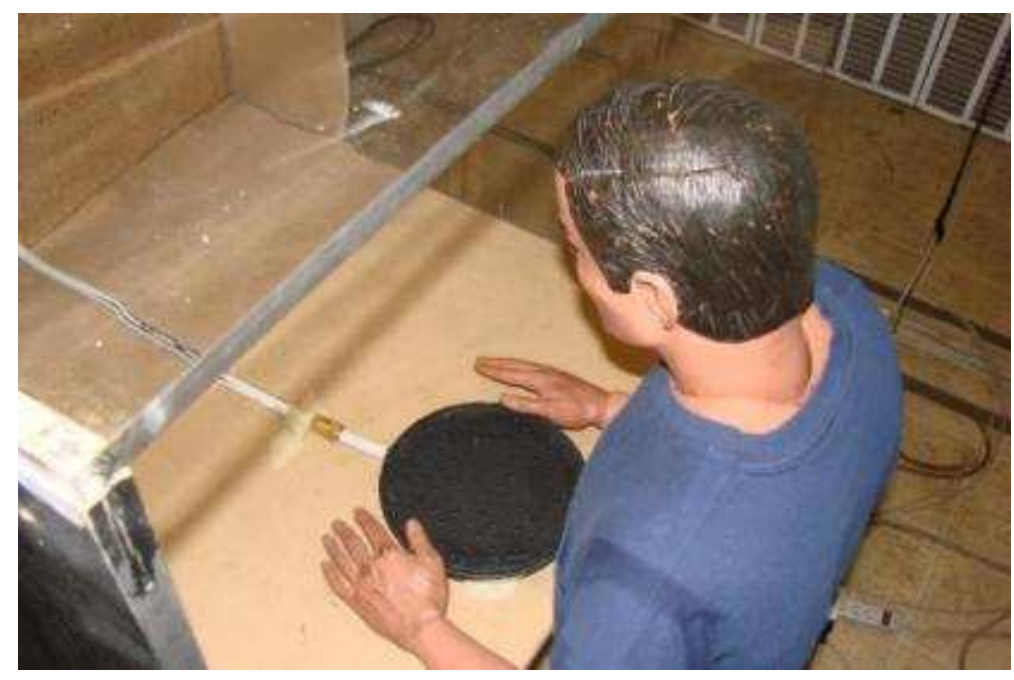

Figure 3. 11: Tracer gas release system part II

\subsubsection{Gas Analyses}

Analysis of Freon-134a / air mixtures was performed using a Gasmet Fourier transform infrared (FT-IR) gas analyzer (Model: DX-4015) (see Figure 3.12). The FT-IR was frequently calibrated using 2 ppm, 10 ppm, 100 ppm and 200 ppm span gases (Air-Gas, Morgantown, WV).

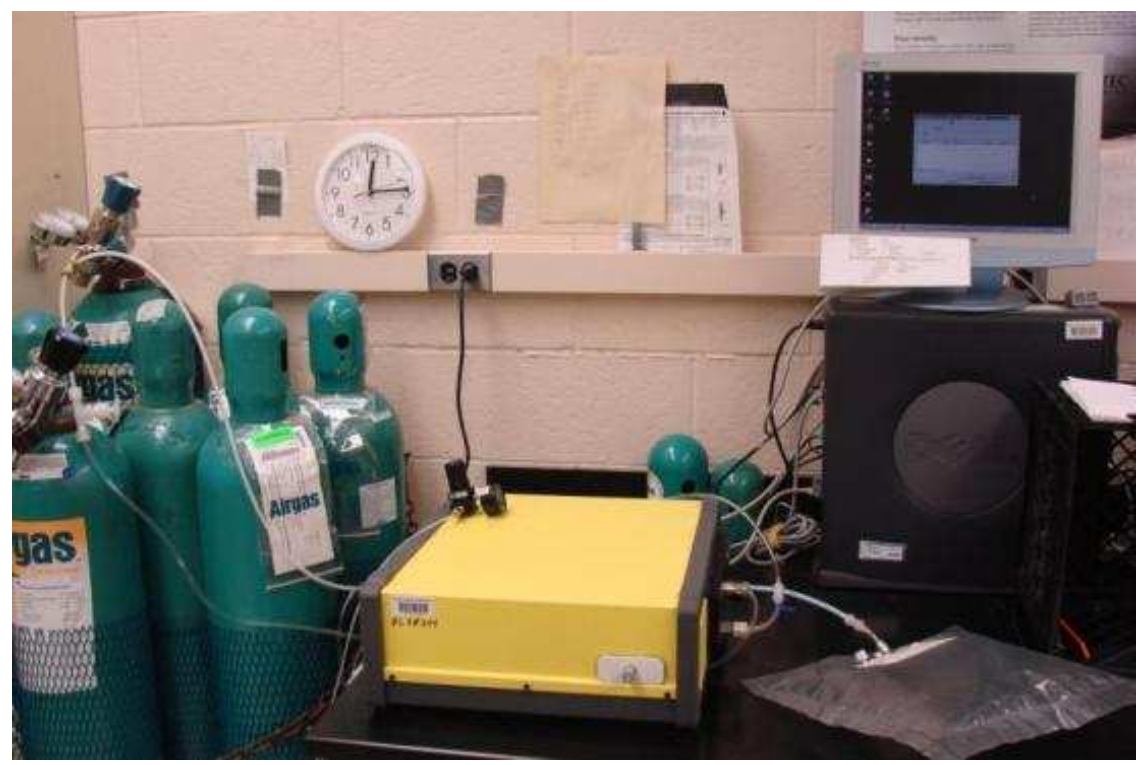

Figure 3. 12: Gas analysis system 


\subsection{Procedure}

The procedure for this study is shown in flow-chart form in Figure 3.13.

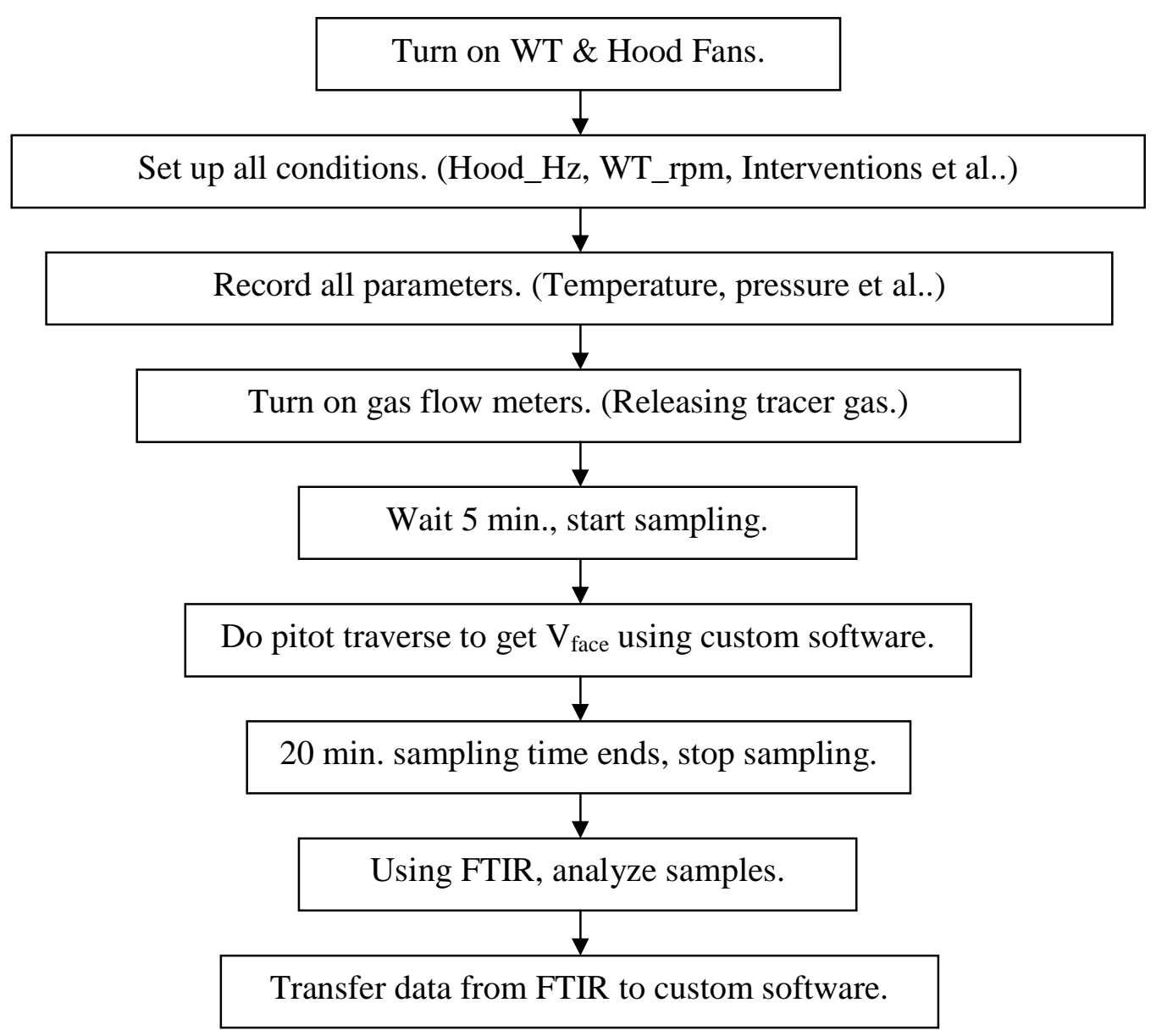

Figure 3.13: Experiment procedure

\subsubsection{Sampling System Preparation Prior To Experiment Runs}

1. Manikin heat turned on at least three hours prior to sampling.

2. Calibrate Low flow pumps.

3. Purge Teflon ${ }^{\mathrm{TM}}$ sampling bags with ambient air. 
4. Purge the ventilation laboratory before sampling.

5. Turn on wind tunnel fan and exhaust hood fan and adjust the fan controllers to desired airflows.

6. Turn on the manikin breathing system.

7. Connect Teflon ${ }^{\mathrm{TM}}$ bag to the sampling pumps according to the labels identifying sampling location.

8. Record wind tunnel environmental conditions (temperature, humidity, barometric pressure).

9. Install intervention onto the enclosing hood, if required.

10. Check manikin posture, location of its head in the plane of the hood face, locations of hands to each side of the source, heating and breathing.

\subsubsection{Tracer Gas Release System}

1. Open valves for helium \& freon cylinders.

2. Turn on mass flow controllers (gas flow meters) for Freon-134a and helium to release tracer gas mixture.

3. Adjust the flow rate for each mass flow controller to $3 L P M$ for Freon134a and $9 L P M$ for helium.

(Note: Tracer gas was released into the hood through a 9" pie-pan placed between the manikin's hands.)

\subsubsection{Sampling Procedure}

1. Switch all sampling pumps to "ON".

2. Close wind tunnel doors tightly. 
3. Wait five minutes before starting the sampling to allow equilibration of the concentration in the wind tunnel.

4. Do pitot traverses at the exhaust hood duct to determine $\mathrm{V}_{\text {duct }}$ and $\mathrm{V}_{\text {face }}$.

5. Wait 20 minutes as the sampling bags are filled by sampling pumps.

6. At the end of the 20 minutes of sampling, disconnect the bags from the pumps and close their valves

7. Take bags to the FT-IR gas analyzer.

\subsubsection{Analysis of Sampling Bags}

1. Run pure nitrogen through the gas analyzer until desired background achieved.

2. Connect a sample bag to the gas analyzer inlet port.

3. Draw sample into the analyzer for $1 \mathrm{~min}$.

4. Analyze sample and note Feron-134a concentration on screen (same value is logged to an ongoing database).

5. Record sampling bag, Freon-134a concentration, residual concentration, and sampling time.

6. Repeat for the next sample bag. 


\subsection{Hypotheses Tested}

The first hypothesis of this research is that enclosing hood face velocity and cross-draft velocity will affect the concentrations at the nose and mouth sampling locations:

$H_{0}: \mu=$ Constant;

$H_{l}: \mu \neq$ Constant .

Expectation: $\mu=f$ \{hood face velocity, cross-draft velocity\}.

Where: $\mu=$ mean concentrations at nose or mouth sampling location.

The second hypothesis tests whether certain interventions reduce the manikin's exposures compared to the plain hood:

$H_{0}: \mu=$ Constant;

$H_{l}: \mu \neq$ Constant

Expectation: $\mu=f$ \{Intervention, hood face velocity, cross-draft velocity\} 


\section{Chapter 4: Results of Study I - Effects of $V_{\text {cross }}$ and $V_{\text {face }}$ on Concentrations for the Plain Hood}

This study tested performance of a plain hood. This study was a complete factorial design, which included 5 levels of hood face velocity $\left(V_{\text {face }}\right)$ and 5 levels of wind tunnel cross-draft velocity $\left(V_{\text {cross }}\right)$. Each test condition was replicated twice in random order. The goal of this study was to find the effects of $V_{\text {face }}$ and $V_{\text {cross }}$ on concentrations measured at different locations. Concentrations were measured at 5 locations: nose $\left(C_{\text {nose }}\right)$, mouth $\left(C_{\text {mouth }}\right)$, outside the wind tunnel $\left(C_{\text {ambient }}\right)$, downstream of the wind tunnel $\left(C_{\text {downstream }}\right)$ and the exhaust duct $\left(C_{\text {duct }}\right)$. Only $C_{\text {mouth }}$ and $C_{\text {nose }}$ are analyzed here. All values of $C_{\text {ambient }}$ were near zero, so it was not necessary to "correct" for ambient concentration. $C_{\text {downstream }}$ was also found to be zero or trivial in all cases.

\subsection{Comparison of $\mathbf{C}_{\text {mouth }}$ to $\mathbf{C}_{\text {nose }}$}

Two samples were taken simultaneously at the manikin's mouth and nose locations. Plausibly, there would be only small differences between $\mathrm{C}_{\text {mouth }}$ and $\mathrm{C}_{\text {nose }}$ because they are close to each other. As shown in Figure 4.1.1, it is very clear that the two dependent variables were highly correlated $\left(\mathrm{R}^{2}=0.91\right)$ with a linear regression slope of 0.9986 .

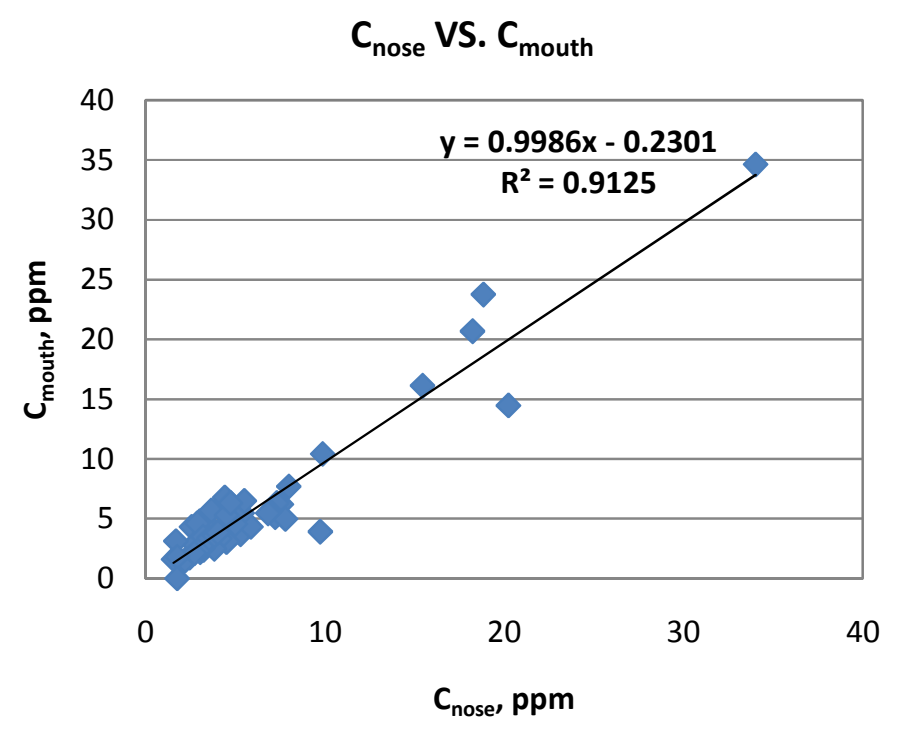

Figure 4.1.1: $\mathbf{C}_{\text {mouth }}$ Versus $\mathbf{C}_{\text {nose }}$ 


\subsection{Effects of Hood Face Velocity $\left(V_{\text {face }}\right)$ on Concentration at Mouth $\left(C_{\text {mouth }}\right)$}

Figures 4.2.1 to 4.2.5 show the effects of hood face velocity on $\mathrm{C}_{\text {mouth. }}$. Five levels of hood face velocity were investigated: 111, 140, 170, 200 and $229 \mathrm{ft} / \mathrm{min}$. As expected, $V_{\text {face }}$ appeared to have strong effects on $C_{\text {mouth }}$, with higher $C_{\text {mouth }}$ levels associated with lower $\mathrm{V}_{\text {face }}$ values. This result is consistent with published research for lab hoods.

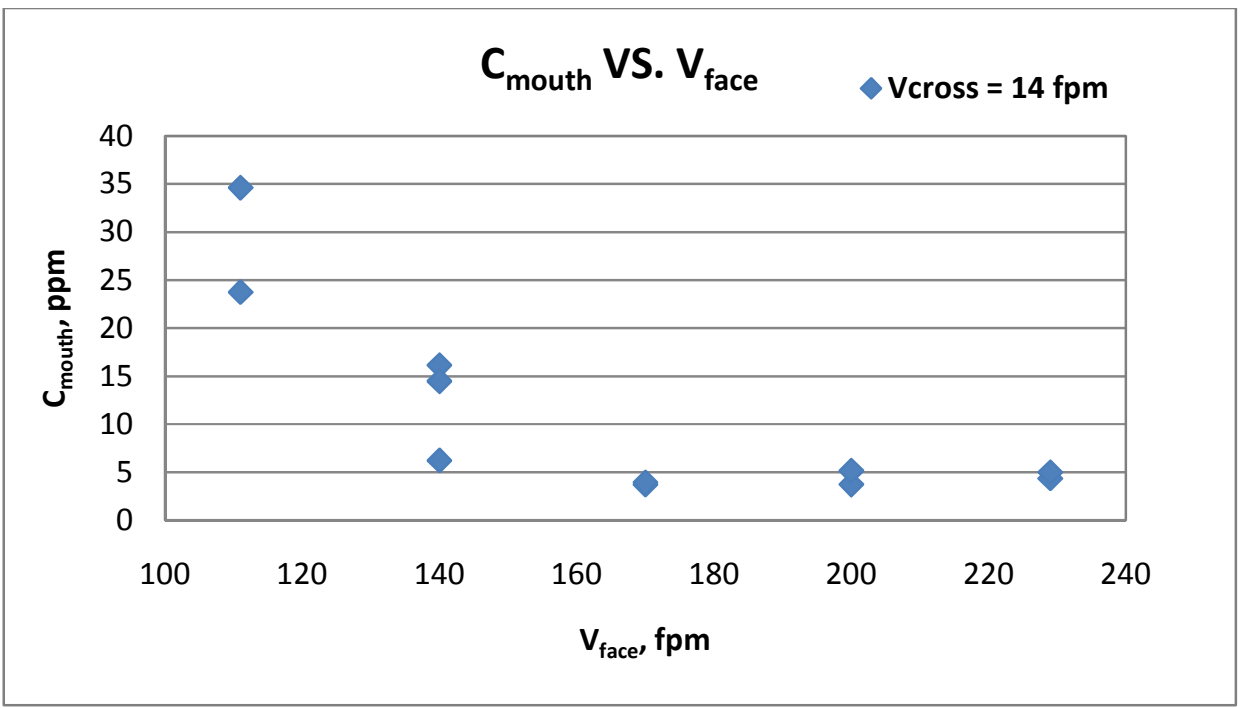

Figure 4.2.1- a: Mouth concentration versus hood face velocity for plain hood $\left(V_{\text {cross }}=14 \mathrm{fpm}\right)$

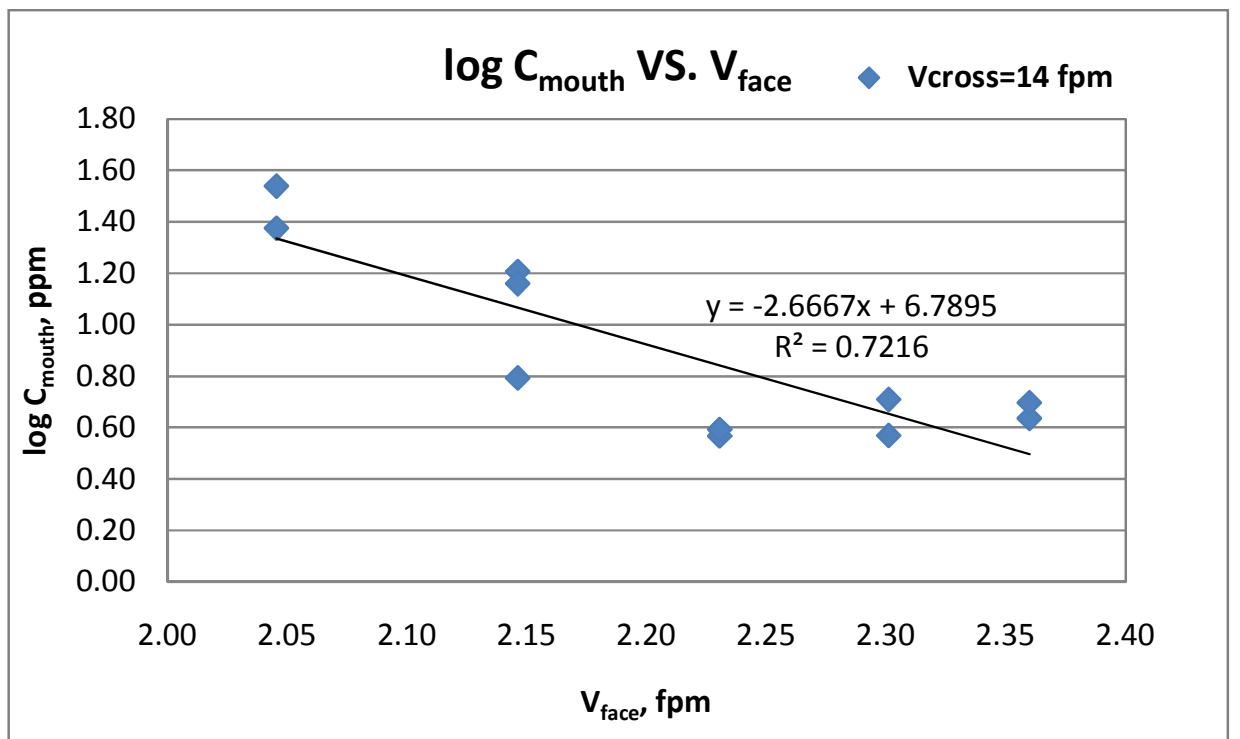

Figure 4.2.1- b: $\log C_{\text {mouth }}$ versus hood face velocity for plain hood $\left(V_{\text {cross }}=14 \mathrm{fpm}\right)$ 


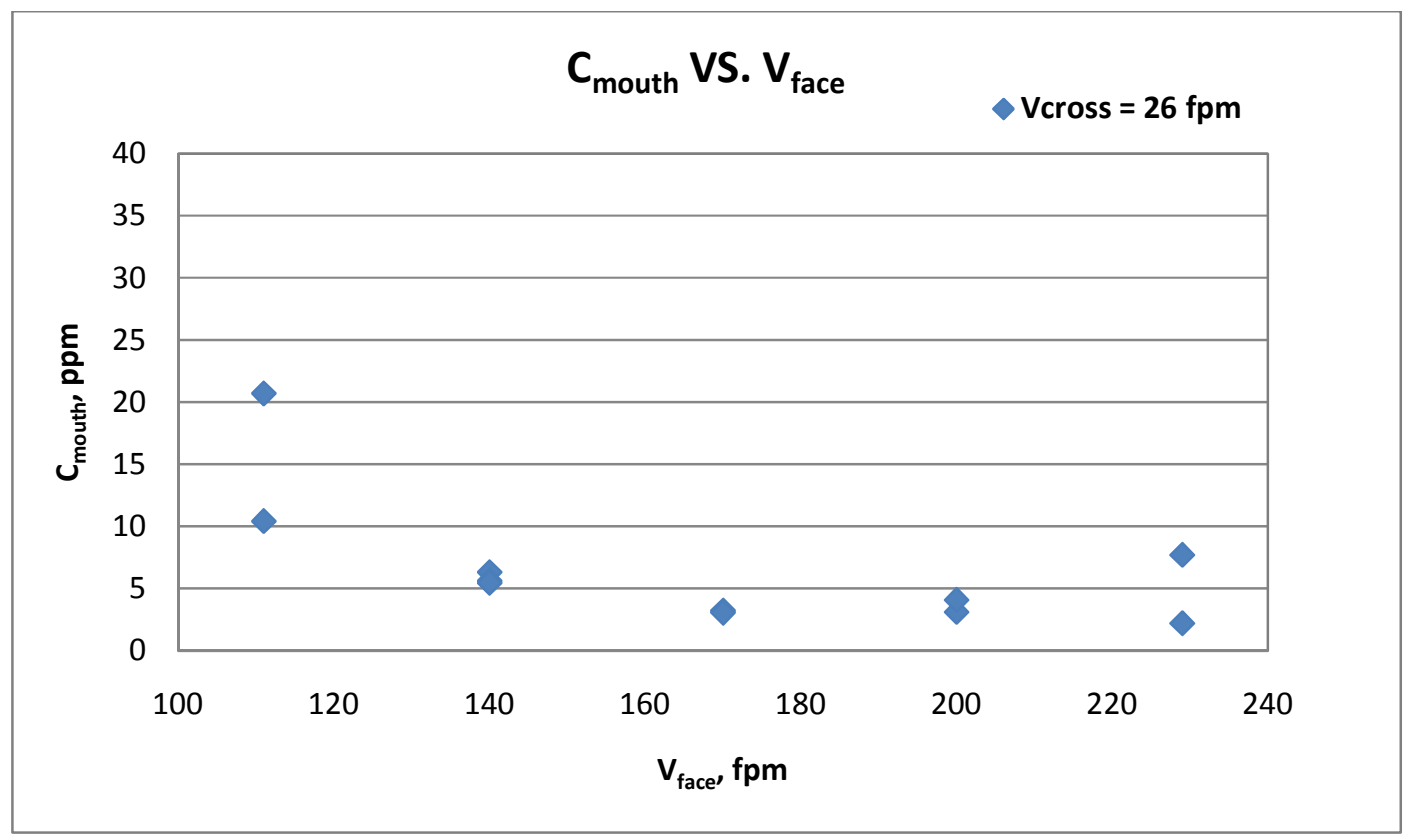

Figure 4.2.2- a: Mouth concentration versus hood face velocity for plain hood $\left(V_{\text {cross }}=26 \mathrm{fpm}\right)$

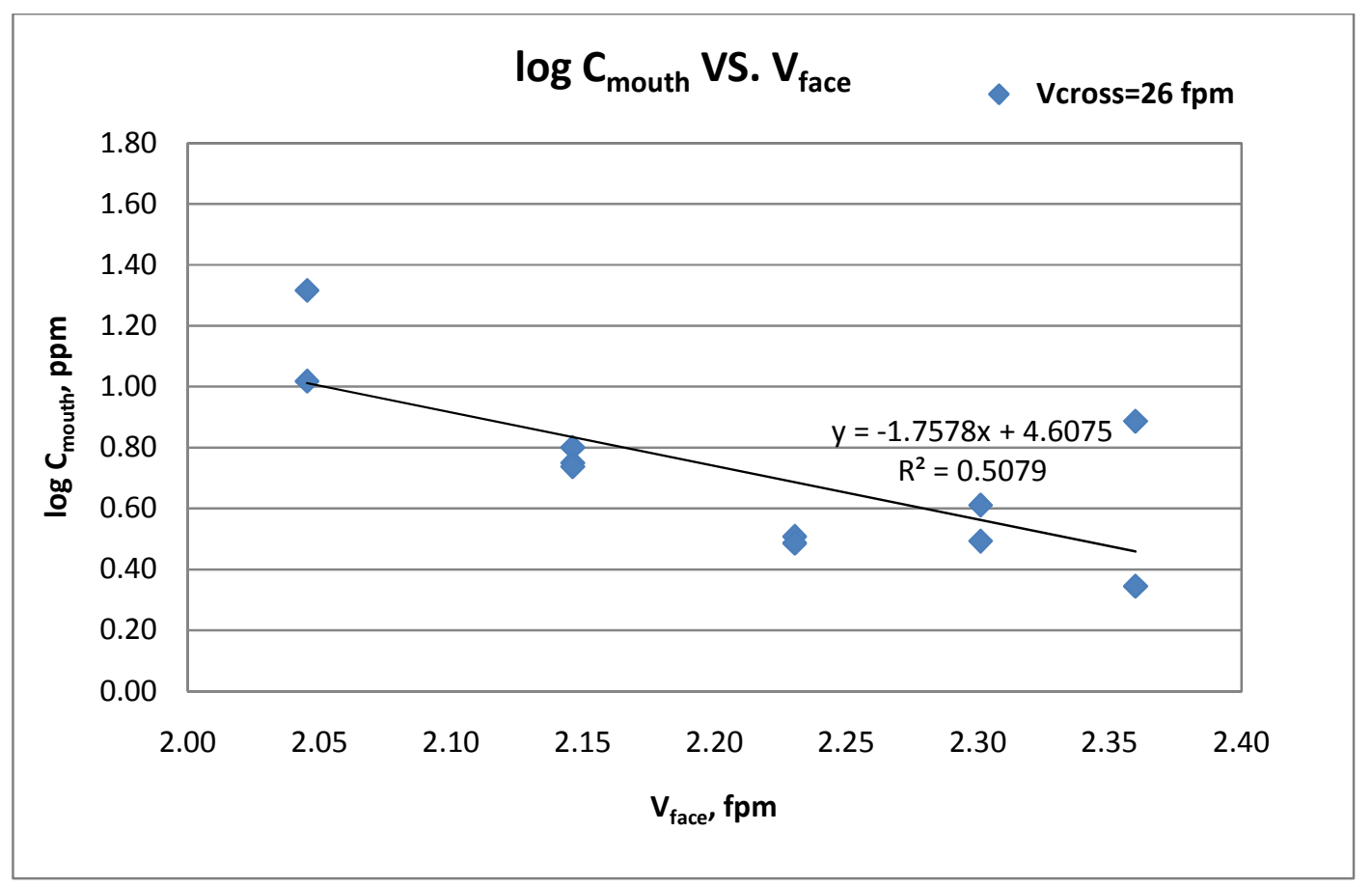

Figure 4.2.2- b: $\log C_{\text {mouth }}$ versus hood face velocity for plain hood $\left(V_{\text {cross }}=26 \mathrm{fpm}\right)$ 


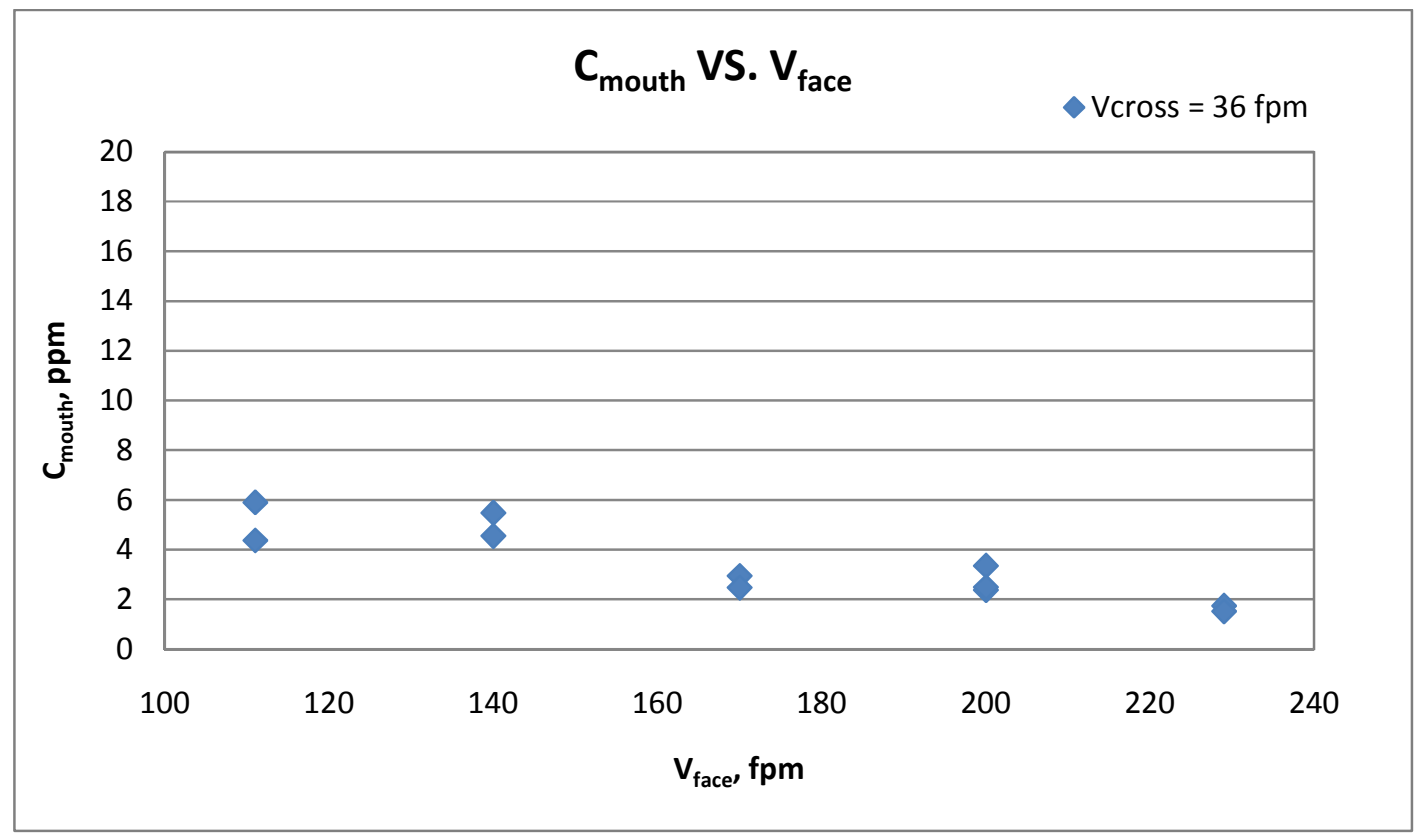

Figure 4.2.3- a: Mouth concentration versus hood face velocity for plain hood $\left(V_{\text {cross }}=36 \mathrm{fpm}\right)$

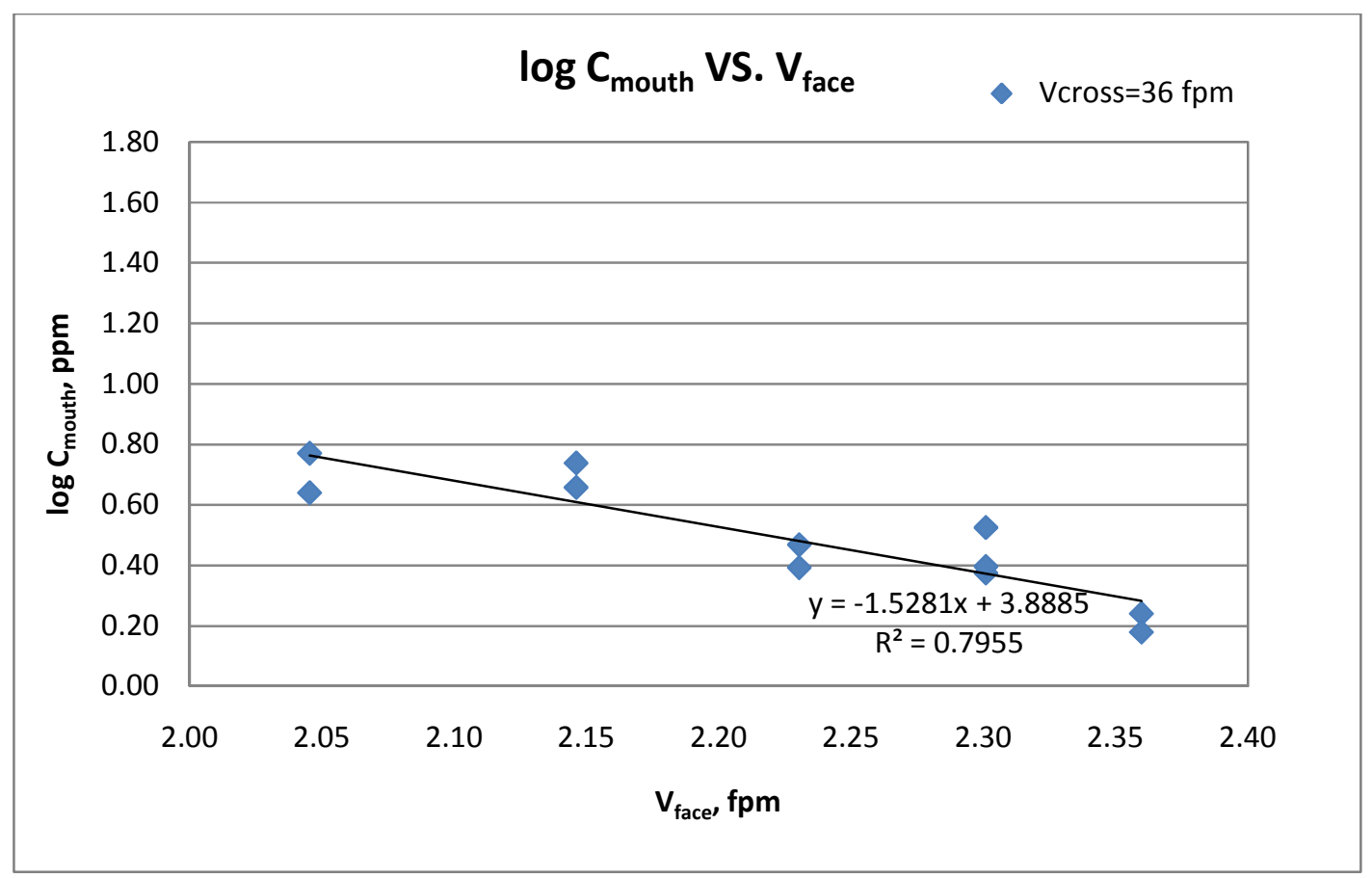

Figure 4.2.3- b: $\log C_{\text {mouth }}$ versus hood face velocity for plain hood $\left(V_{\text {cross }}=36 \mathrm{fpm}\right)$ 


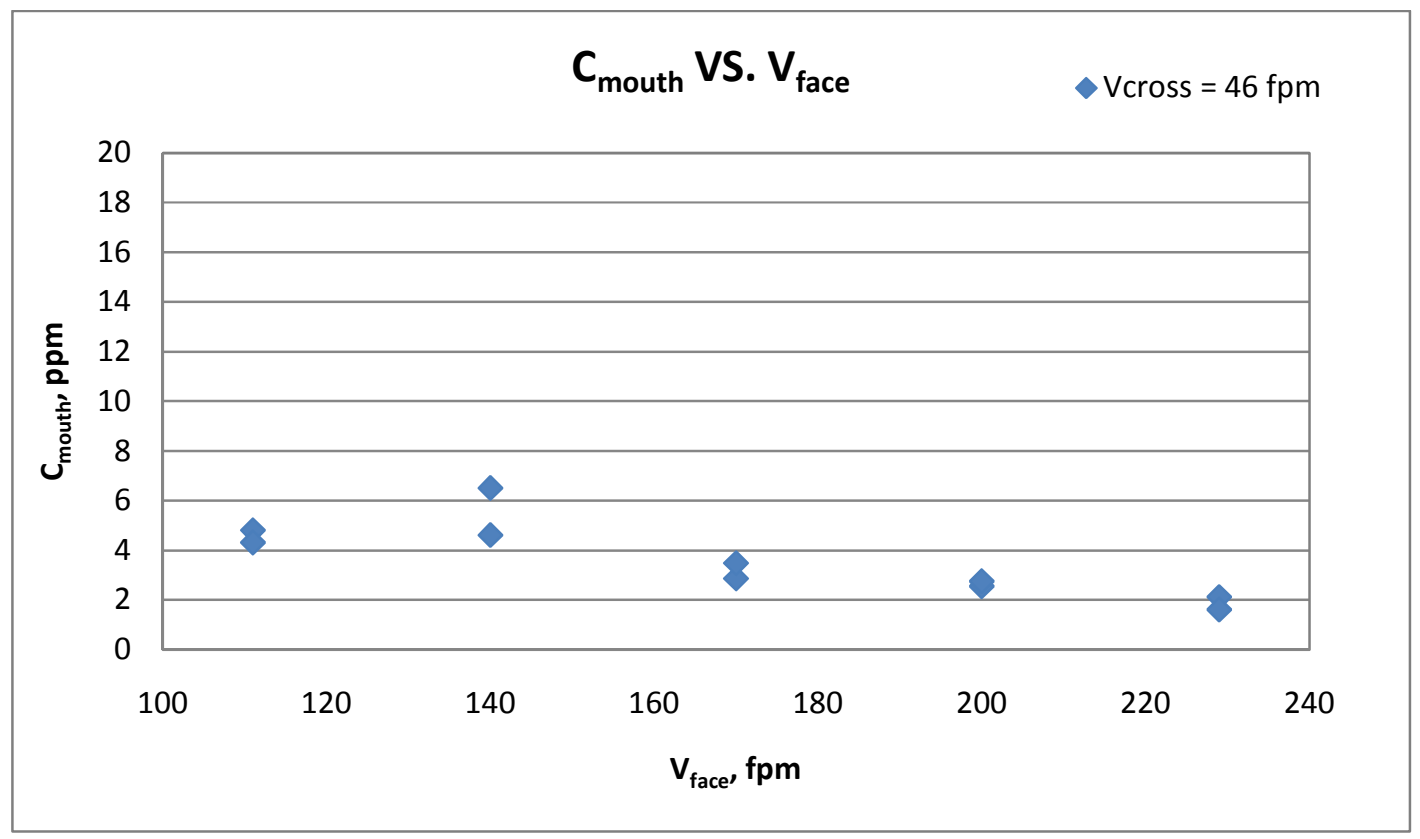

Figure 4.2.4- a: Mouth concentration versus hood face velocity for plain hood $\left(V_{\text {cross }}=46 \mathrm{fpm}\right)$

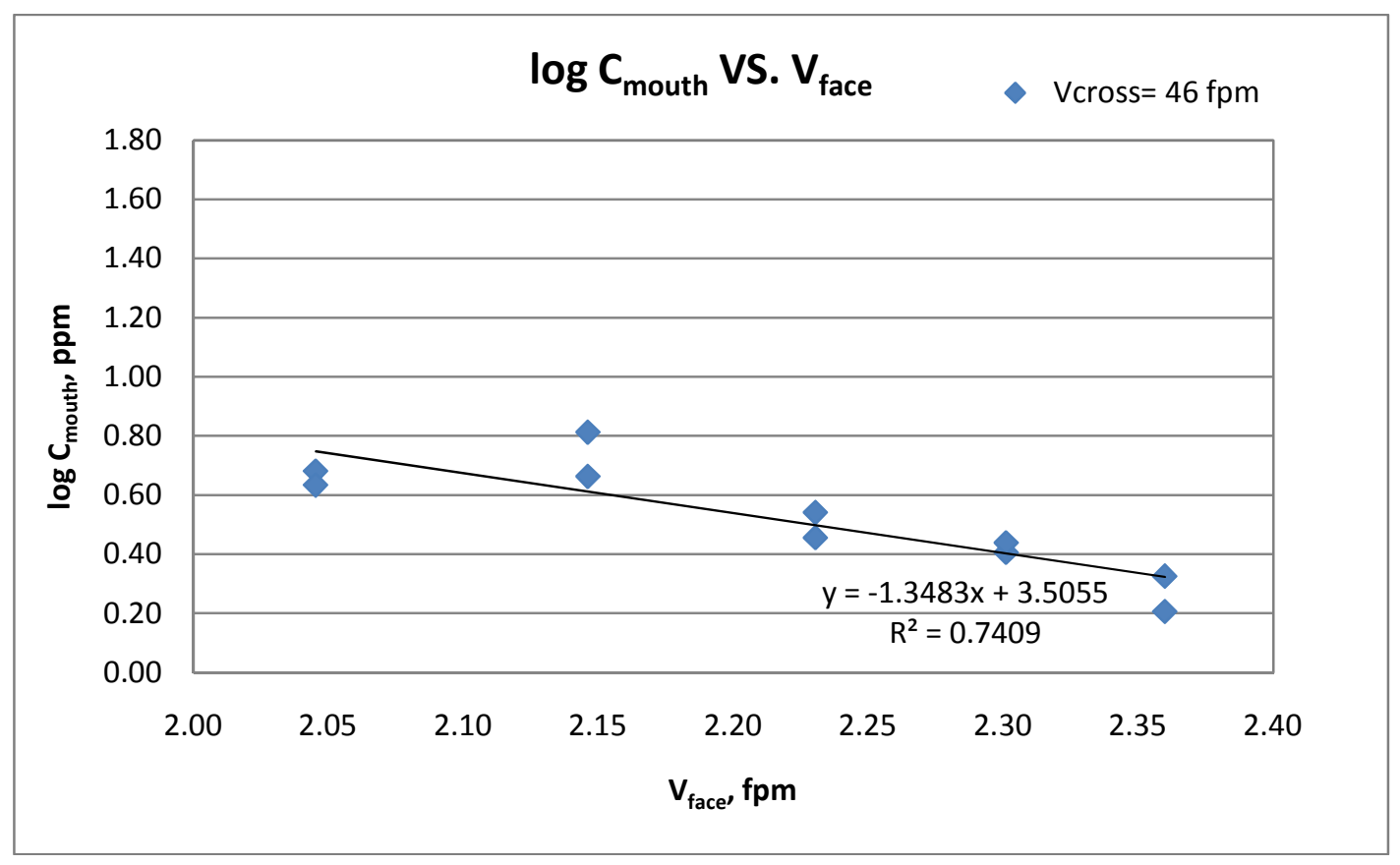

Figure 4.2.4- b: $\log C_{\text {mouth }}$ versus hood face velocity for plain hood $\left(V_{\text {cross }}=46 \mathrm{fpm}\right)$ 


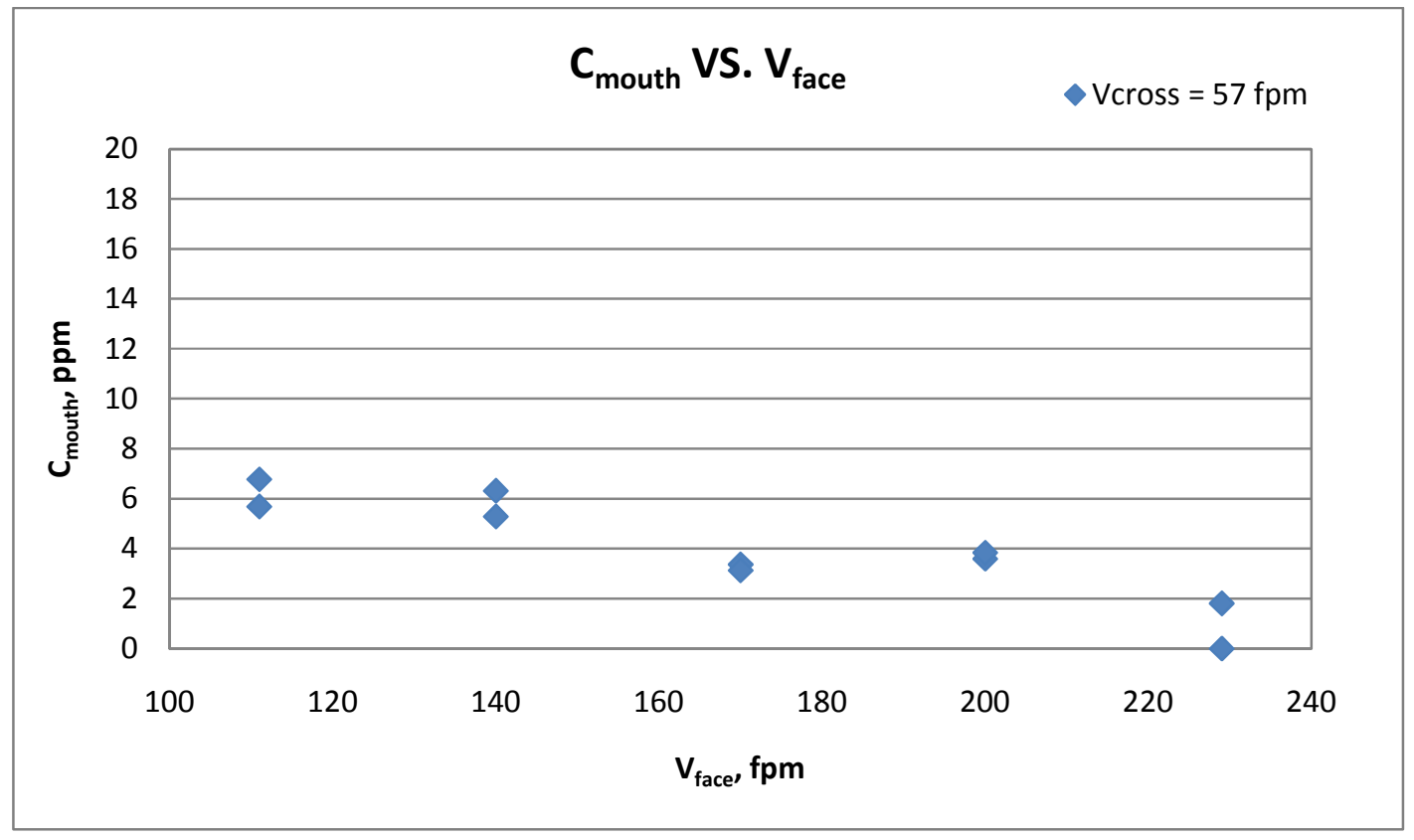

Figure 4.2.5- a: Mouth concentration versus hood face velocity for plain hood $\left(V_{\text {cross }}=57 f p m\right)$

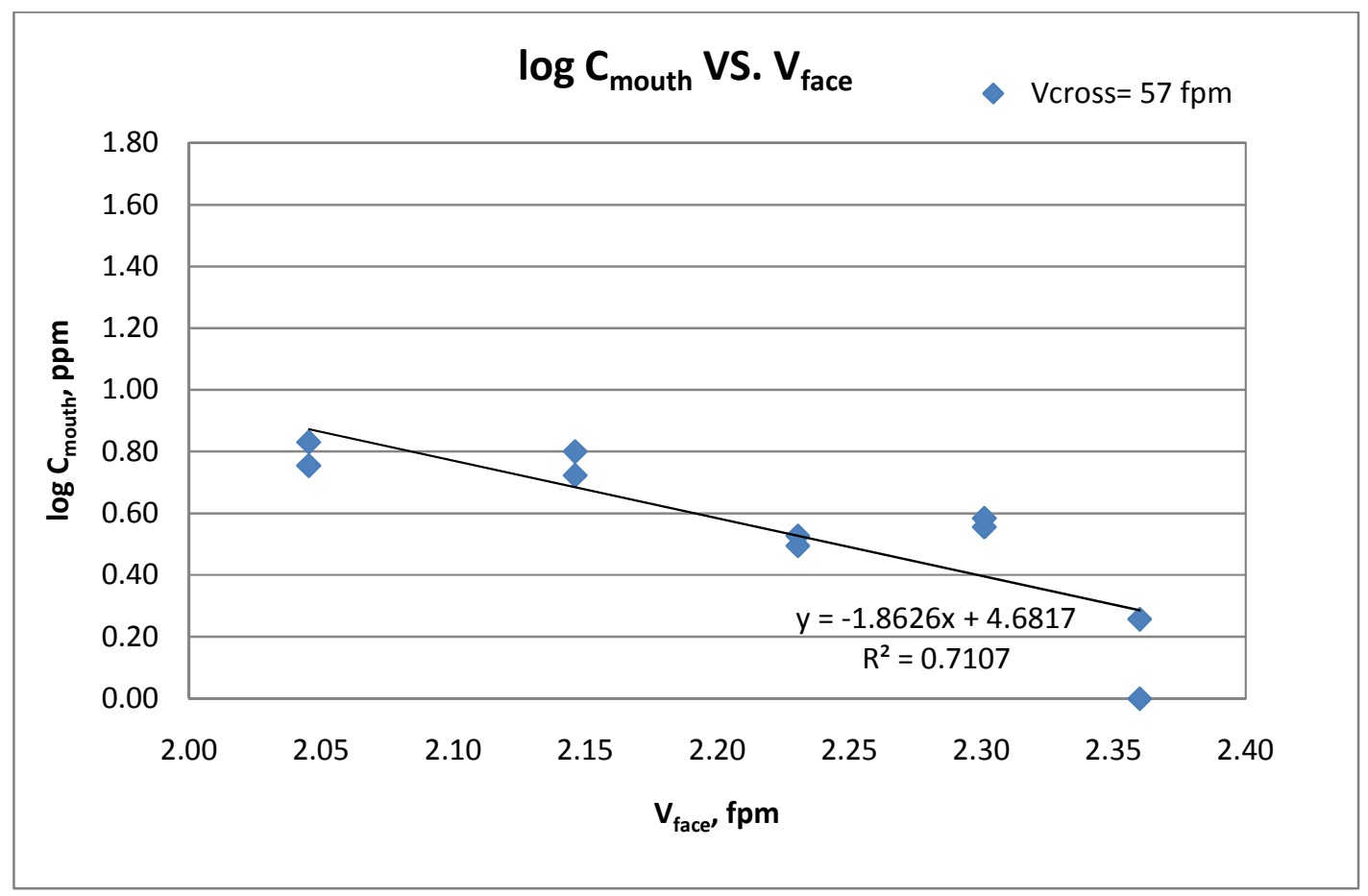

Figure 4.2.5- b: $\log C_{\text {mouth }}$ versus hood face velocity for plain hood $\left(V_{\text {cross }}=57 \mathrm{fpm}\right)$ 


\subsection{Effects of Wind Tunnel Cross-Draft $\left(V_{\text {cross }}\right)$ on Concentration at Mouth $\left(C_{\text {mouth }}\right)$}

Wind tunnel cross-draft velocity was another factor which could affect the performance of an enclosing hood. Five levels of cross-draft velocity were studied: 14, 26, 36, 46 and $57 \mathrm{ft} / \mathrm{min}$ at five levels of $\mathrm{V}_{\text {face }}: 111,140,170,200$ and $229 \mathrm{ft} / \mathrm{min}$.

Many researchers studying laboratory fume hoods state that cross-draft velocity made the hood performance worse and should be reduced as low as possible (Brent A. Altemose, 1998) (Caplan, 1982).

However, the results of this study do not support that assumption. As shown in Figures 4.3.1 to 4.3.5, the lower values of $\mathrm{V}_{\text {cross }}$ are associated with the higher $\mathrm{C}_{\text {mouth }}$ values in every case. The lowest $\mathrm{C}_{\text {mouth }}$ values were found in the middle range of cross-draft, $V_{\text {cross }}=36 \mathrm{fpm}$.

One reason is perhaps that previous studies investigated laboratory fume hoods, whose sash profoundly affects flow into the hood. 


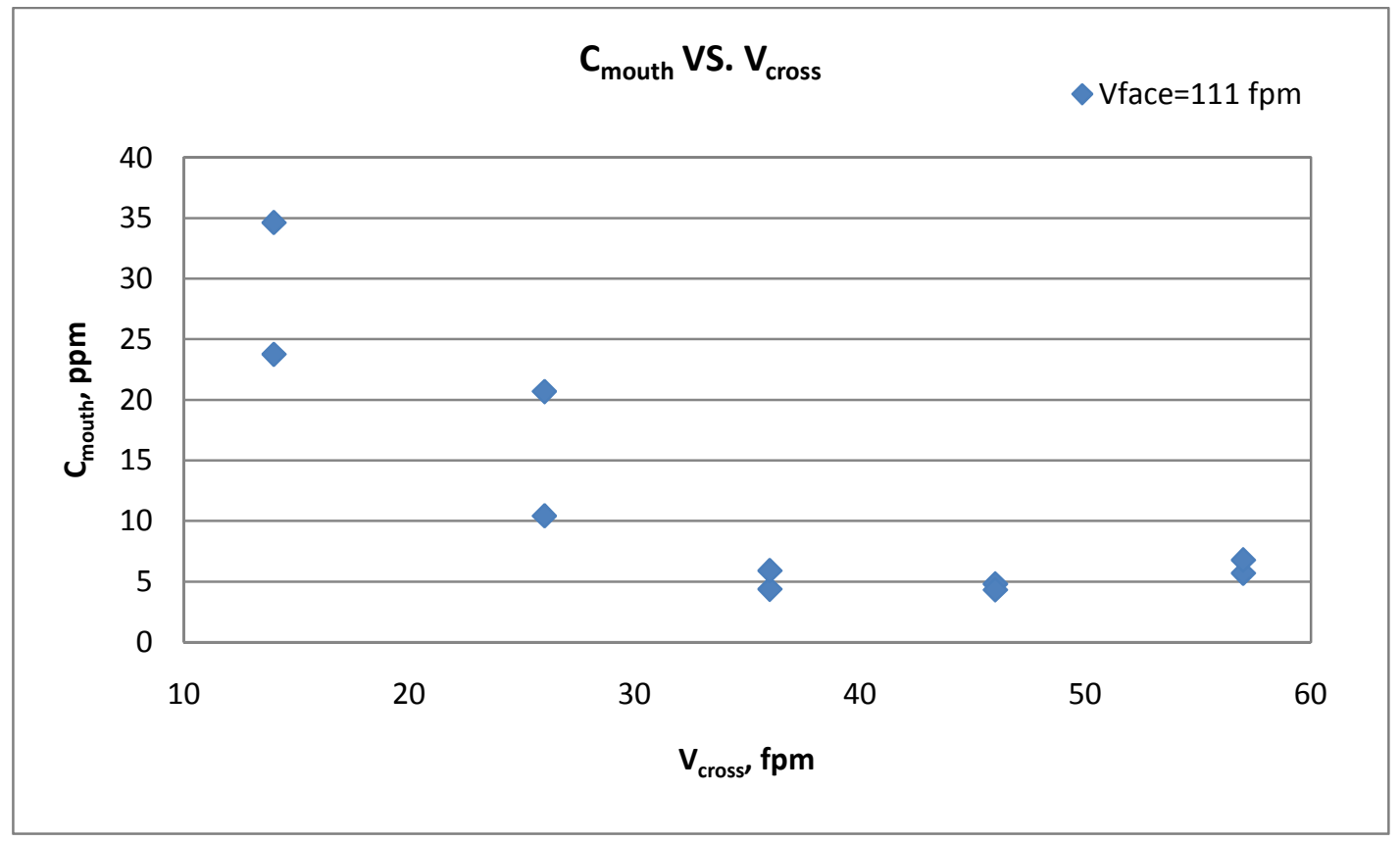

Figure 4.3- a: Mouth concentration versus wind tunnel cross-draft velocity for plain hood $\left(V_{\text {face }}=\right.$ $111 \mathrm{fpm}$ )

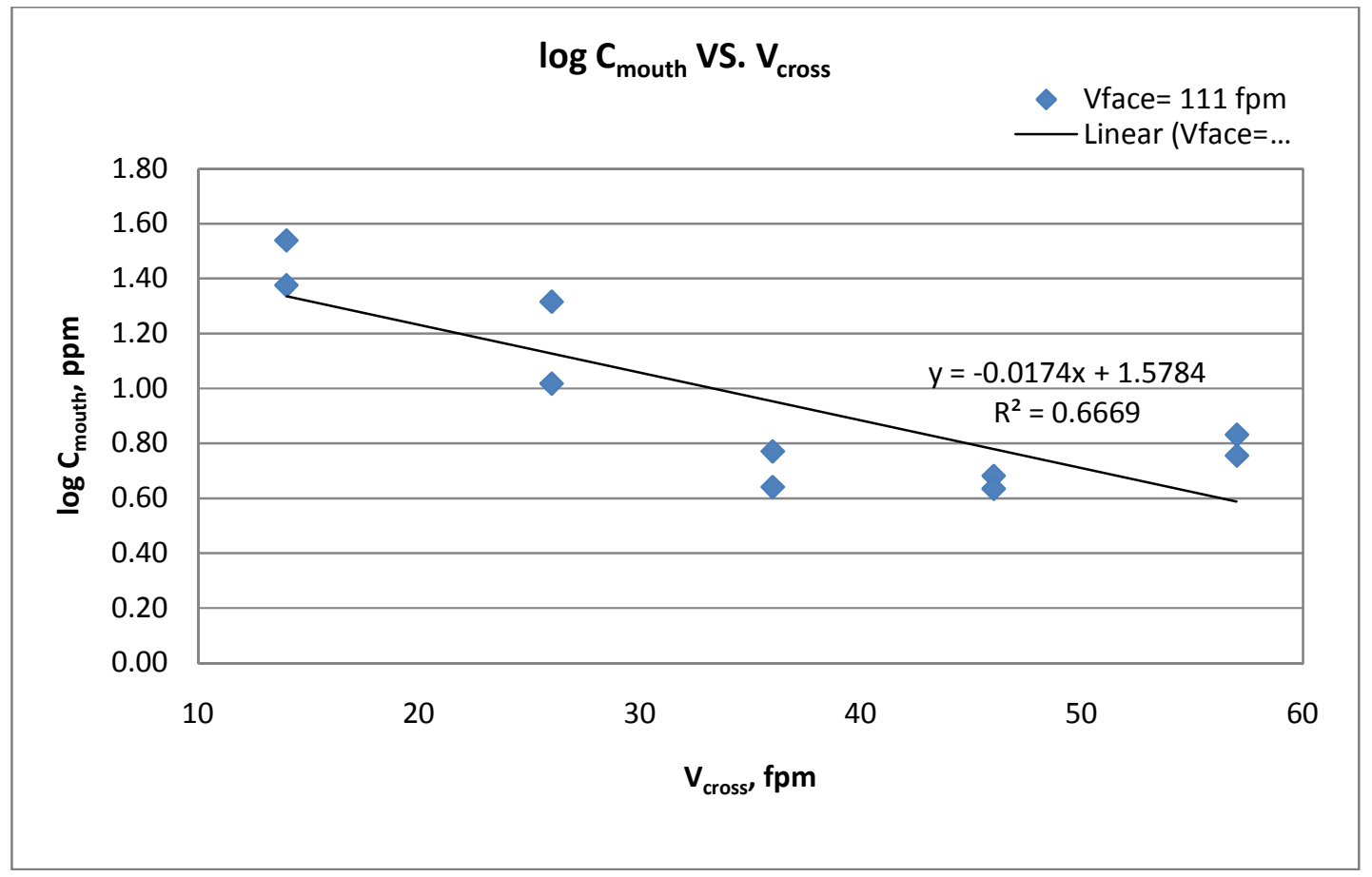

Figure 4.3- b: $\log C_{\text {mouth }}$ versus wind tunnel cross-draft velocity for plain hood $\left(V_{\text {face }}=111 \mathrm{fpm}\right)$ 


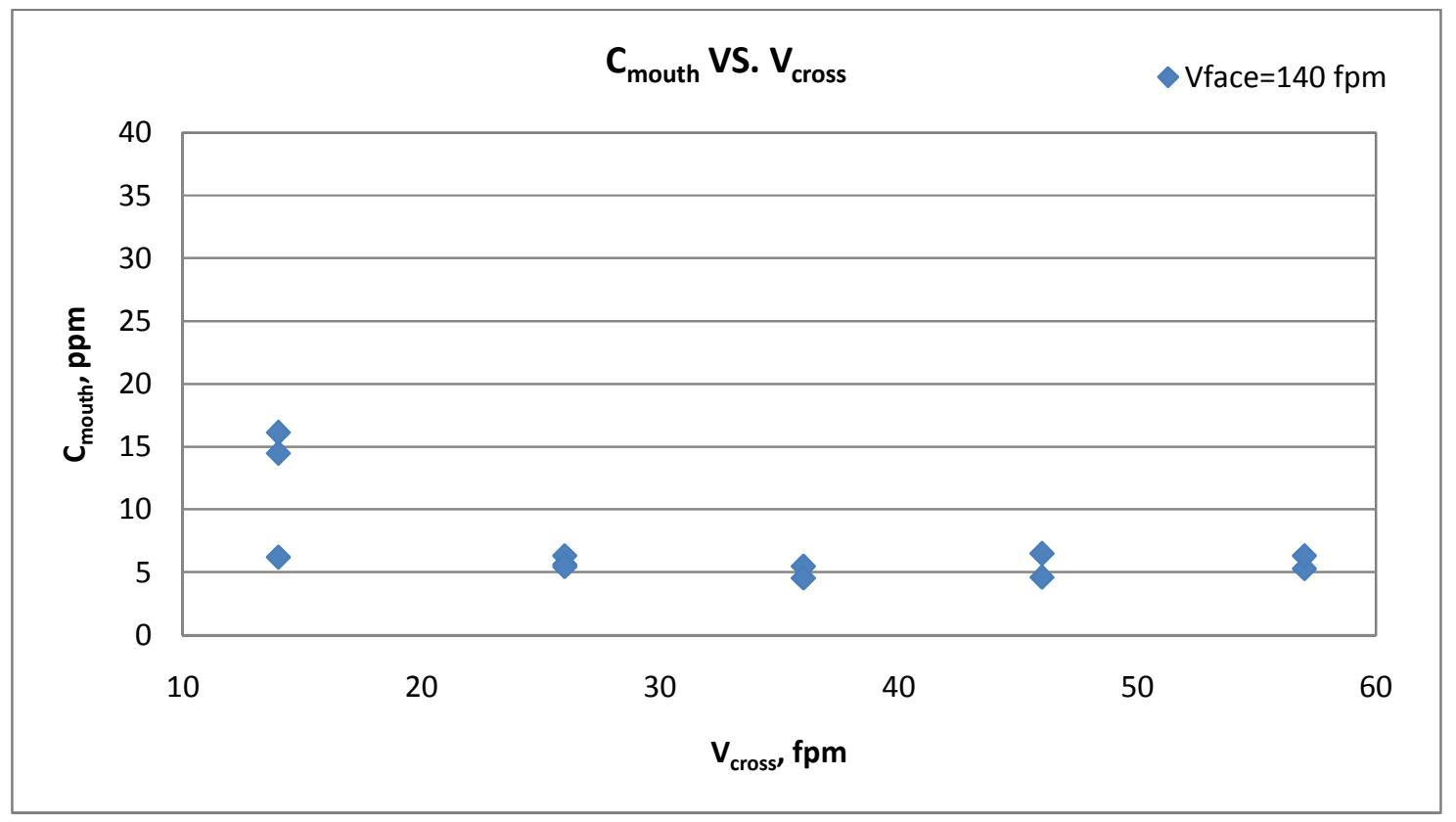

Figure 4.3- c: Mouth concentration versus wind tunnel cross-draft velocity for plain hood $\left(V_{\text {face }}=\right.$ $140 \mathrm{fpm}$ )

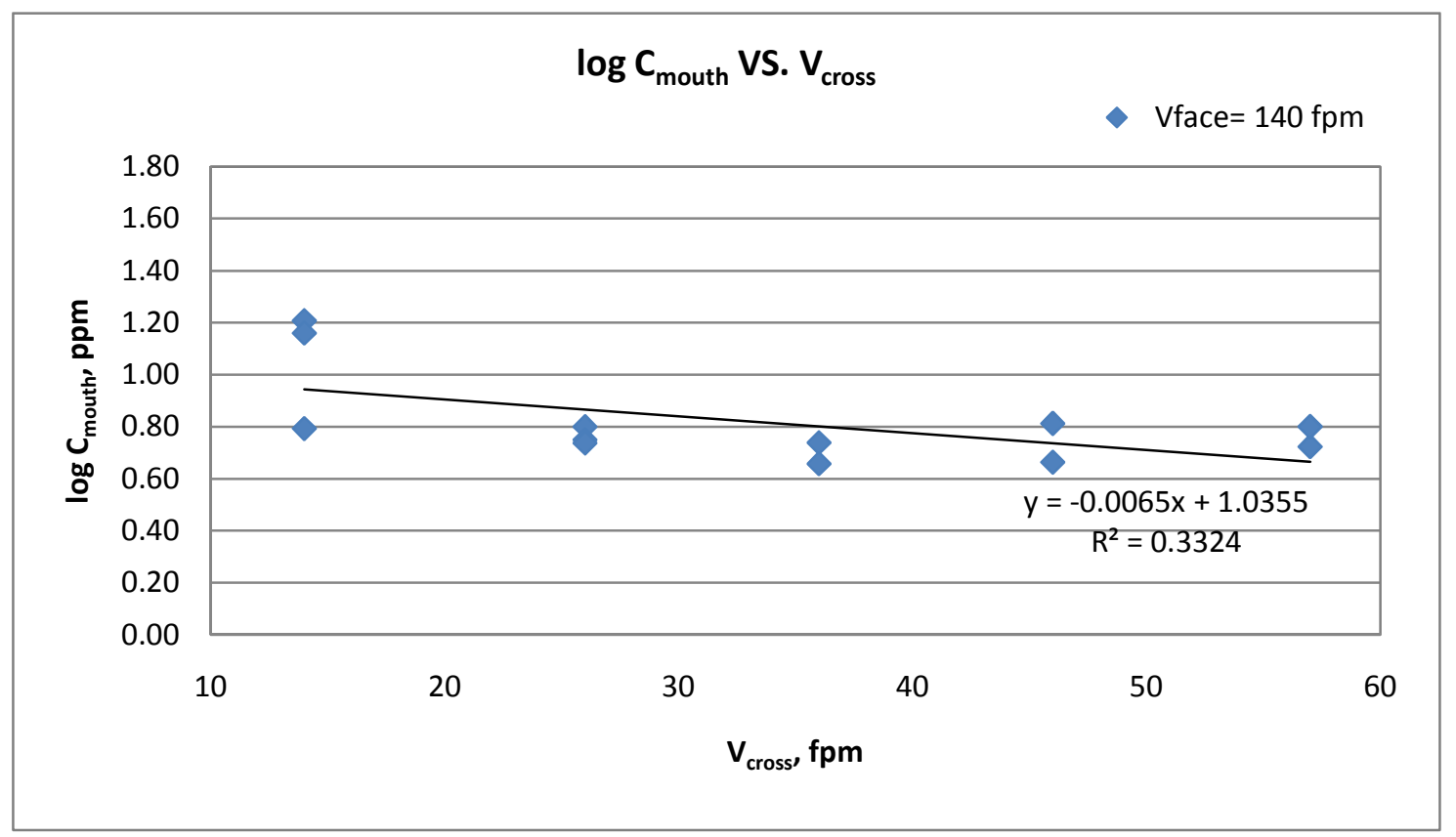

Figure 4.3- d: $\log C_{\text {mouth }}$ versus wind tunnel cross-draft velocity for plain hood $\left(V_{\text {face }}=140 \mathrm{fpm}\right)$ 


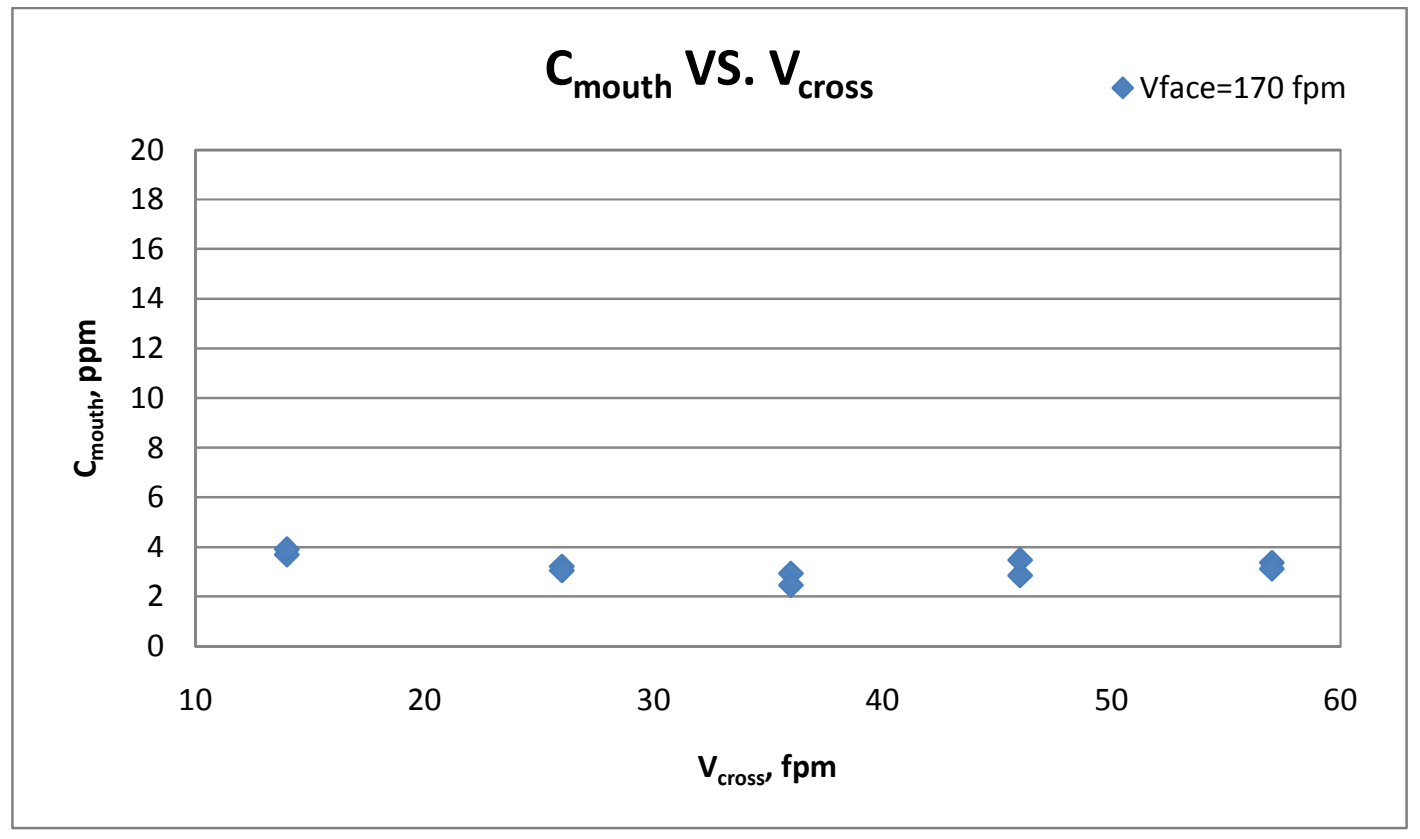

Figure 4.3- e: Mouth concentration versus wind tunnel cross-draft velocity for plain hood $\left(V_{\text {face }}=\right.$ $170 \mathrm{fpm}$ )

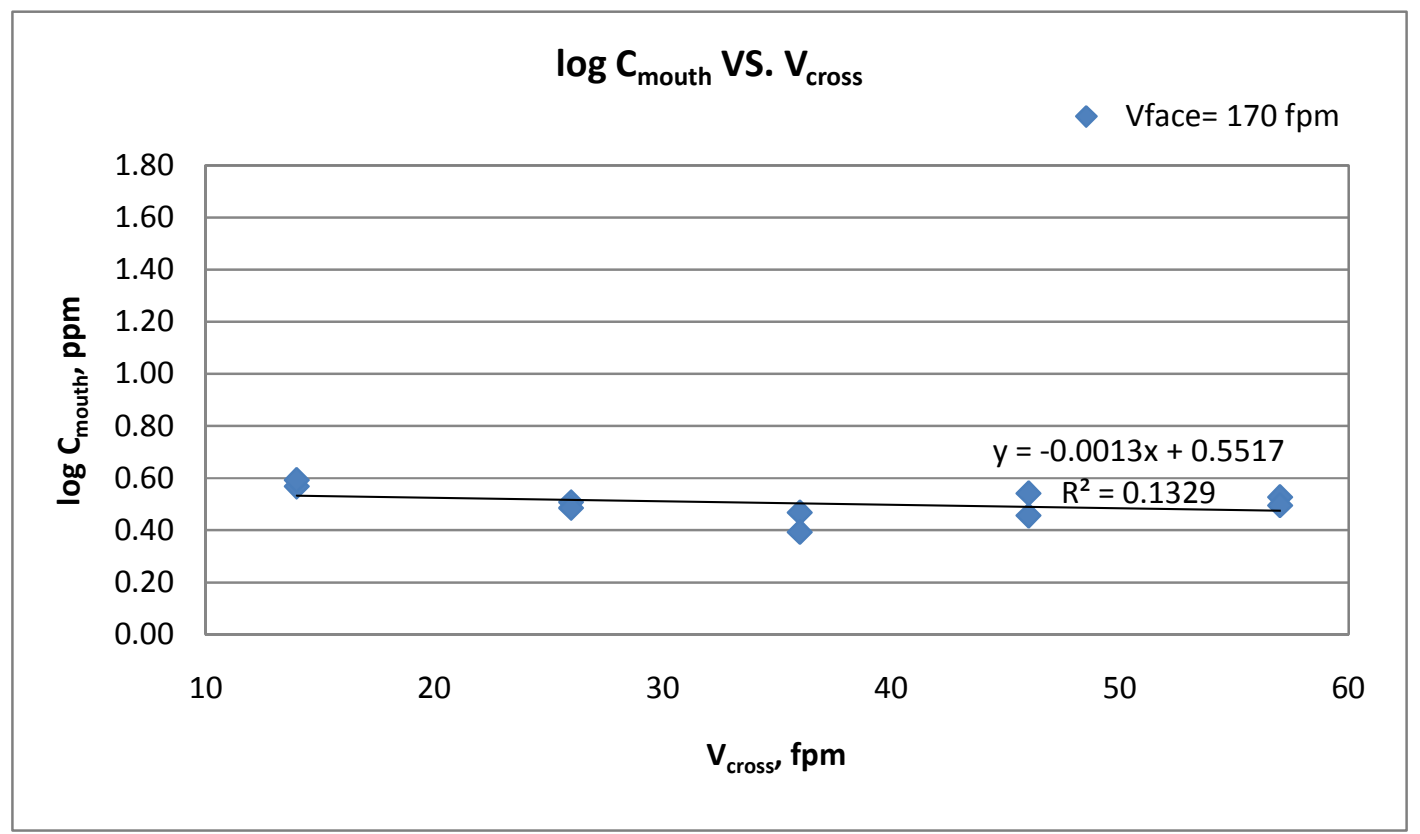

Figure 4.3- f: $\log \mathrm{C}_{\text {mouth }}$ versus wind tunnel cross-draft velocity for plain hood $\left(V_{\text {face }}=170 \mathrm{fpm}\right)$ 


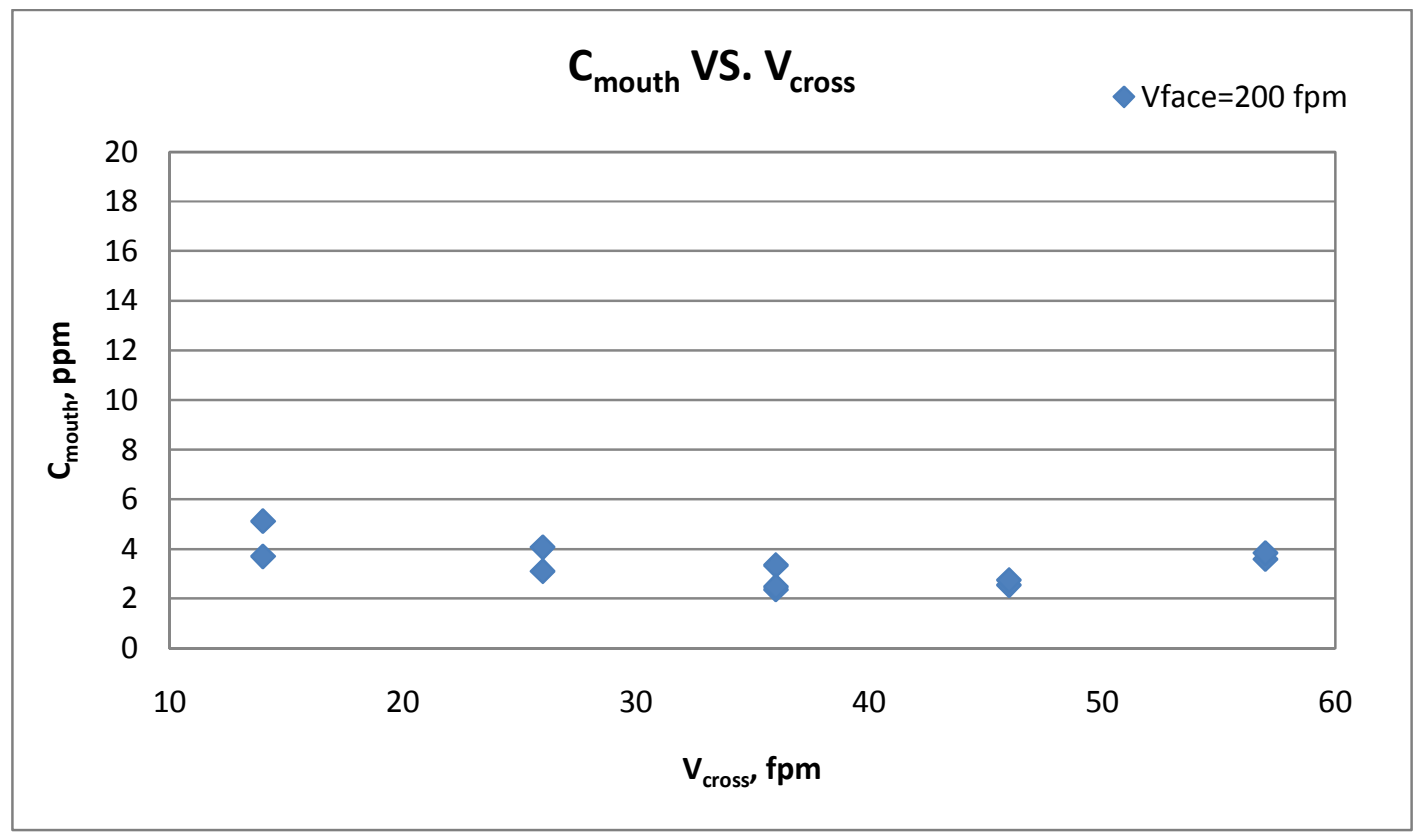

Figure 4.3- $\mathrm{g}$ : Mouth concentration versus wind tunnel cross-draft velocity for plain hood ( $V_{\text {face }}$ $=200 \mathrm{fpm}$ )

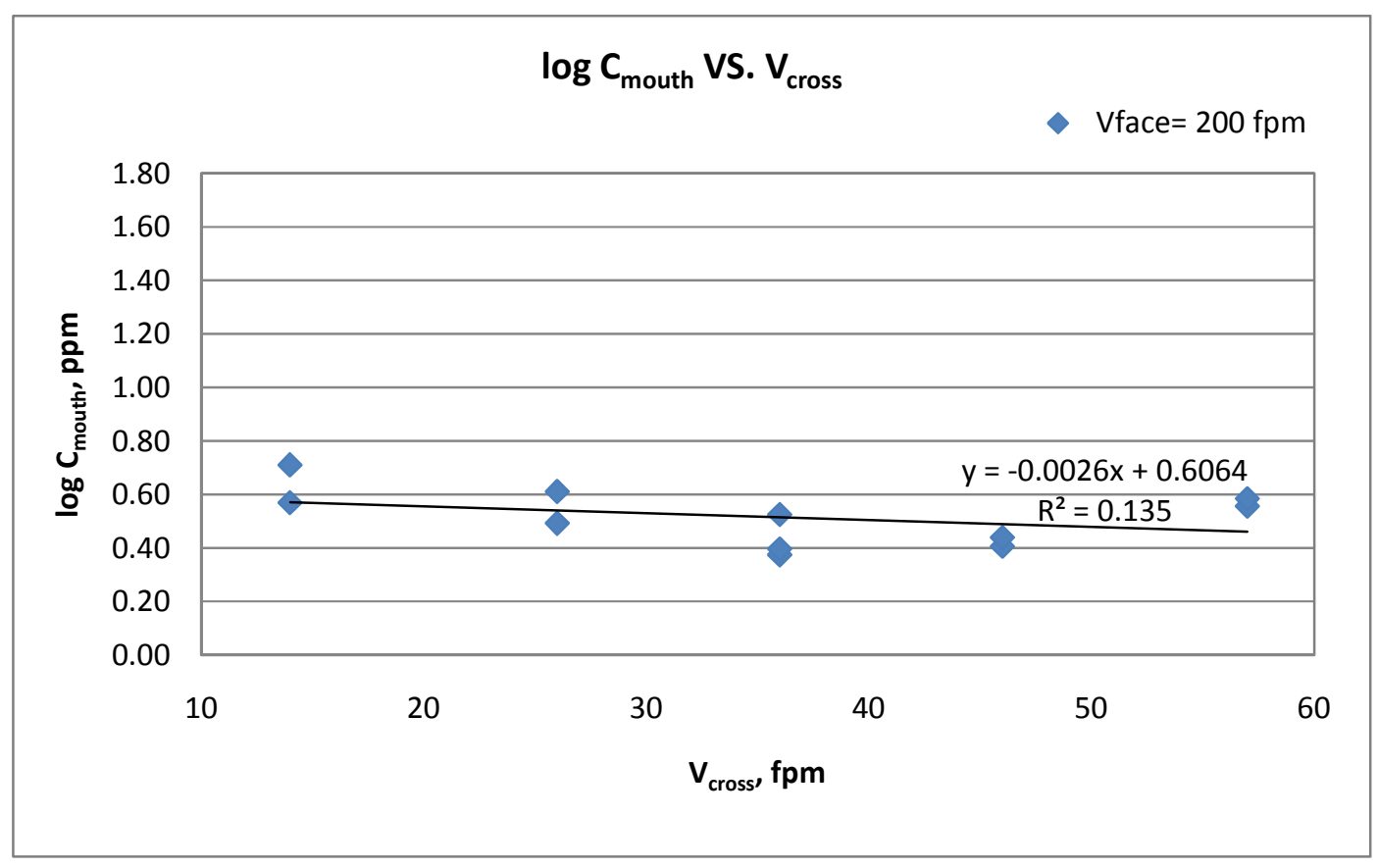

Figure 4.3- h: $\log C_{\text {mouth }}$ versus wind tunnel cross-draft velocity for plain hood $\left(V_{\text {face }}=200 \mathrm{fpm}\right)$ 


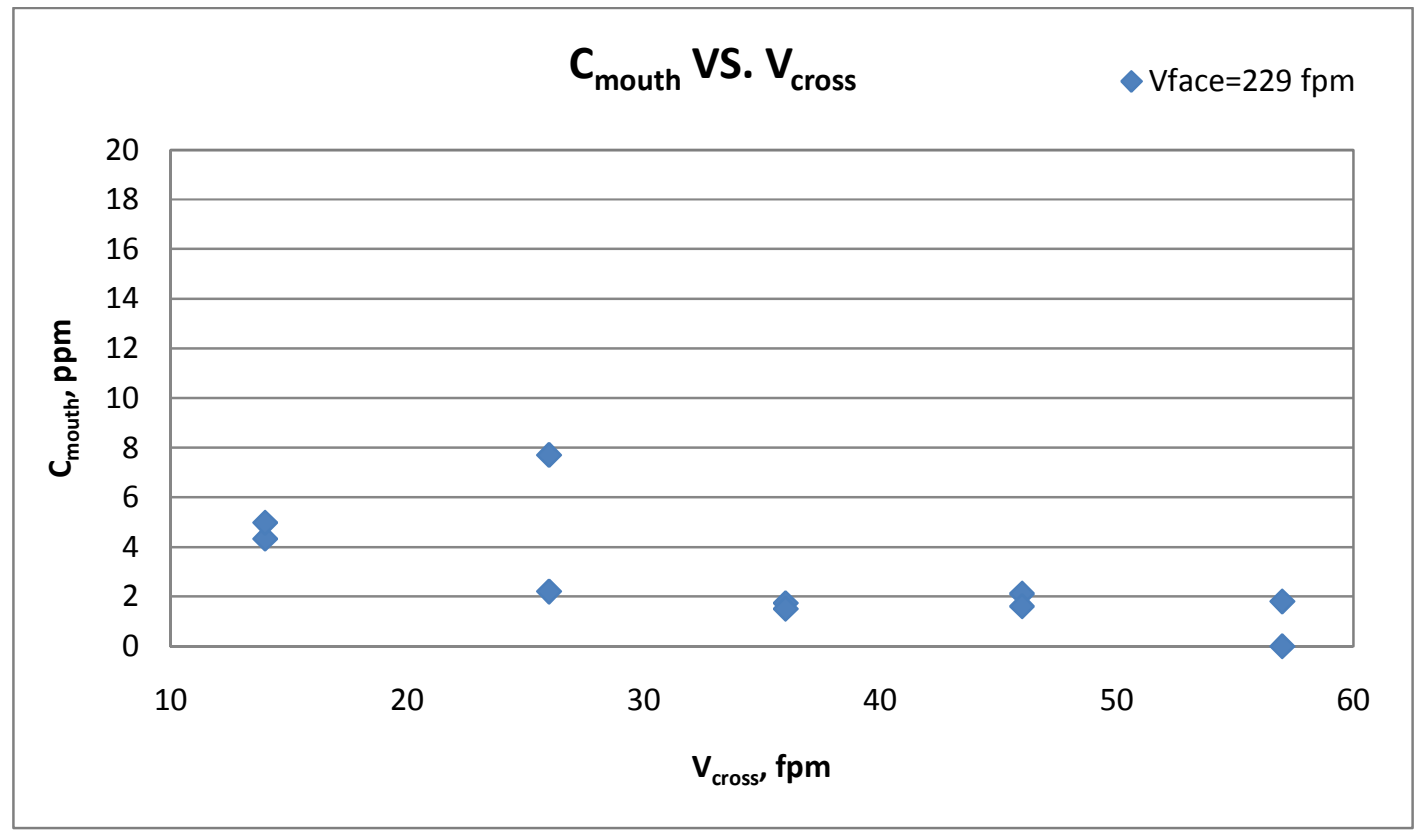

Figure 4.3- i: Mouth concentration versus wind tunnel cross-draft velocity for plain hood $\left(V_{\text {face }}=\right.$ 229 fpm)

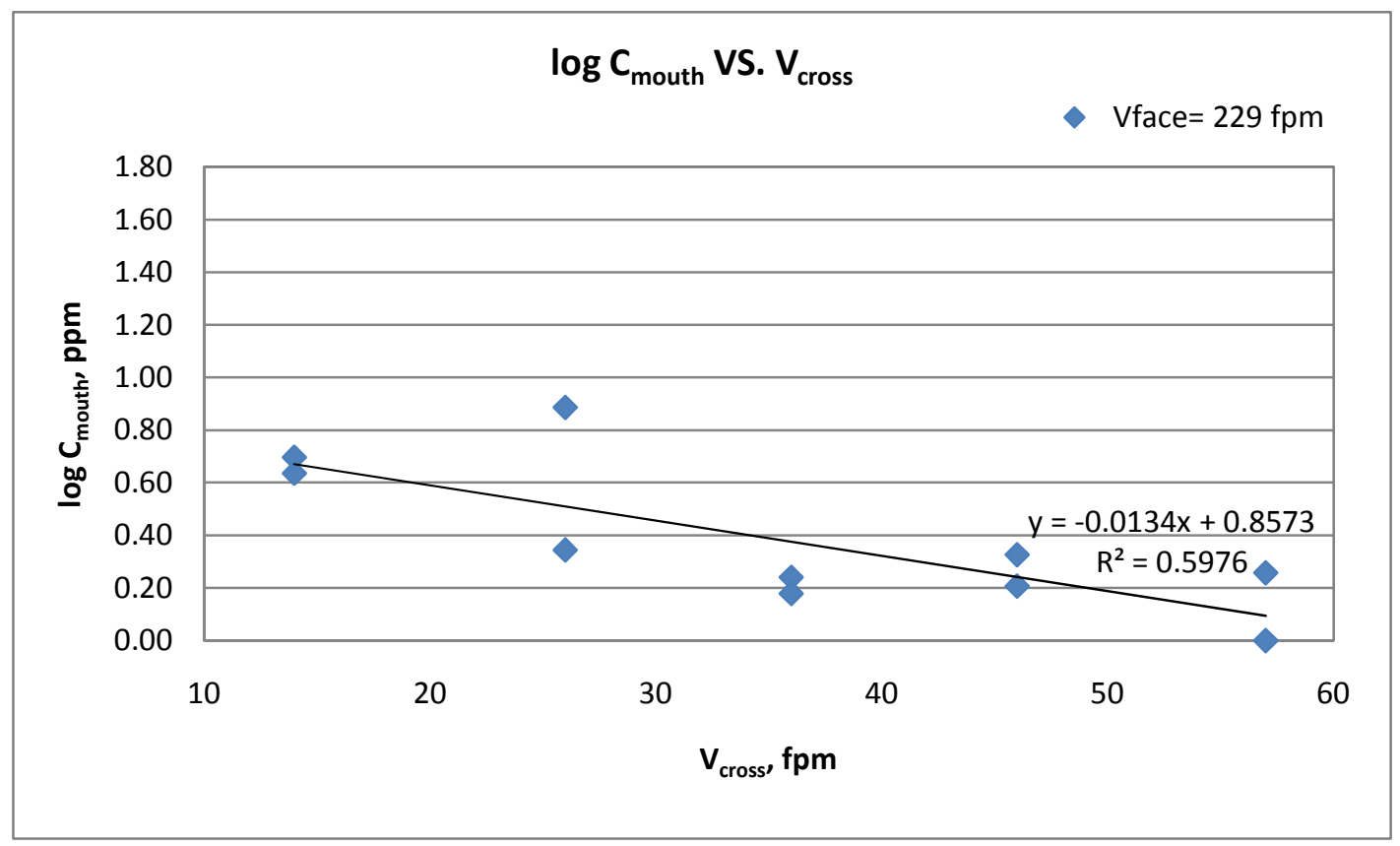

Figure 4.3- $\mathrm{j}$ : $\log \mathrm{C}_{\text {mouth }}$ versus wind tunnel cross-draft velocity for plain hood $\left(V_{\text {face }}=229 \mathrm{fpm}\right)$ 


\section{Chapter 5: Discussions of Study I}

\subsection{Effects of Independent Variables on Mouth Concentration}

In this study, there were two independent variables, $V_{\text {face }}$ and $V_{\text {cross }}$. As shown in Figures 5.1 to 5.4, each affects $C_{\text {mouth }}$. The lowest $C_{\text {mouth }}$ occured at $V_{\text {face }}=170 \mathrm{fpm}$ and $V_{\text {cross }}=36 \mathrm{fpm}$.

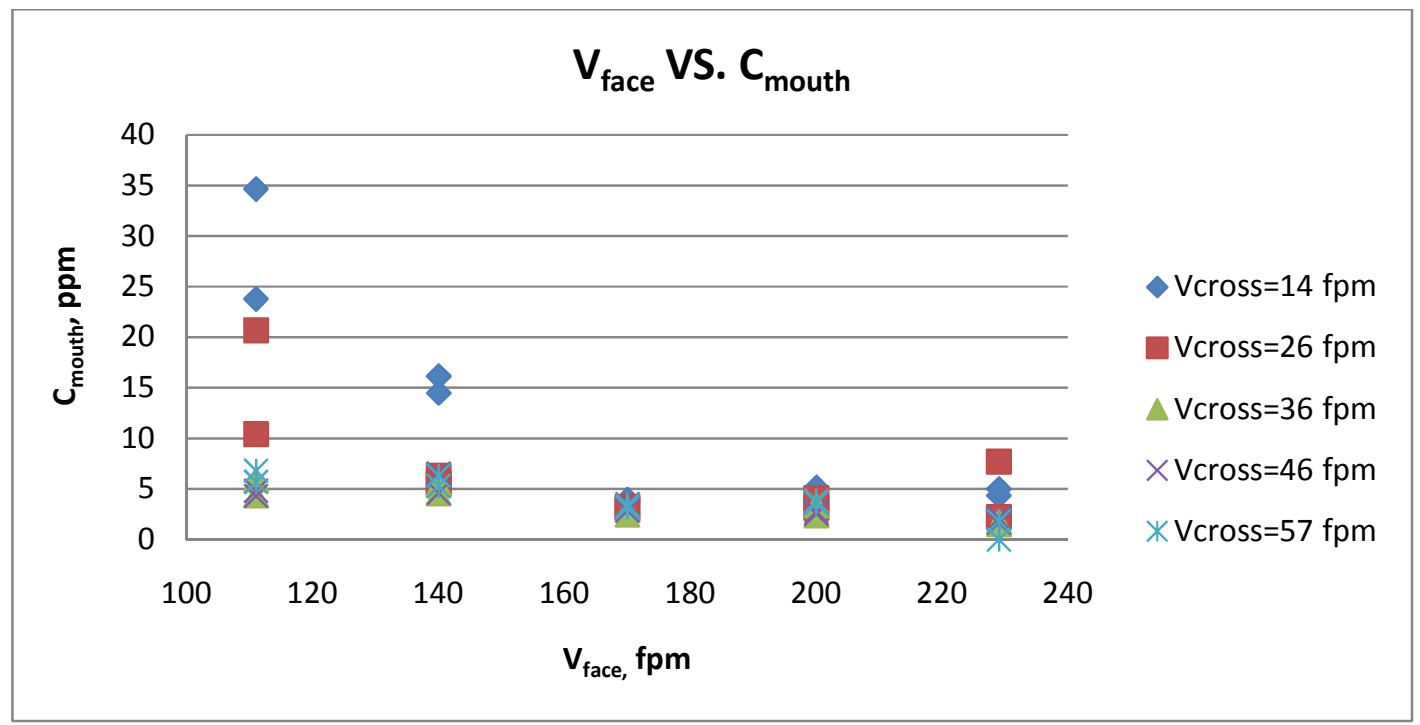

Figure 5. 1: Hood face velocity versus mouth concentration for plain hood regardless of the levels of wind tunnel cross-draft velocity

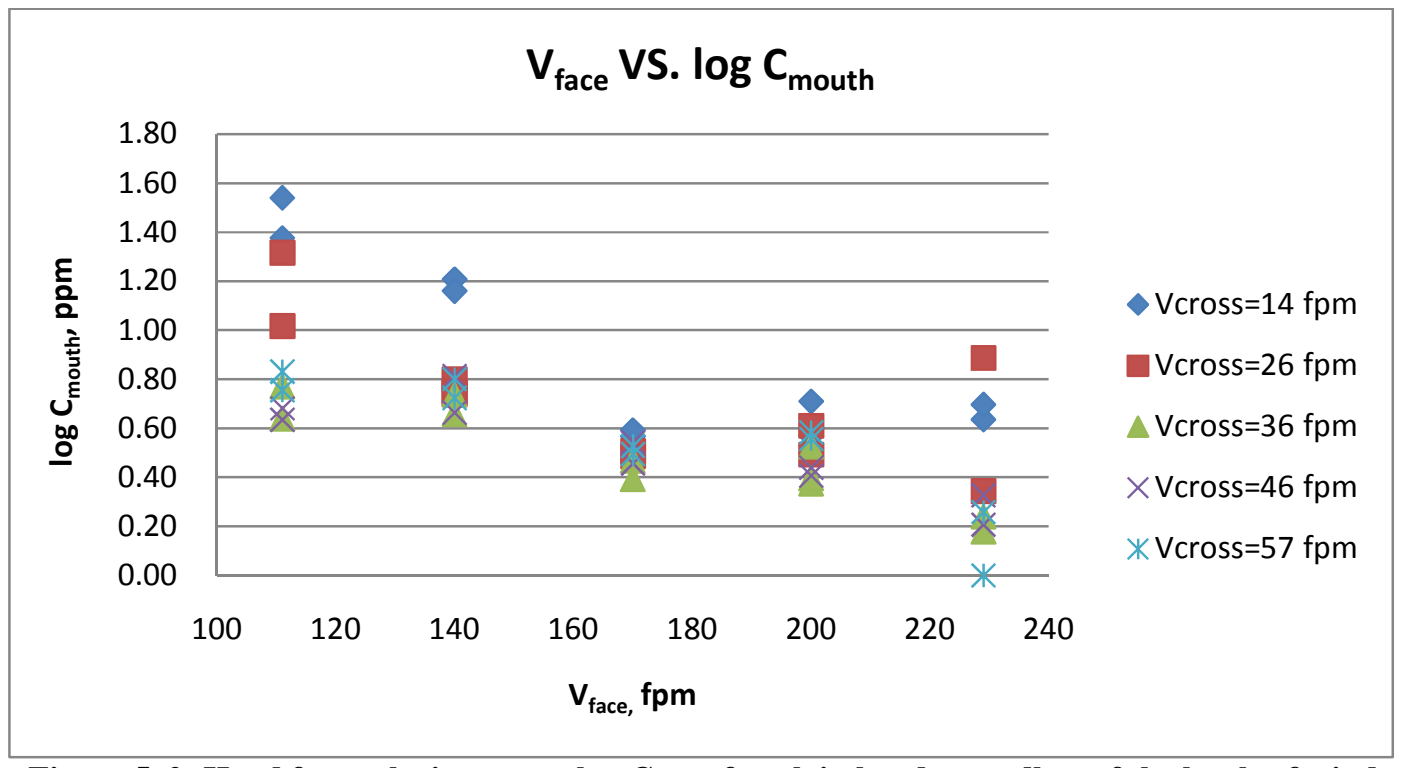

Figure 5. 2: Hood face velocity versus $\log C_{\text {mouth }}$ for plain hood regardless of the levels of wind tunnel cross-draft velocity 


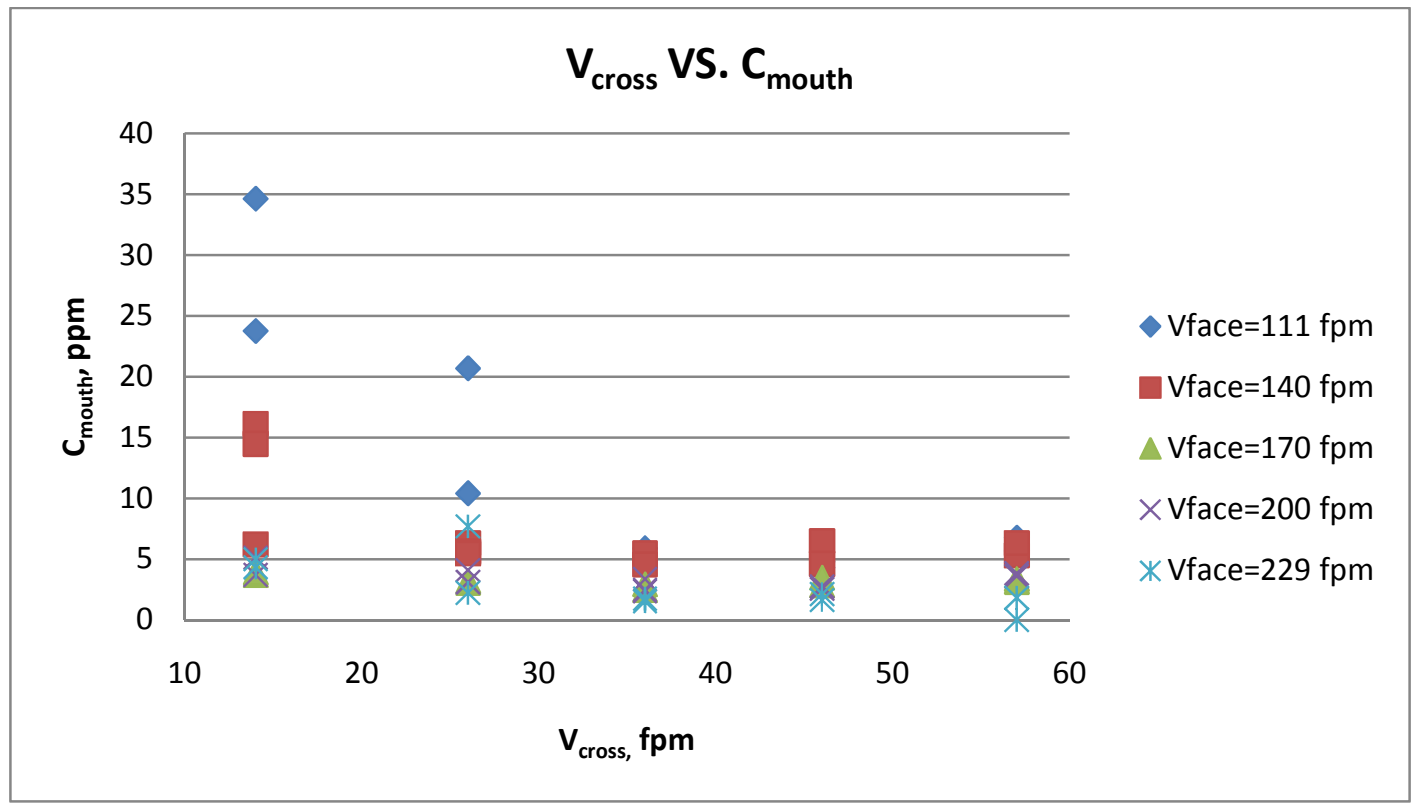

Figure 5. 3: Wind tunnel cross-draft velocity versus moth concentration for plain hood regardless of the levels of hood face velocity

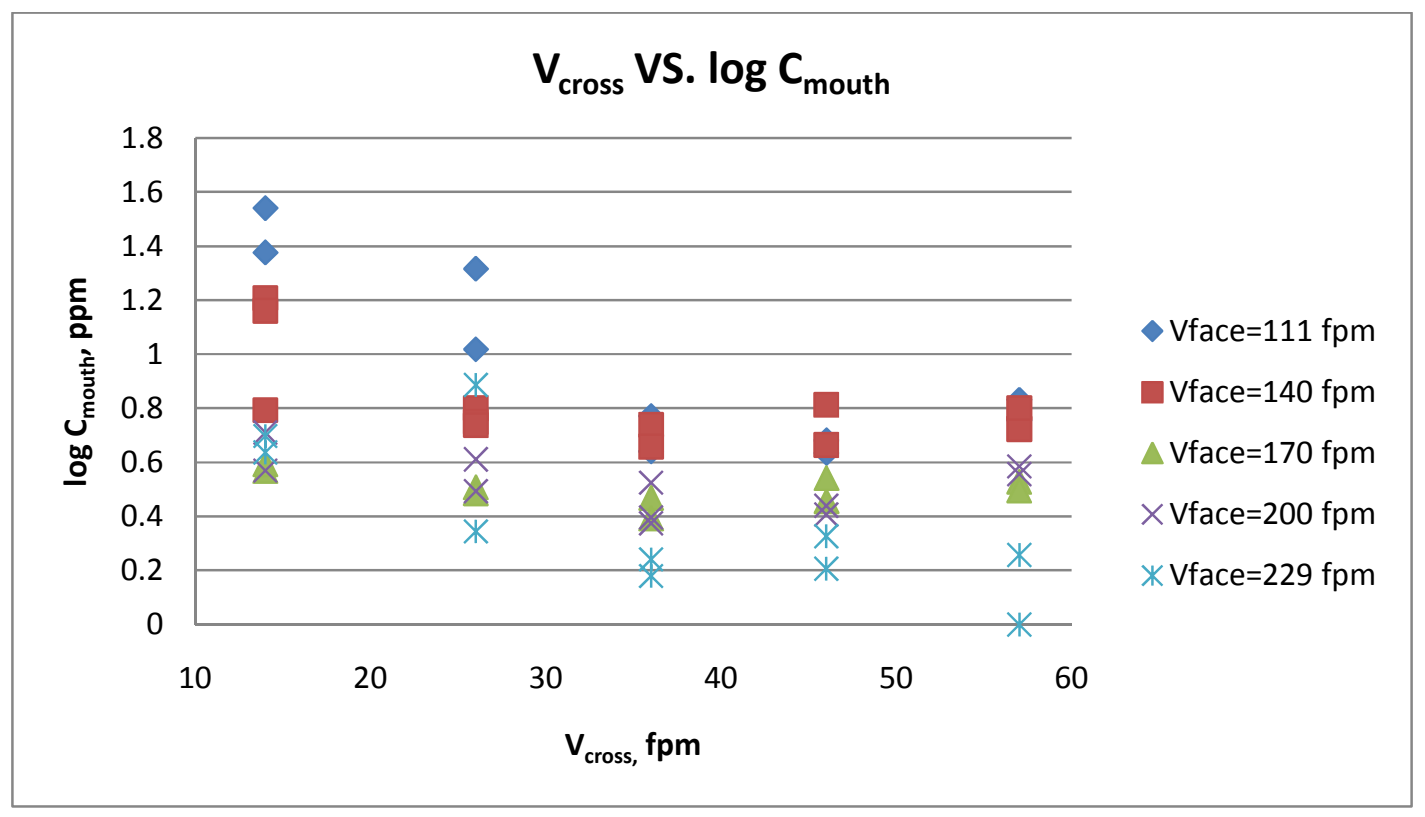

Figure 5. 4: Wind tunnel cross-draft velocity versus $\log C_{\text {mouth }}$ for plain hood regardless of the levels of hood face velocity 


\subsection{Simple Regression Analysis}

Regression analysis was performed on log transformed concentrations at the mouth location with hood face velocity $\left(\mathrm{V}_{\text {face }}\right)$ and wind tunnel cross-draft velocity $\left(\mathrm{V}_{\text {cross }}\right.$ ) separately. Table 5.2.1 and 5.2.2 each summarizes adjusted $\mathrm{R}^{2}$, regression coefficients, and $P$-values obtained from regression analysis for each sample treatment (see Appendix J).

Table5.2. 1: Simple Regression Analysis Results for $\log \mathbf{C}_{\text {mouth }}$ with Hood Face Velocity $\left(\mathbf{V}_{\text {face }}\right)$

\begin{tabular}{c|c|c|c|c}
\hline \hline $\begin{array}{c}\text { Dependent Variable } \\
\log \mathrm{C}_{\text {mouth }}\end{array}$ & $P$-value & $\operatorname{Adj}_{\mathrm{R}} \mathrm{R}^{2}(\%)$ & $\mathrm{C}_{0}$ & $\mathrm{C}_{1}$ \\
\hline @ $\boldsymbol{V}_{\text {cross }}=\mathbf{1 4} \mathrm{fpm}$ & $\mathbf{0 . 0 0 2 9}$ & $\mathbf{6 0 . 6}$ & $\mathbf{2 . 0 1 5 6}$ & $\mathbf{- 0 . 0 0 6 6 9}$ \\
\hline @ $\boldsymbol{V}_{\text {cross }}=\mathbf{2 6} \mathrm{fpm}$ & $\mathbf{0 . 0 2 7 4}$ & $\mathbf{3 7 . 2}$ & $\mathbf{1 . 4 4 8 5}$ & $\mathbf{- 0 . 0 0 4 3 3}$ \\
\hline @ $V_{\text {cross }}=36 \mathrm{fpm}$ & $\mathbf{0 . 0 0 0 1}$ & $\mathbf{7 9 . 9}$ & $\mathbf{1 . 2 0 6 7}$ & $\mathbf{- 0 . 0 0 4 1 5}$ \\
\hline @ $\boldsymbol{V}_{\text {cross }}=46 \mathrm{fpm}$ & $\mathbf{0 . 0 0 0 6}$ & $\mathbf{7 6 . 4}$ & $\mathbf{1 . 1 3 8 2}$ & $\mathbf{- 0 . 0 0 3 6 5}$ \\
\hline @ $\boldsymbol{V}_{\text {cross }}=57 \mathrm{fpm}$ & $\mathbf{0 . 0 0 1 0}$ & $\mathbf{7 3 . 3}$ & $\mathbf{1 . 4 2 5 8}$ & $\mathbf{- 0 . 0 0 5 1 3}$ \\
\hline \hline
\end{tabular}

* Model: $\log C_{\text {mouth }}=C_{0}+C_{1} * V_{\text {face }}+\varepsilon$

Table5.2. 2: Simple Regression Analysis Results for $\log \mathbf{C}_{\text {mouth }}$ with Cross-draft Velocity ( $\left.\mathbf{V}_{\text {cross }}\right)$

\begin{tabular}{|c|c|c|c|c|}
\hline $\begin{array}{c}\text { Dependent Variable } \\
\log C_{\text {mouth }}\end{array}$ & $P$-value & Adj_R ${ }^{2}(\%)$ & $\mathrm{C}_{0}$ & $\mathrm{C}_{1}$ \\
\hline$@ V_{f a c e}=111 \mathrm{fpm}$ & 0.0040 & 62.3 & 1.5814 & -0.01740 \\
\hline$@ V_{\text {face }}=140 \mathrm{fpm}$ & 0.0479 & 27.0 & 1.0371 & -0.00655 \\
\hline$@ V_{f a c e}=170 f p m$ & 0.3211 & 1.30 & 0.5508 & -0.00128 \\
\hline$@ V_{f a c e}=200 f p m$ & 0.0270 & 3.70 & 0.6060 & -0.00253 \\
\hline$@ V_{\text {face }}=229 f p m$ & 0.0091 & 54.3 & 0.8590 & -0.01341 \\
\hline
\end{tabular}

* Model: $\log C_{\text {mouth }}=C_{0}+C_{1} * V_{\text {cross }}+\varepsilon$ 
As can be inferred from Tables 5.2.1 and 5.2.2, for most values of $\mathrm{V}_{\text {face, }}, \mathrm{V}_{\text {cross }}$ is not quite linearly related to $\log \mathrm{C}_{\text {mouth }}$; meanwhile, for each level of $\mathrm{V}_{\text {cross }}, \mathrm{V}_{\text {face }}$ is moderately linearly proportional to $\log \mathrm{C}_{\text {mouth }}$. Since the regression slopes are negative in every case, $\mathrm{C}_{\text {mouth }}$ declines exponentially with both $\mathrm{V}_{\text {face }}$ and $\mathrm{V}_{\text {cross. }}$.

\subsection{Analysis of Variance (ANOVA)}

The independent variables for this study were the $\mathrm{V}_{\text {face }}$ (five levels, 111, 140, 170, 200 and $229 \mathrm{fpm}$ ) and $\mathrm{V}_{\text {cross }}$ (five levels, 14, 26, 36, 46, $57 \mathrm{fpm}$ ). The dependent variables were the concentrations at the mouth and nose locations.

Data Desk $^{\circledR}$ (Data Description, Cornell, NY) software was used for ANOVA. The results are listed in Tables 5.4.1.

Table 5.3. 1: The ANOVA table for $\mathrm{C}_{\text {mouth }}$ on the plain hood

\begin{tabular}{lrrrrr}
\hline \hline Analysis of Variance For & \multicolumn{2}{l}{ Log $\mathbf{C}_{\text {mouth }}$} \\
& df & Sums of Squares & Mean Square & F-ratio & Prob \\
Source & 1 & 22.0817 & 22.0817 & 1531.7 & $<0.0001$ \\
Const & 4 & 2.10098 & 0.525244 & 36.433 & $<0.0001$ \\
Vface & 4 & 1.08876 & 0.27219 & 18.88 & $<0.0001$ \\
Vcross & 16 & 0.558423 & 0.0349015 & 2.4209 & 0.0207 \\
Vface*Vcross & 27 & 0.38925 & 0.0144167 & & \\
Error & 51 & 4.20092 & & & \\
Total & & & & & \\
\hline \hline
\end{tabular}

We can see that both the $V_{\text {face }}$ and $V_{\text {cross }}$ have highly significant statistically effects $(p<0.005)$ on concentrations at both the mouth and nose locations. It should be noted that all velocities were pre-determined, and the ANOVA model is a fixed effect one. Consequently, the results obtained are good only for these specific velocities. 


\section{Chapter 6: Results of Study II - Flange, Cowl and Sash Tests}

Study I established that hood face velocity $\left(\mathrm{V}_{\text {face }}\right)$ and wind tunnel cross-draft velocity $\left(\mathrm{V}_{\text {cross }}\right)$ were important factors affecting hood performance. Study I only focused on the plain enclosing hood (without any intervention added). Study II tested the effects on the hood performance of adding different interventions at the hood face or just inside the hood (sashes). This study was a complete factorial design. Each test condition was done twice in random order.

The apparatus and methods were identical to Study I except for adding the specific modifications to the hood. The goal for Study II was to determine whether interventions (see Table 6.1) to the hood improved its performance.

Table 6. 1: Levels for independent variables for study II

\begin{tabular}{c|c}
\hline \hline Independent Variables & Levels \\
\hline Hood face velocity $(f t / m i n)$ & $111,170,229$ \\
\hline Cross-draft velocity $(f t / m i n)$ & 14,46 \\
\hline \multirow{2}{*}{ Intervention } & Collar flange \\
\cline { 2 - 2 } & Bottom flange \\
\cline { 2 - 2 } & Cowling \\
\cline { 2 - 2 } & Sash \\
\cline { 2 - 2 } & Plain Hood (No Intervention) \\
\hline \hline
\end{tabular}




\subsection{Comparison of Effects of Different Interventions on Concentration at}

\section{Mouth and Nose Locations}

Table-6.2 lists Concentrations at $C_{\text {mouth }}$ and $C_{\text {nose }}$ for each intervention (no intervention is treated as an intervention here).

Table 6. 2: Results of $C_{\text {mouth }}$ and $C_{\text {nose }}$ by giving different interventions

\begin{tabular}{ccccc}
\hline \hline Interventions & $\mathbf{V}_{\text {face }}, \mathbf{f p m}$ & $\mathbf{V}_{\text {cross }}, \mathbf{f p m}$ & $\begin{array}{c}\mathbf{C}_{\mathbf{n o s e} \_\mathbf{A v e},} \\
\mathbf{p p m}\end{array}$ & $\begin{array}{c}\mathbf{C}_{\mathbf{m o u t h}} \mathbf{A v e} \\
\mathbf{p p m}\end{array}$ \\
\hline No Intervention & 111 & 14 & 96.0 & 91.4 \\
No Intervention & 111 & 46 & 10.7 & 18.8 \\
No Intervention & 170 & 14 & 53.3 & 43.6 \\
No Intervention & 170 & 46 & 42.0 & 46.8 \\
No Intervention & 229 & 14 & 25.6 & 17.1 \\
No Intervention & 229 & 46 & 23.8 & 22.2 \\
FlangeTopSides12in & 111 & 14 & 156.7 & 208.4 \\
FlangeTopSides12in & 111 & 46 & 36.3 & 43.7 \\
FlangeTopSides12in & 170 & 14 & 71.9 & 130.7 \\
FlangeTopSides12in & 170 & 46 & 34.9 & 28.4 \\
FlangeTopSides12in & 229 & 14 & 47.0 & 39.6 \\
FlangeTopSides12in & 229 & 46 & 136.0 & 107.1 \\
FlangeBottom 12in & 111 & 14 & 36.1 & 63.3 \\
FlangeBottom 12in & 111 & 46 & 61.9 & 88.7 \\
FlangeBottom 12in & 170 & 14 & 64.1 & 127.4 \\
FlangeBottom 12in & 170 & 46 & 79.9 & 129.6 \\
FlangeBottom 12in & 229 & 14 & 89.6 & 141.5 \\
FlangeBottom 12in & 229 & 46 & 197.4 & 227.2 \\
CowlTopSides12in & 111 & 14 & 75.6 & 220.9 \\
CowlTopSides12in & 111 & 46 & 214.6 & 383.2 \\
CowlTopSides12in & 170 & 14 & 197.6 & 249.8 \\
CowlTopSides12in & 170 & 46 & 230.3 & 196.4 \\
CowlTopSides12in & 229 & 14 & 167.4 & 147.8 \\
CowlTopSides12in & 229 & 46 & 389.1 & 497.3 \\
Sash 17in & 111 & 14 & -0.01 & -0.02 \\
Sash 17in & 111 & 46 & -0.01 & -0.01 \\
Sash 17in & 170 & 14 & -0.01 & -0.01 \\
Sash 17in & 170 & 46 & -0.02 & -0.03 \\
Sash 17in & 229 & 14 & -0.03 & -0.03 \\
Sash 17in & 229 & 46 & -0.01 & -0.02 \\
\hline \hline
\end{tabular}




\subsection{Results of $C_{\text {mouth }}$ for each Intervention}

In order to see the effects of the interventions added on the hood, the results were plotted in Figures 6.2.1 - 6.2.3. Through these figures, we can clearly see that the sash dramatically reduced concentrations in all cases. Flanges and Cowl performed worse than no intervention.

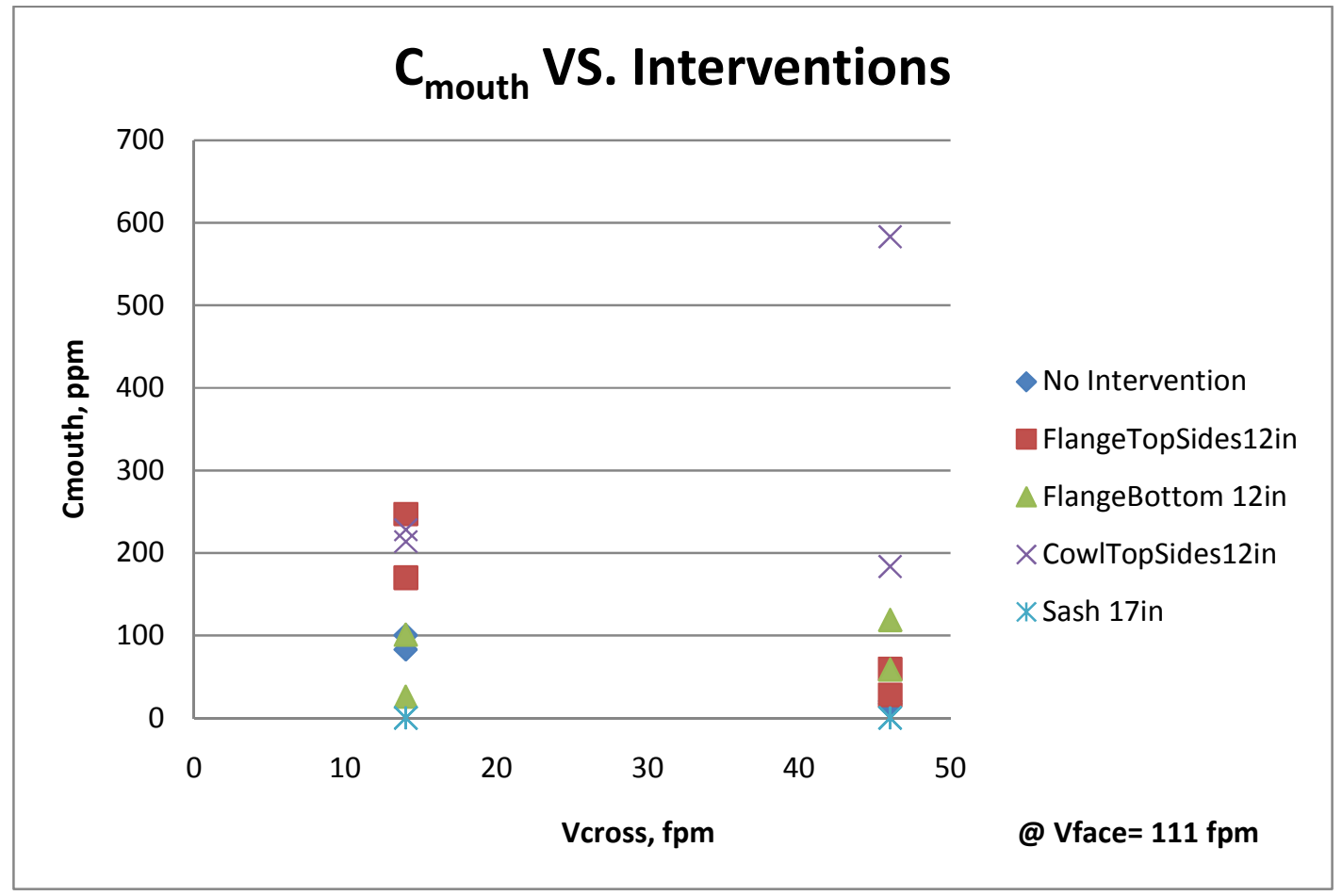

Figure 6.2. 1: $\mathrm{C}_{\text {mouth }}$ versus four different interventions $\left(V_{\text {face }}=111 \mathrm{fpm} ; V_{\text {cross }}=14,46 \mathrm{fpm}\right)$ 


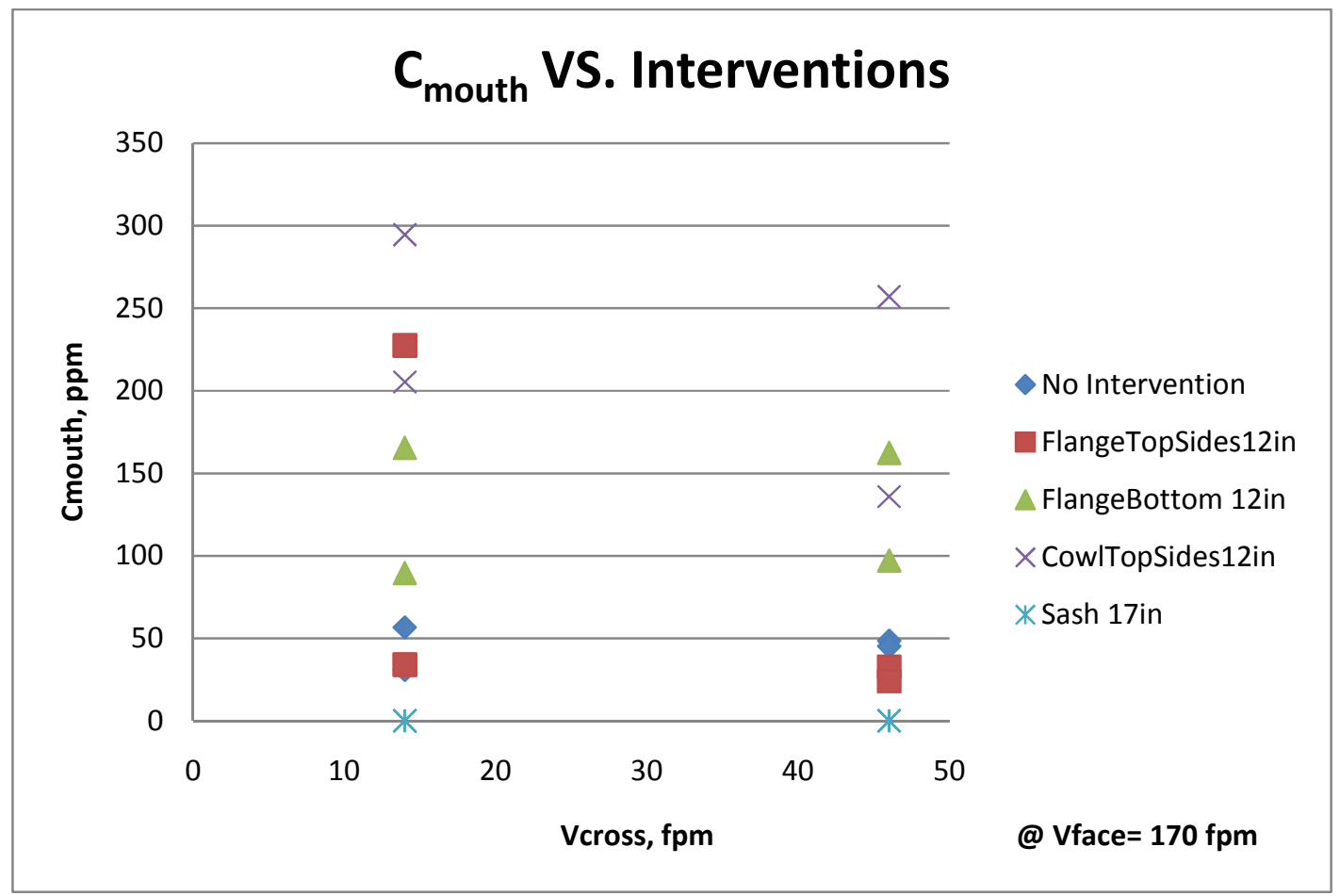

Figure 6.2.2: $\mathrm{C}_{\text {mouth }}$ versus four different interventions $\left(V_{\text {face }}=170 \mathrm{fpm} ; V_{\text {cross }}=14,46 \mathrm{fpm}\right)$

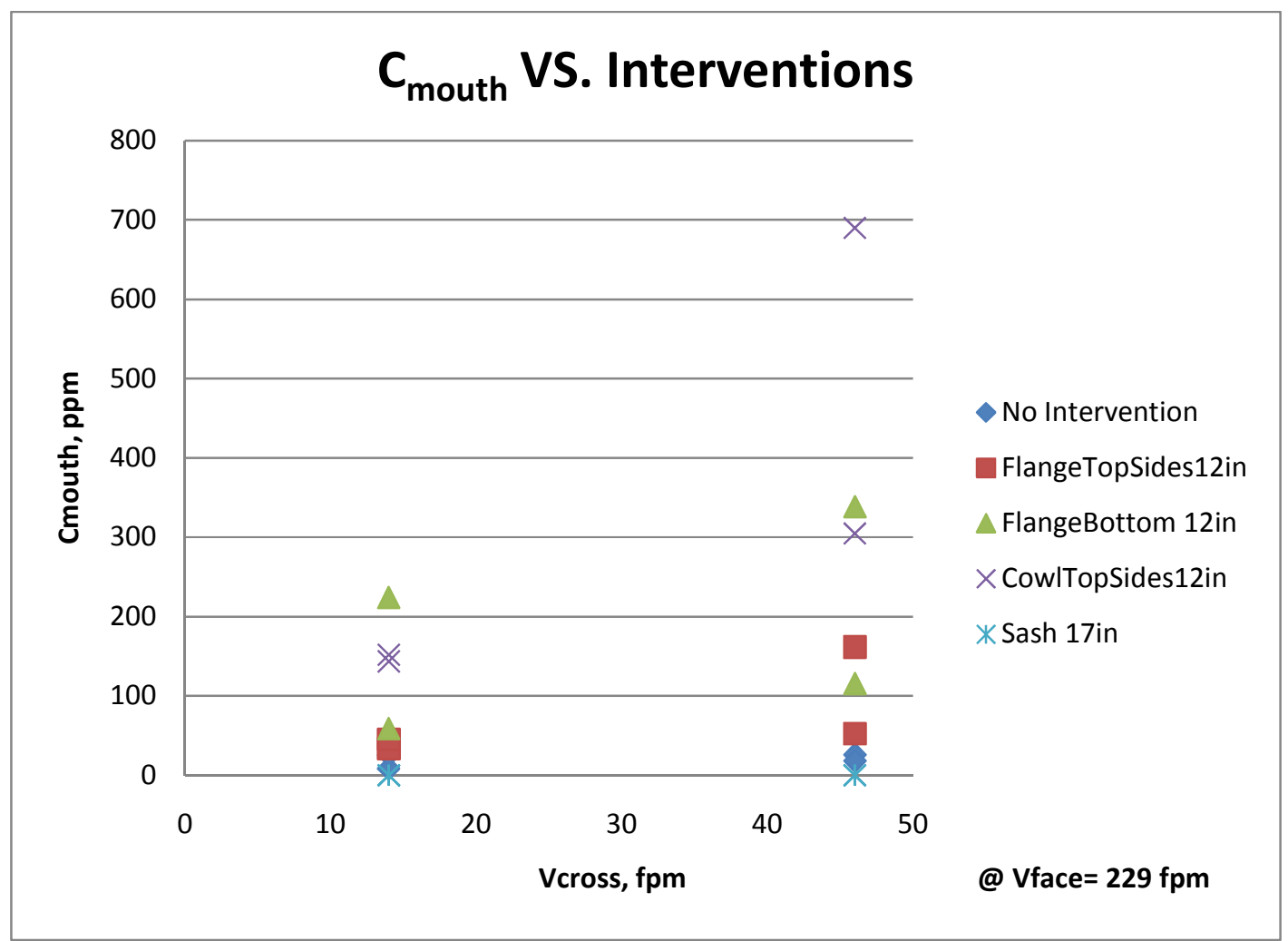

Figure 6.2. 3: $\mathrm{C}_{\text {mouth }}$ versus four different interventions $\left(V_{\text {face }}=229 \mathrm{fpm} ; V_{\text {cross }}=14,46 \mathrm{fpm}\right)$ 


\section{Chapter 7: Discussions of Study II}

\subsection{Comparison of $\mathbf{C}_{\text {mouth }}$ to $\mathbf{C}_{\text {nose }}$}

As with Study I, two samples were taken simultaneously at the manikin's mouth and nose. Figure 7.1 plots $C_{\text {mouth }}$ against $C_{\text {nose }}$ with all conditions included. It is clear that the two dependent variables were highly correlated $\left(\mathrm{R}^{2}=0.87\right)$ with a linear regression slope of 1.229 .

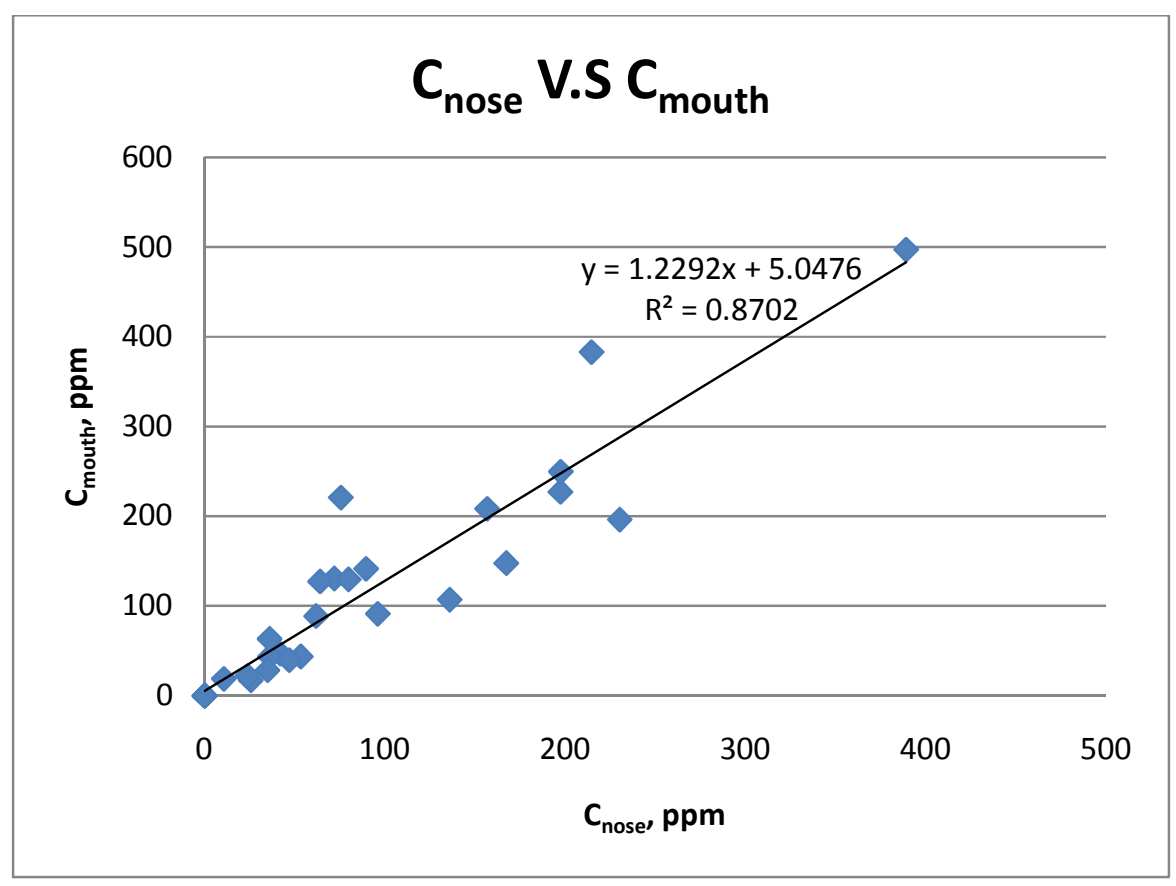

Figure 7. 1: $\mathbf{C}_{\text {mouth }}$ Versus $\mathbf{C}_{\text {nose }}$

\subsection{Effects of Intervention Variables on Mouth and Nose Concentration}

Intervention variables included: no intervention, collar flange, bottom flange and cowl. Regardless of the levels of hood face velocity and wind tunnel cross-draft velocity, the effects of interventions on $C_{\text {mouth }}$ and $C_{\text {nose }}$ are shown as Figure 7.2.1 and Figure 7.2.2. 


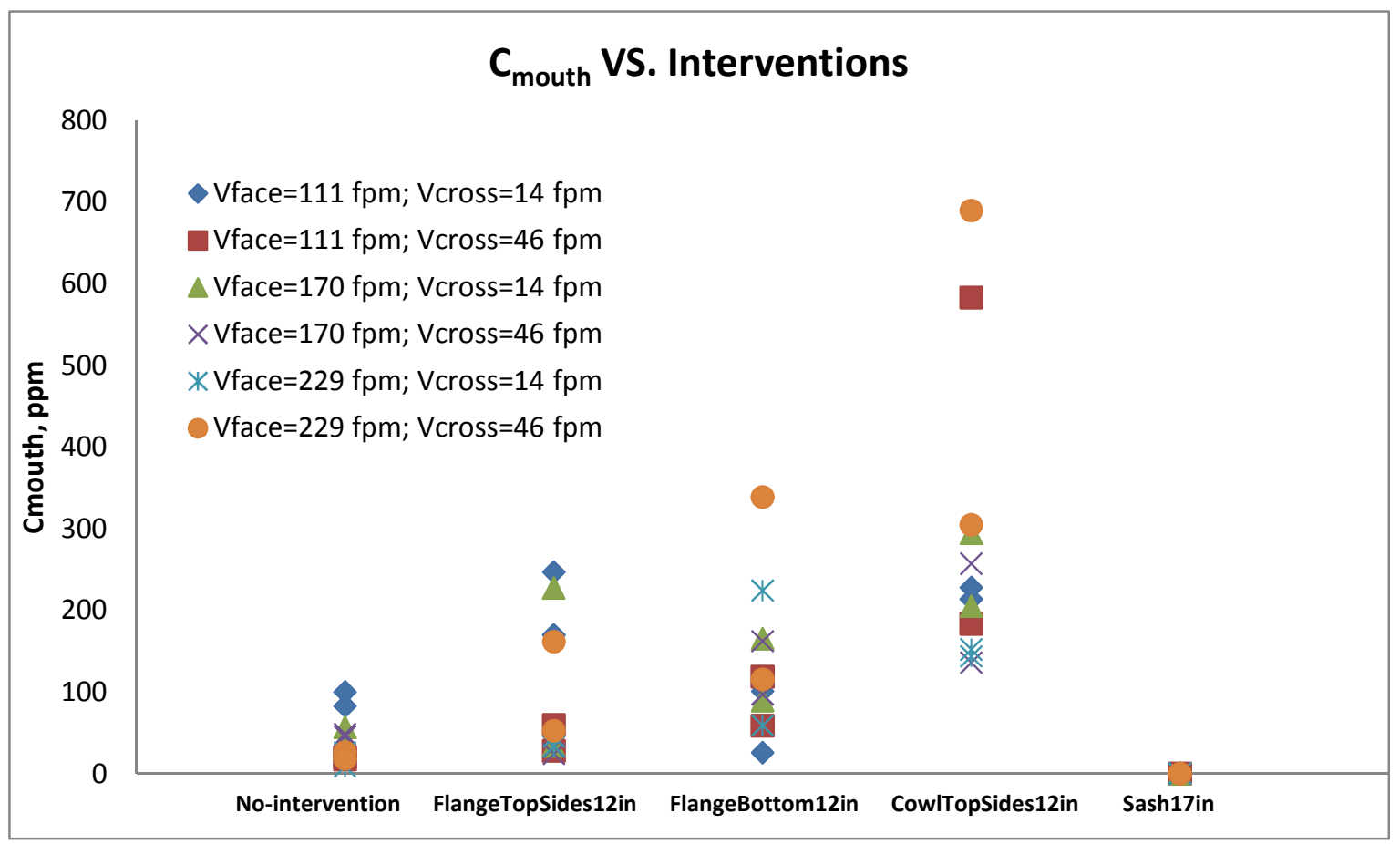

Figure 7. 2.1: Effects of interventions on $C_{\text {mouth }}$ regardless of $V_{\text {face }}$ and $V_{\text {cross }}$

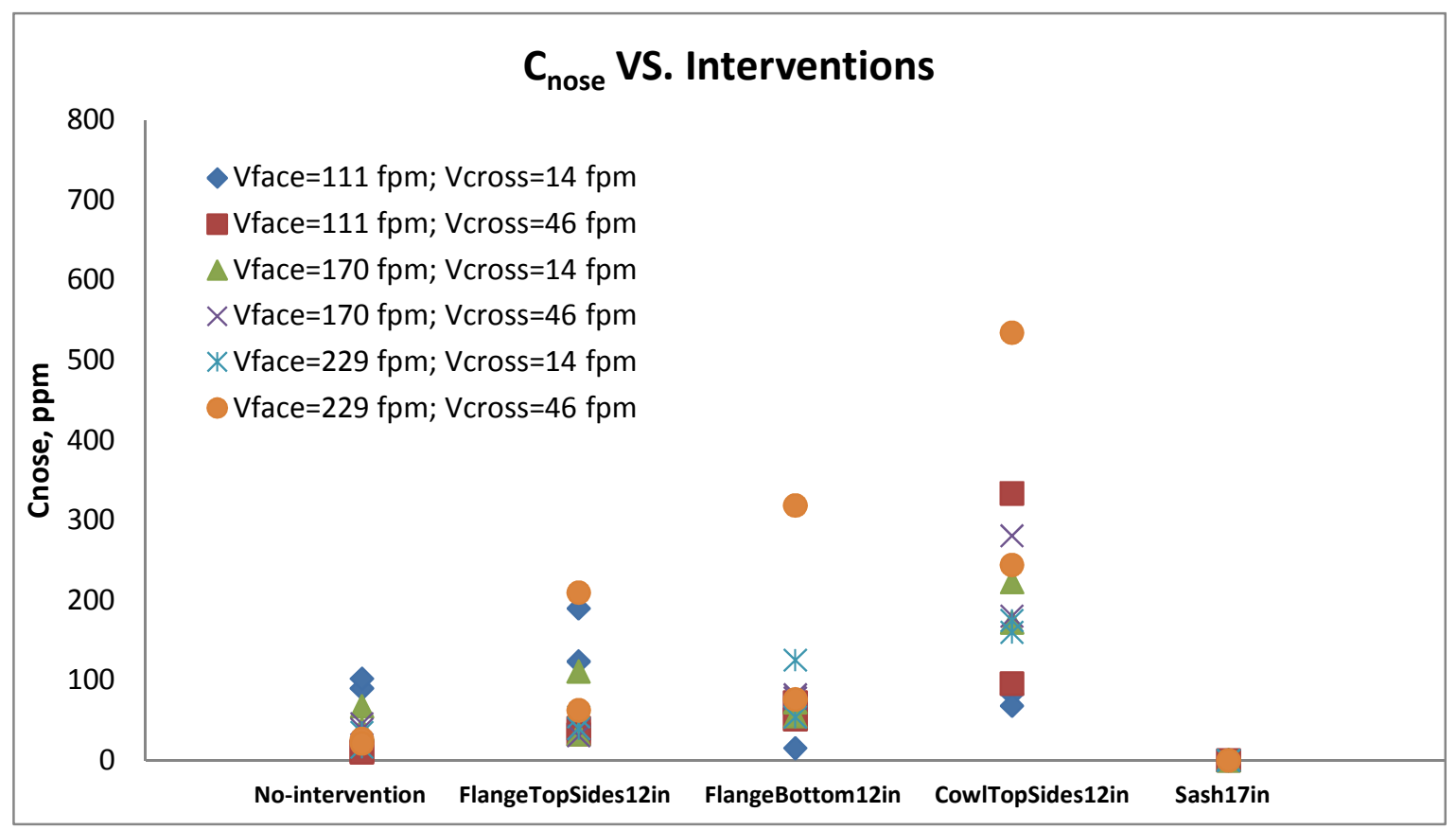

Figure 7. 2.2: Effects of interventions on $C_{\text {nose }}$ regardless of $V_{\text {face }}$ and $V_{\text {cross }}$ 


\subsection{Analysis of Variance (ANOVA)}

ANOVA was performed to answer the question, "Do all the five groups (five different interventions) have the same mean?"

Null Hypothesis, $H_{0}: \mu_{1}=\mu_{2}=\mu_{3}=\mu_{4}=\mu_{5}$;

Alternative Hypothesis, $H_{1}$ : At least one mean is not equal to the others.

Data Desk $^{\circledR}$ (Data Description, Cornell, NY) software was used to do analysis of variance (ANOVA) for $\log \mathrm{C}_{\text {mouth }}$ and $\log \mathrm{C}_{\text {nose. }}$. The analysis results are listed on Table 7.3.1 and 7.3.2.

Table 7.3. 1 The ANOVA table for $\log C_{\text {mouth }}$ on intervention tests

\begin{tabular}{lrrrrr}
\hline \hline Analysis of Variance For & \multicolumn{2}{l}{ Log $\mathbf{C}_{\text {mouth }}$} & & & \\
Source & df & Sums of Squares & Mean Square & F-ratio & Prob \\
Const & 1 & 179.582 & 179.582 & 2581.2 & $<0.0001$ \\
Vface & 2 & 0.0194982 & 0.00974912 & 0.1401 & 0.8698 \\
Vcross & 1 & 0.00683852 & 0.00683852 & 0.0983 & 0.7561 \\
Vface*Vcross & 2 & 0.721652 & 0.360826 & 5.1863 & 0.0116 \\
Intervention & 3 & 5.00621 & 1.66874 & 23.986 & $<0.0001$ \\
Vface*Intervention & 6 & 0.816875 & 0.136146 & 1.9569 & 0.1038 \\
Vcross*Intervention & 3 & 0.464231 & 0.154744 & 2.2242 & 0.1058 \\
Error & 30 & 2.08717 & 0.0695724 & & \\
Total & 47 & 9.12248 & & & \\
\hline \hline
\end{tabular}

Since the velocities and intervention methods were fixed, the ANOVA model is a fixed effect model, and the results apply only for these fixed values. 
Table 7.3. 2: The ANOVA table for $\log \mathrm{C}_{\text {nose }}$ on intervention tests

\begin{tabular}{lrrrrr}
\hline \hline Analysis of Variance For & \multicolumn{5}{l}{ Log $C_{\text {nose }}$} \\
& & & & & \\
Source & df & Sums of Squares & Mean Square & F-ratio & Prob \\
Const & 1 & 165.041 & 165.041 & 2753.8 & $<0.0001$ \\
Vface & 2 & 0.200233 & 0.100116 & 1.6705 & 0.2052 \\
Vcross & 1 & 0.000271219 & 0.000271219 & 0.0045 & 0.9468 \\
Vface*Vcross & 2 & 0.453926 & 0.226963 & 3.7869 & 0.0342 \\
Intervention & 3 & 3.37685 & 1.12562 & 18.781 & $<0.0001$ \\
Vface*Intervention & 6 & 0.68634 & 0.11439 & 1.9086 & 0.112 \\
Vcross*Intervention & 3 & 0.798193 & 0.266064 & 4.4394 & 0.0107 \\
Error & 30 & 1.79799 & 0.0599329 & & \\
Total & 47 & 7.3138 & & & \\
\hline \hline
\end{tabular}

Surprisingly, $P$-values are very large for all variables except Intervention. However, some of the interventions between variables had small $P$-values. It is critical to know that all the sash tests produced zero mouth and nose concentrations, meanwhile the cowling produced extremely high concentration $(>300 \mathrm{ppm})$, which played tremendous effects in the above ANOVA analysis. It is very clear that the interventions didn't all have the same mean for both $\mathrm{C}_{\text {mouth }}$ and $\mathrm{C}_{\text {nose }}$. 


\section{Chapter 8: Conclusions and Recommendations}

The main purpose of this research was to investigate the effects of face velocity, cross-draft velocity, flanges, cowling, and a custom sash on the performance of a specific benchtop enclosing hood. This study consisted of two parts: 1) studying the effects of hood face velocity and wind tunnel cross-draft velocity on a plain, benchtop enclosing hood, and 2) studying the effects of specific interventions -+on the performance of the same enclosing hood.

\subsection{Conclusions for Plain Enclosing Hood Study}

Five levels of hood face velocity $\left(V_{\text {face }}=111,140,170,200\right.$ and $\left.229 \mathrm{fpm}\right)$ and five levels of cross-draft velocity $\left(V_{\text {cross }}=14,26,36,46\right.$ and $\left.57 \mathrm{fpm}\right)$ were studied in the experiment to determine the effects of $V_{\text {face }}, V_{\text {cross }}$, and their interactions on the performance of a benchtop enclosing hood. Concentrations were measured at a heated, "breathing" anthropometrically scaled manikin's mouth and nose. Results from this study indicate that:

- Enclosing hood face velocity $\left(\mathrm{V}_{\text {face }}\right)$, wind tunnel cross-draft velocity $\left(\mathrm{V}_{\text {cross }}\right)$ and their interactions all had statistically significant effects on logtransformed concentrations ( $\log C_{\text {mouth }}$ and $\left.\log C_{n o s e}\right)$, ${ }^{(2-5,6,12)}$ which is in agreement with many published papers. However, $\mathrm{V}_{\text {cross }}$ at the lowest level (14fpm) increased concentrations at the manikin's mouth and nose, which is not consistent with common recommendations ${ }^{(6,7,23)}$ that the cross-draft velocity has negative effect and should be kept as low as possible. One possible reason is that the differences between a lab hood and the plain hood. Lab hoods have aerodynamically-shaped entries, while typical benchtop enclosing hoods generally have plain sides. As we have observed with smoke tests on an enclosing hood in our wind tunnel, the wake from the wall can extend nearly to the hood user when the crossdraft is from the side. 
- Higher face velocity and higher cross-draft velocity were associated with lower $\mathrm{C}_{\text {nose }}$ and $\mathrm{C}_{\text {mouth. }}$. Once $\mathrm{V}_{\text {face }}$ exceeded $170 \mathrm{fpm}$ and $\mathrm{V}_{\text {cross }}$ exceeded $36 \mathrm{fpm}$, the concentrations no longer declined substantially.

\subsection{Conclusions for the Interventions Study}

Five interventions: no intervention, collar flange, bottom flange, cowl and sash, along with three levels of $\mathrm{V}_{\text {face }}(111,170,229 \mathrm{fpm})$ and two levels of $\mathrm{V}_{\text {cross }}(14$, $46 \mathrm{fpm}$ ) were studied to determine the effects of interventions on the performance of the same enclosing hood. It was found that:

- All interventions were found to significantly affect on the performance of the enclosing hood.

- TopSides12in Cowl produced the highest mouth and nose concentrations compare to other interventions. A possible reason is that the $12 \mathrm{in}$ cowl induced a substantial region of separation that enlarged the manikin's wake zone. This could have increased flow from the source to the manikin.

- The flanges at best were not better than having no intervention. The average concentration values with flanges were greater than with no intervention, which is consistent with Guffey and Barnea (1994).

- The most important finding is that the sash reduced the concentrations dramatically. Zero exposures were achieved at all combinations of of $\mathrm{V}_{\text {face }}$ and $\mathrm{V}_{\text {cross. }}$ The reason for it could possibly be that the custom sash reshaped the manikin's wake zone, thus keeping manikin's breathing zone out of its wake zone. On the other hand, the sash keeps the worker's face separated from the contaminant, so it is unlikely that the manikin would be over exposed.

\subsection{Recommendations}


- A similar sash should be used when feasible.

- The hood face velocity should be at least $170 \mathrm{fpm}$.

- Neither external flanges nor cowls should be used.

\subsection{Caveats and Limitations}

- The results may have been sensitive to the position of the manikin's face, suggesting that even minor changes in posture could have substantial effects.

- This study was done in a wind tunnel with airflows that are more uniform than would exist in a work place, also this study examined only a few of levels of $\mathrm{V}_{\text {face }}, \mathrm{V}_{\text {cross }}$, and interventions. The results found apply only to the conditions investigated. More levels of $\mathrm{V}_{\text {face }}$ and $\mathrm{V}_{\text {cross }}$ combinations to be studied.

- Results may different from results found with human subjects. The manikin did not move, and its arms and legs were not heated. 


\section{References}

1. AlHA (2004). Industrial Ventilation A Manual of Recommended Practice. Cincinnati, Ohio: ACGIH .

2. Abrams, DS, Reist, PC, Derment, JM, (1986). An Evaluation of a Receive Lab Hood, AlHAJ 47 (1): 22- 26.

3. Altemose, BA, Flynn, MR, Sprankle, J, (1998), Application of a Tracer Gas Challenge with a Human Subject to Investigate Factors Affecting the Performance of Lab Hoods; AlHAJ 59: 321- 327.

4. Brent A. Altemose, M. R. (1998). Application of a Tracer Gas Challenge with a Human Subject to Investigate Factors Affecting the Performance of Laboratory Fume Hoods. American Industrial Hygiene Association Journal, 59:321-327.

5. Caplan, K.J. and Knutson, G.W., (1982), A Performance Test for Laboratory Fume Hoods; Am. Ind. Hyg. Assoc. 43:722-737.

6. Caplan, K.J. and Knutson, G.W., (1982), Influence of Room Air Supply on Laboratory Hoods; Am. Ind. Hyg. Assoc. 43:738-746.

7. DiBerardinis, $L$ [and 20 others], (2003), Report of the Howard Hughes prod inst. Workshop on the performance of lab hood, AlHAJ 64:228-237.

8. DiBerardinis, LJ, First, MW, and Ivany, RE, (1991) Field results of an in-place, quantified performance test of lab hoods, AOEH 6:227-231.

9. Greenley, PL, Billings CE, Diberardinis, $L$, (1999), Containment testing of lab hoods on as-used conditions ANSI 110 manikin \& human not compared, ASHRAE Transactions Vol. 105, Part I.

10. Guffey SE and Barnea N (1994). "Effects of Face Velocity, Flanges, and Manikin Position on the Effectiveness of a Benchtop Enclosing Hood in the Absence of CrossDrafts". Am. Ind. Hyg. Assoc. J., 55(2):132-139.

11. Guffey SE, Flanagan ME and van Belle G, (2001). Air Sampling at the Chest and Ear As Representative of the Breathing Zone. AlHA Journal: Vol. 62, No. 4, pp. 416-427.

12. Hitchings, DT (1995), "ANSI/ ASHRAE 110 fume hood performance testing", Lab Safety Environment Man 3(6):4.

13. Ivany, RE, First, MW and DiBerardinis (1989), A new method for quantitative in-use testing of fume hoods, AlHAJ 50 (5) 275-280.

14. Jon L. BARNETT, MAX L. RICHARD (1983), "A tracer Method for Quantifying Contamination of Building Supply Air: Reentrainment of Laboratory Hood Exhausts", Am. Ind. Hyg. Assoc. J. 44(8): 580-582

15. Johnson, A.E. and Fletcher, B. (1992) "Containment Testing of Fume Cupboards - I: Methods." Ann. Occup. Hyg. 36: 239-252. 
16. Johnson, A.E. and Fletcher, B. (1992) "Containment Testing of Fume Cupboards - II: Test Room Measurements." Ann. Occup. Hyg. 36: 395-40.

17. Knutson, G.W. (1987): Testing containment of laboratory hoods: a field study. ASHRAE Trans. 93:1801-1912

18. Kwangseog Ahn, S. W. (2008). A Review of Published Quantitative Experimental Studies on Factors Affecting Laboratory Fume Hood Performance. Journal of Occupational and Environmental Hygiene, 5: 735-753.

19. Kulmala, I, Saamanen, A. and Enbom, S. (1996) "The Effect of Contaminant Source Location on Worker Exposure in the Near-Wake Region." Ann. Occup. Hyg. Vol. 40, pp. 511-523.

20. Ljungvist, B, (1991) "Aerodynamic design of fume cupboards", Safety Health Practices, 36-40.

21. Maupins, K \& Hitchings, DJ. (1998) Reducing employees' exposure potential using ANSI (10 method of testing performance of lab fume hoods as a diagnostic tool; AIHAI 59: 133- 138.

22. Pathanjali, C. and Rahman, M.M. (1996) "Study of Flow Patterns in Fume Hood Enclosures." IEEE J. 36:2003-2008.

23. Rake, B.W. (1978): Influence of cross drafts on the performance of a biolosical safety cabinet. App. Env. Microbiol. 36:278-283.

24. Rota, R.; Canossa, L. and Nano, G. (2000) "Analysis of Air Draught Influence on the Local Ventilation Efficiency through CFD Modeling." 6th International Symposium on Ventilation for Contaminant Control 4-7 June 2000, Helsinki, Finland.

25. Saamanen, A., Kulmala, I., Welling, I., Rosen, G., Andersson, I.M. (2000) "Person in a Uniform Airflow - Effects of Freestream Air Velocity and Body Convection," Proceedings of the Ventilation 2000, 6th International Symposium on Ventilation for Contaminant Control 4-7 June 2000, Helsinki, Finland

26. Smith, T.C., M.R. Flynn, and J.M. Dement (1994): A design and performance analysis of laboratory fume hoods. Appl. Occup. Environ. Hyg. 9:117-124.

27. Trevelyan P.M.J.; Ingham, D.B. and Elliott, L. (2000) "The effect of Ventilation and Sash Handles on the Flow in Fume Cupboards." 6th International Symposium on Ventilation for Contaminant Control 4-7 June 2000, Helsinki, Finland.

28. Wood, J.D., and J.L.Birkett (1979): External Airflow Effects on Personal Brit. Occup. Hyg. 22: 299-310.

29. William A. Burgess, M. J. (2004). Ventilation for control of the work environment. Hoboken, N.J.: Wiley-Interscience, c2004.

30. El Nahass W. (2005): Effects of Heating, Breathing, Hair Style, Posture, and air Velocity on breathing zone concentrations for an Anthropometrically-correct Manikin in a Wind Tunnel. Doctoral Dissertation, West Virginia University.

31. Santosh Kulkarni (2003): Comparison of Concentrations in the Breathing Zone. Master Thesis, West Virginia University. 


\section{Appendix A}

\section{Gasmet $^{\circledR}$ Fourier Transform Infrared (FT-IR) Gas Analyzer}

\section{*Gasmet}

Gasmet - USA $^{\mathrm{m}}$

\section{Gasmet" DX-4015}

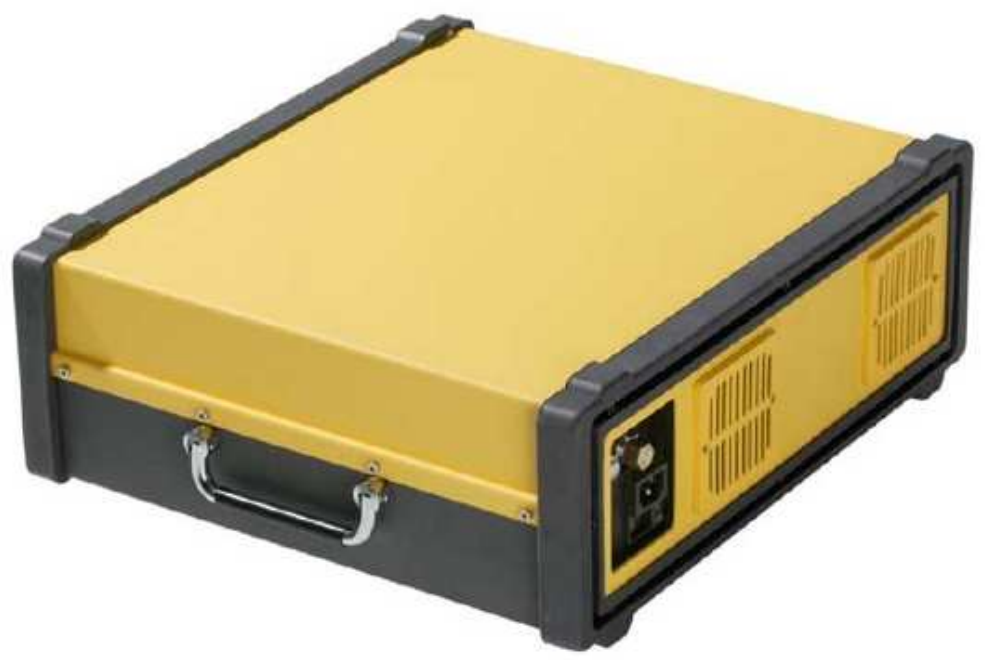

Multicomponent FTIR Gas Analyzer

GASMET ON-SITE SERIES includes portable multicomponent gas analyzers for demanding applications. The GASMET DX - 4015 features a Fourier Transform Infrared (FTIR) spectrometer, a temperature controlled sample cell with a built-in pump, and signal processing electronics. The sample cell can be heated to $50^{\circ} \mathrm{C}$. Sample cell absorption path length is selected according to the application. This analyzer offers versatility and high performance for different applications.

The GASMET DX-4015 is designed for on site measurements at low concentrations in ambient air. Typical usage areas include industrial hygiene and emergency response situations.

The GASMET DX-4015 is factory calibrated using certified single component calibration gases. There is no need for the user to do any span calibrations after that. The user can also easily configure the analyzer for a new set of compounds.

\begin{tabular}{|c|c|}
\hline \multicolumn{2}{|l|}{ General parameters } \\
\hline Measuring principle: & Fourier Iransform Infraged, FTIR \\
\hline Performance: & $\begin{array}{l}\text { Simultaneous analysis of up to } 50 \\
\text { gas compounds }\end{array}$ \\
\hline Response time, $T_{\infty}$ : & $\begin{array}{l}\text { Typically }<120 \mathrm{~s} \text {, depending on } \\
\text { the gas flow and measurement } \\
\text { time }\end{array}$ \\
\hline Operating temperature: & $\begin{array}{l}\text { Short term } 20 \pm 20^{\circ} \mathrm{C} \\
\text { long term } 15-25^{\circ} \mathrm{C} \\
\text { non condensing }\end{array}$ \\
\hline Storage temperature: & $-20-60^{\circ} \mathrm{C}$, non condensing \\
\hline Power supply: & $\begin{array}{l}100-115 \text { or } 230 \mathrm{~V} / 50-60 \mathrm{~Hz} \\
12 \mathrm{VDC}\end{array}$ \\
\hline Power consumption: & $300 \mathrm{~W}$ \\
\hline \multicolumn{2}{|l|}{ Spectrometer } \\
\hline Resolution: & $8 \mathrm{~cm}^{-1}$ or $4 \mathrm{~cm}^{-1}$ \\
\hline Scan frequency: & 10 scans / 5 \\
\hline Detector: & Peltier cooled MCT \\
\hline Source: & SiC. $1550 \mathrm{~K}$ \\
\hline Beamsplitter: & ZnSe \\
\hline Window material: & ZnSe \\
\hline Wavenumber range: & $900-4200 \mathrm{~cm}^{-1}$ \\
\hline
\end{tabular}

GASMET-USA Tel: 512.331.0073 Fax: 512.331 .5353 sales $\widehat{a}$ Gasmet-USA.com www.Gasmet-USA.com Gasmet Technologies Oy 
"Gasmet

Gasmet - USA ${ }^{m}$

\begin{tabular}{ll|}
\hline Sample Cell & \\
\hline Structure: & Multi-pass, fixed path length $8.8 \mathrm{~m}$ \\
Material: & $100 \%$ Rhodium coated aluminium \\
Mirrors: & Fixed, protected gold coating \\
Volume: & 0.41 \\
Connectors: & Inlet Swagelok $6 \mathrm{~mm}$ \\
& Outlet Swagelok $8 \mathrm{~mm}$ \\
Gaskets: & Viton ${ }^{\circ}$ O-rings \\
Temperature: & $50^{\circ} \mathrm{C}$, maximum \\
Valve: & Manual Swagelok \\
Window material: & Ar coated ZnSe \\
\hline
\end{tabular}

Measuring parameters

Zero point calibration: 24 hours, calibration with nitrogen (4.0 or higher $\mathrm{N}_{2}$ recommended)

Zero point drift: $\quad<2 \%$ of measuring range per zero point calibration interval

Sensitivity drift: none

Linearity deviation:

Temperature drifts:

$<2 \%$ of measuring range

$<2 \%$ of measuring range per 10 $K$ temperature change

Pressure influence: $\quad 1 \%$ change of measuring value

for $1 \%$ sample pressure chan

Ambient pressure changes

Electrical Connectors:

$\begin{array}{ll}\text { Digital Interface: } & \begin{array}{l}\text { 9-pole D-Connector for RS-232 } \\ \text { Analyzer is connected to an } \\ \text { external computer via RS-232C } \\ \text { cable. The external computer } \\ \text { controls the GASMET. }\end{array} \\ \text { Power connection: } & \text { Standard plug CEE-22 }\end{array}$

Analysis Software (for external PC)

Operating system: Windows XP

Analysis software: CALCMET 2005 for Windows

Options

Sample Cell:

Multi-pass, fixed path

Analog Signals (ext PC): PCMCIA card for 8 analog inputs

Sample cell gaskets: Teflon coated Viton "or Kalrez"

Power supply cables: $12 \mathrm{~V}$ cables with battery clips or cigarette lighter connector

Trolley:

Wheeled cart for the analyzer and

laptop computer

\begin{tabular}{|ll|}
\hline Enclosure & \\
\hline Material: & Aluminium \\
Dimensions (mm): & $438^{*} 164$ ' 445 \\
Weight: & $14.8 \mathrm{~kg}$ \\
CE- Label: & According to EMl guideline \\
& $89 / 336 / \mathrm{EC}$
\end{tabular}
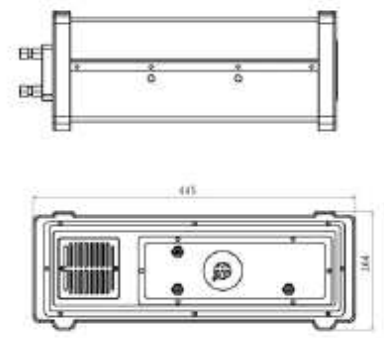

Gas Inlet and Outlet Conditions

\begin{tabular}{ll|} 
Gas temperature: & $\begin{array}{l}\text { Non-condensing, the sample gas } \\
\text { temperature should be the same } \\
\text { as the sample cell temperature } \\
120-600 \text { I per hour }\end{array}$ \\
\begin{tabular}{ll} 
Flow rate: & $\begin{array}{l}\text { Filtration of particulates }(2 \mu) \\
\text { required }\end{array}$ \\
Gas filtration: & Ambient \\
Sample gas pressure: & Internal, for ambient air only \\
Sample pump: & Dynamic range $95 \mathrm{~dB}$ \\
\hline Electronics & 32-bit floating point DSP \\
120 MFLOPS speed
\end{tabular} \\
$\begin{array}{ll}\text { AD Converter: } & \text { External, not included }\end{array}$ \\
\hline Signal Processor:
\end{tabular}

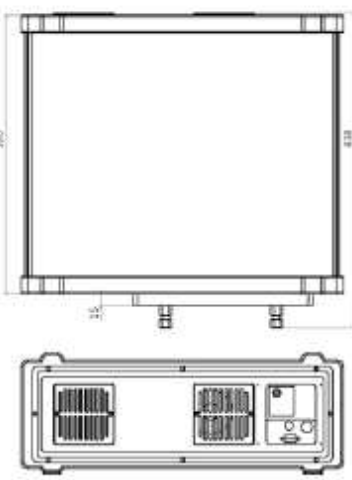
GASMET-USA Tel: 512.331 .0073 Fax: 512.331 .5353 sales $\propto$ Gasmet-USA.com www,Gasmet-USA.com Gasmet Technologies Oy
\begin{tabular}{l|l} 
Finland & FAx: +358975900 450 \\
EMaic contoctogasmet.fí
\end{tabular}
WEB: wiWh gasmet. $f$ f
VAT NO: FI19526395




\section{Appendix B}

\section{SKC $^{\circledR}$ Quality Sample Bag}

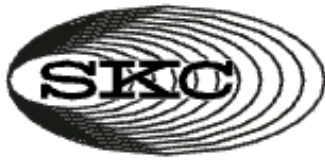

Operating Instructions

863 Valley View Road, Eighty Four PA 15330 USA Tel: 724-941-9701 Fax: 724-941-1369 www.skcinc.com

\section{Dual Stainless Steel Fitted Bags 231 and 237 Series Sample Bags}

The 231 and 237 Series sample bags feature dual stainless steel fittings - an inlet valve for flushing and filling and a Teflon-lined septum fitting for removing samples.

\section{Guidelines for Bag Sampling}

1. Ensure that the bag material and fittings are appropriate for the compounds to be sampled.

2. Use only Teflon tubing to connect the sample bag to the pump to prevent sample loss by adsorption on tubing walls.

3. Before using, flush the bag thoroughly with purified air or nitrogen.

4. Analyze the sample within 24 to 48 hours. Long-term storage of air-contaminant mixtures in bags is not recommended.

5. Do not ship sample bags by air unless the cargo cabin is pressurized.

\section{Cautions}

(D) The O-rings inside the bag fittings resist heat to $225 \mathrm{~F}$ (107 C). Do not sample compounds that exceed this specification.

(D) 237 Series FlexFilm bag material can withstand temperatures up to $140 \mathrm{~F}$ (60 C). Do not exceed this specification.

(D) Do not use sample bags to sample compounds with boiling points $>249.8 \mathrm{~F}$ (121 C).

D SKC sample bags are designed for sampling air at atmospheric pressure only. Attempting to pressurize the bag can result in bag rupture and sample loss. Do not ship bag samples by air freight in a non-pressurized cargo cabin. Bags can burst under such conditions.

(D) All federal and state packaging and transporting regulations apply.

(D) Failure to follow warnings and cautions voids any warranty.

(D) Sample bags are designed for single use only. 


\section{Operation}

1. Flush the bag at least 3 times with purified air or nitrogen before use.

2. To fill a bag, connect Teflon tubing from the exhaust port of an air sample pump to the hose connection on the bag (stem protruding from the top of the inlet fitting).
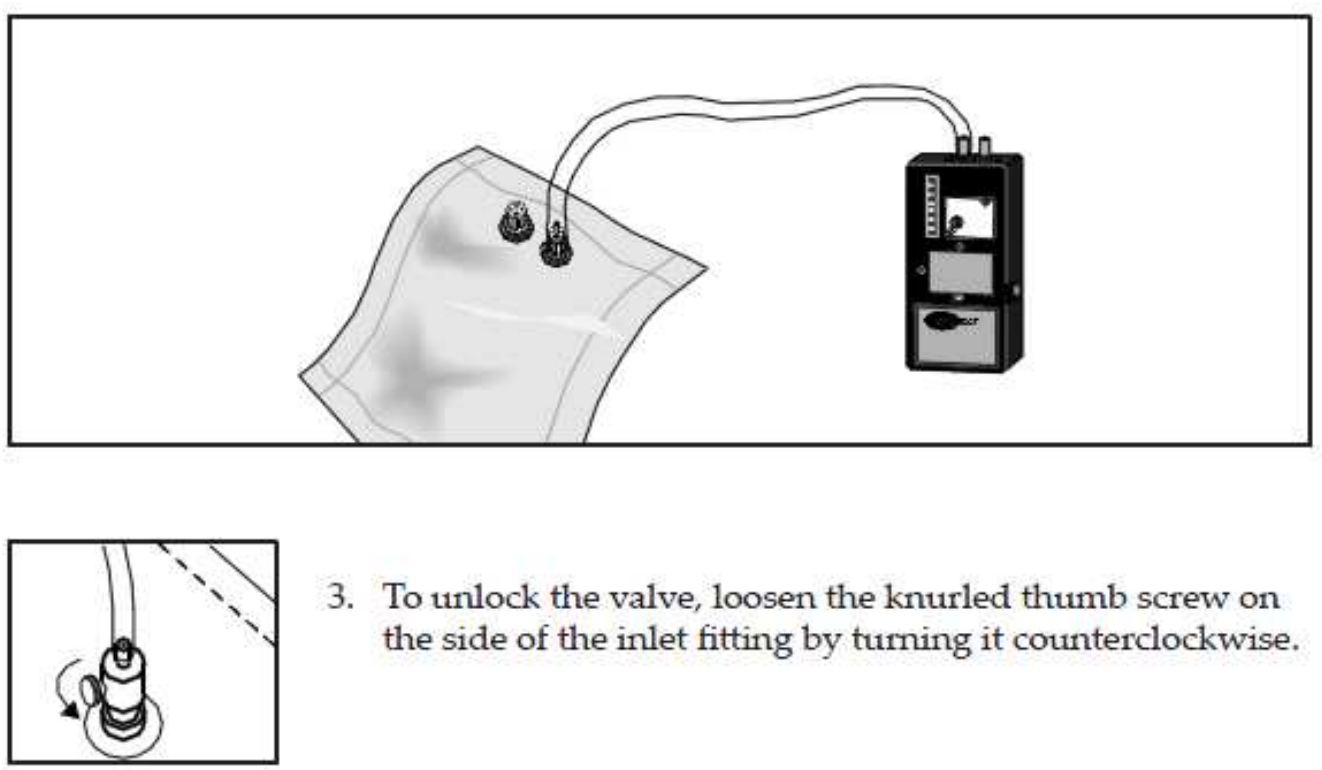

3. To unlock the valve, loosen the knurled thumb screw on the side of the inlet fitting by turning it counterclockwise.

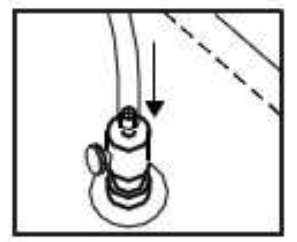

4. Push the stem of the valve down to open the inlet fitting for sampling.

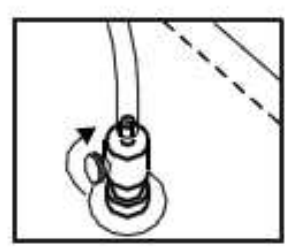

5. To lock the valve open, re-tighten the knurled thumbscrew on the side of the inlet fitting by turning it clockwise. Turn on the sample pump to fill the bag (see Proper Bag Inflation).

(D) Do not sample compounds that exceed the $225 \mathrm{~F}$ (107.2 C) temperature rating of the fitting $\mathrm{O}$-rings.

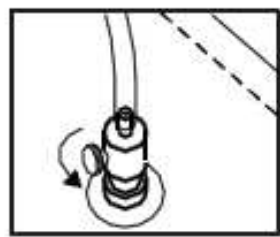

(D) When using 237 Series FlexFilm bags, do not sample compounds that exceed $140 \mathrm{~F}(60 \mathrm{C})$ temperature.

(D) Do not use sample bags to sample compounds with boiling points $>249.8 \mathrm{~F}$ (121 C).

6. When sampling is complete, turn off the pump and loosen the knurled thumbscrew.

7. Close the shut-off valve by pulling up on the valve stem (Note: Ensure the Teflon tubing is not pulled off while pulling up on the valve stem). Tighten the knurled screw to lock the valve closed. 
8. To withdraw samples using a needle and syringe, carefully insert the needle into the port in the septum fitting and pierce the septum.

(D) Do not allow the needle to puncture the bag material when piercing the septum.

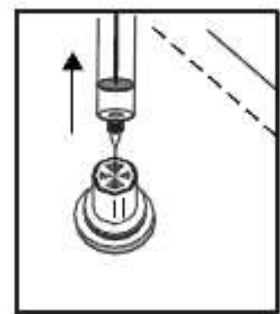

\section{Proper Bag Inflation}

Avoid filling any bag more than $80 \%$ of its maximum volume. At the end of the sampling period, turn the pump off and close the valve on the bag. Tighten the knurled screw to lock the valve closed.

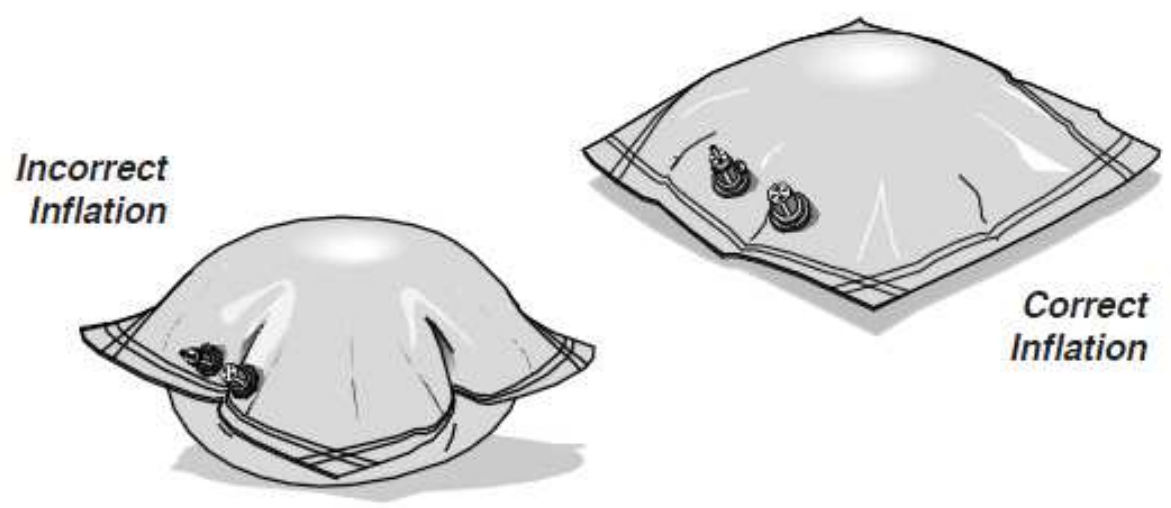

\section{Silicone Background}

All SKC fittings are lubricated with grease that contains silicone. This may produce high peaks for silicone in a GC-MS analysis.

SKC sample bags are available in Tedlar, black Tedlar, Teflon, SamplePro ${ }^{\otimes}$ FlexFilm, and FlexFoil ${ }^{\oplus}$ with fittings made of stainless steel, polypropylene, or Teflon in sizes ranging from 10 milliliters to 100 liters. SKC also manufactures custom sample bags. Contact SKC at 724-941-9701 or skctech@skcinc.com. 


\section{Appendix C}

\section{SKC ${ }^{\circledR}$ Low Flow Sample Pump 222 Series}

\section{Description}

SKC 222 Series Low Flow Pumps are miniature diaphragm-type pumps for personal or area sampling of gases and vapors in air using sorbent tubes or sample bags. These reliable lightweight pumps are motor-operated and powered by a rechargeable battery pack. Featuring reliable stroke counter technology, the pump's stroke counter indicates the number of times the pump's diaphragm has pulsed (or stroked) during the sampling period. By multiplying this stroke number by the volume of air per stroke, an accurate determination of air volume can be made. SKC sample pumps have special patented valves that close positively, ensuring zero leaks. All working parts are housed in a sturdy, shock-resistant case with belt clip. Model 222-3 pumps provide flows from 50 to $200 \mathrm{ml} / \mathrm{min}$; Model $222-4$ pumps provide flows from 20 to $80 \mathrm{ml} / \mathrm{min}$.

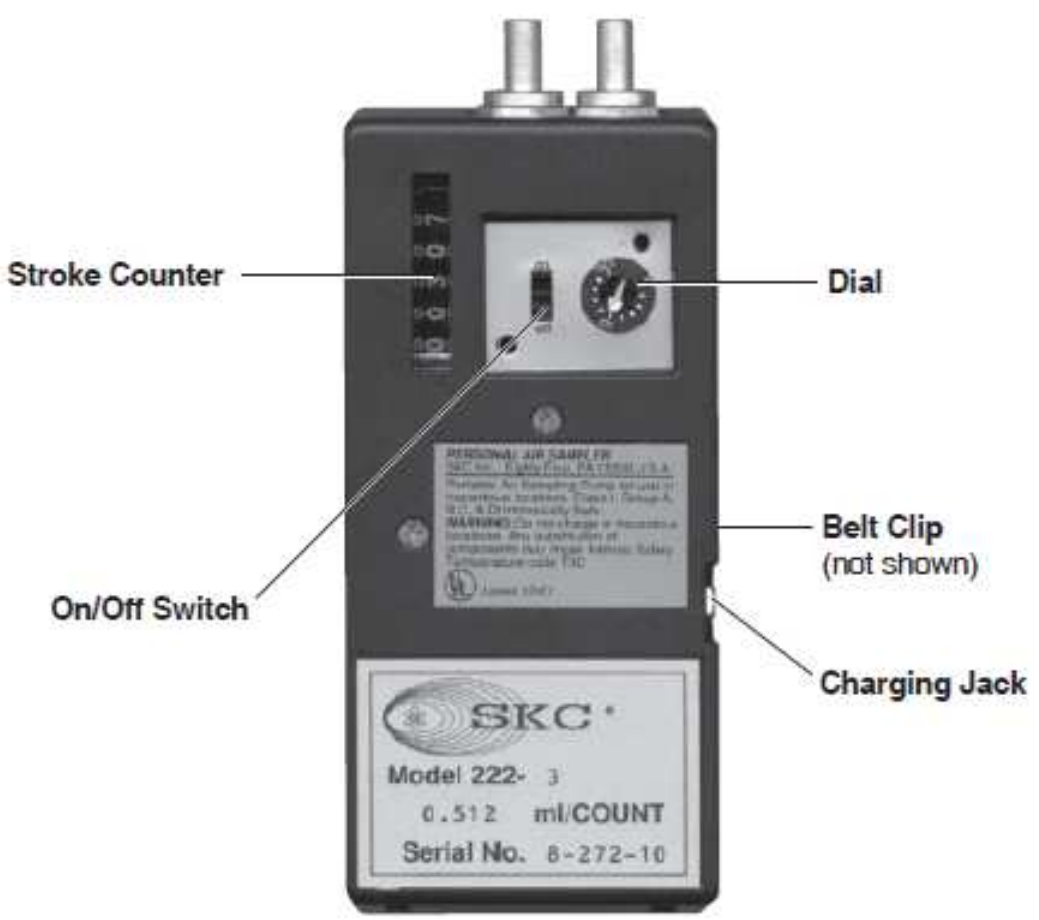

222-3 Low Flow Pump 


\section{Performance Profile}

222-3: $\quad 50$ to $200 \mathrm{ml} / \mathrm{min}$

222-4: $\quad 20$ to $80 \mathrm{ml} / \mathrm{min}$

Operation Time: $\quad 10 \mathrm{hrs}$ per battery charge

Case: $\quad$ Sturdy, lightweight plastic

Battery: Rechargeable NiGad, 2.4 V

Charge Time: $\quad 6$ to 8.5 hrs with PowerFlex charger

(varies with capacity

and level of charge)

Battery Regulator: Holds voltage constant

Counter Readout: Shows pump strokes up to six digits

Valves: Zero-leak valves

Pumping Action: Diaphragm

Temperature Ranges: Operating: 32 to $113 \mathrm{~F}$ ( 0 to $45 \mathrm{G}$ )

Charging: $\quad 32$ to $113 \mathrm{~F}$ ( 0 to $45 \mathrm{G}$ )

Storing: $\quad-4$ to $113 \mathrm{~F}(-20$ to $45 \mathrm{G})$

(I) Protect sample pump from weather when in use outdoors.

Size:

$5.1 \times 2.5 \times 1.25$ in $(13 \times 6.4 \times 3.2 \mathrm{~cm})$

Weight:

$12 \mathrm{oz}(340 \mathrm{gm})$

Approvals:

UL Listed for intrinsic safety; Class I, Groups A, B, G, and D GE marked

(I) Use only the SKC-approved battery and charger for this model to ensure reliable performance and to maintain the $U L$ Listing for intrinsic safety. Failure to do so voids any warranty. 


\section{Appendix D}

\section{Oakton ${ }^{\circledR}$ Infrared Thermometer}

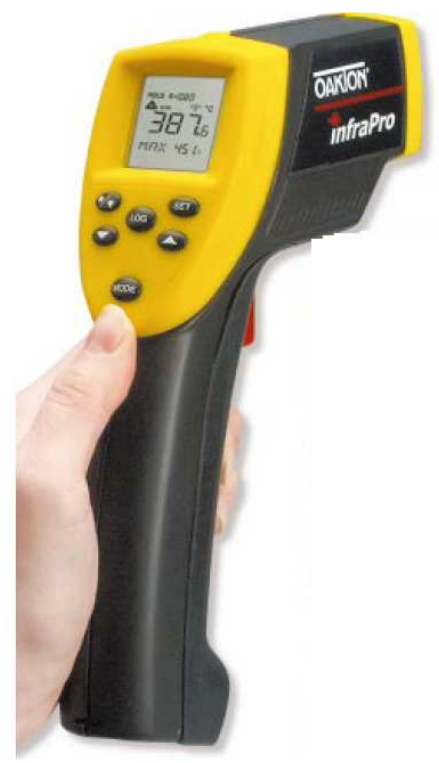

- Specifications

\begin{tabular}{|c|c|c|c|c|c|}
\hline Catalog number & WD-35629-00 & WD-35629-10 & WD-35629-20 & WD-35629-30 & WD-35629-40 \\
\hline Description & Infrapro" 1 & Infrapro 2 & Infrapro 3 & Infrapro 4 & Infrapro 5 \\
\hline Range & $\begin{array}{l}-32 \text { to } 400^{\circ} \mathrm{C} \\
\left(-25 \text { to } 750^{\circ} \mathrm{F}\right)\end{array}$ & $\begin{array}{l}-32 \text { to } 545^{\circ} \mathrm{C} \\
\left(-25 \text { to } 950^{\circ} \mathrm{F}\right)\end{array}$ & $\begin{array}{l}-32 \text { to } 600^{\circ} \mathrm{C} \\
\left(-25 \text { to } 1100^{\circ} \mathrm{F}\right)\end{array}$ & $\begin{array}{l}-32 \text { to } 760^{\circ} \mathrm{C} \\
\left(-25 \text { to } 1400^{\circ} \mathrm{F}\right)\end{array}$ & $\begin{array}{l}-32 \text { to } 760^{\circ} \mathrm{C} \\
\left(-25 \text { to } 1400^{\circ} \mathrm{F}\right)\end{array}$ \\
\hline Resolution & \multicolumn{5}{|c|}{$0.2^{\circ} \mathrm{C}\left(0.5^{\circ} \mathrm{F}\right)$} \\
\hline Accuracy & \multicolumn{5}{|c|}{ $\pm 1 \%$ of the reading or $\pm 1^{\circ} \mathrm{C}\left( \pm 2^{\circ} \mathrm{F}\right)$ whichever is greater } \\
\hline Repeatability & \multicolumn{5}{|c|}{ $\pm 0.5 \%$ of reading or $\pm 1^{\circ} \mathrm{C}\left( \pm 2^{\circ} \mathrm{F}\right)$ whichever is greater } \\
\hline Spectral range & \multicolumn{5}{|c|}{8 to $14 \mu \mathrm{m}$} \\
\hline Response time & \multicolumn{5}{|c|}{$500 \mathrm{msec}$} \\
\hline Emissivity & Fixed at 0.95 & Fixed at 0.95 & 0.10 to 1.00 & 0.10 to 1.00 & 0.10 to 1.00 \\
\hline Laser sighting & $\begin{array}{l}\text { Single spot, } \\
\text { class II laser }\end{array}$ & $\begin{array}{l}\text { Offset circle, } \\
\text { class II laser }\end{array}$ & $\begin{array}{l}\text { Offset circle, } \\
\text { class II laser }\end{array}$ & $\begin{array}{l}\text { Offset circle, } \\
\text { class II laser }\end{array}$ & $\begin{array}{l}\text { Offset circle, } \\
\text { class II laser }\end{array}$ \\
\hline Distance-to-target ratio & $12: 1$ & $12: 1$ & $30: 1$ & $50: 1$ & $50: 1$ \\
\hline HOLD function & Yes & Yes & Yes & Yes & Yes \\
\hline Maximum reading & Yes & Yes & Yes & Yes & Yes \\
\hline Minimum reading & - & - & Yes & Yes & Yes \\
\hline Differential reading & - & - & Yes & Yes & Yes \\
\hline Average reading & - & - & Yes & Yes & Yes \\
\hline High/low alarms & - & - & Yes & Yes & Yes \\
\hline Datalogging & - & - & up to 12 points & up to 12 points & up to 12 points \\
\hline External RTD probe & - & - & Optional & Optional & Included \\
\hline $\begin{array}{l}\text { Trigger lock } \\
\text { (for long-term monitoring) }\end{array}$ & - & - & Yes & Yes & Yes \\
\hline Intrinsically safe & - & - & - & - & Yes \\
\hline Operating range & \multicolumn{5}{|c|}{0 to $50^{\circ} \mathrm{C}\left(32\right.$ to $\left.120^{\circ} \mathrm{F}\right)$} \\
\hline Power & \multicolumn{5}{|c|}{$9 \mathrm{~V}$ battery; display features low battery indicator } \\
\hline Battery life & 10 hours continuous & 10 hours continuous & 14 hours continuous & 14 hours continuous & 14 hours continuous \\
\hline Dimensions & \multicolumn{5}{|c|}{ 8"L x 6"W x 2"H } \\
\hline Weight & \multicolumn{5}{|c|}{$11 \mathrm{oz}(320 \mathrm{~g})$ unit only; $2 \mathrm{lbs}(1 \mathrm{~kg})$ boxed } \\
\hline
\end{tabular}

\section{Appendix E}




\section{Bios $^{\circledR}$ Defender 510-M DryCal ${ }^{\circledR}$}

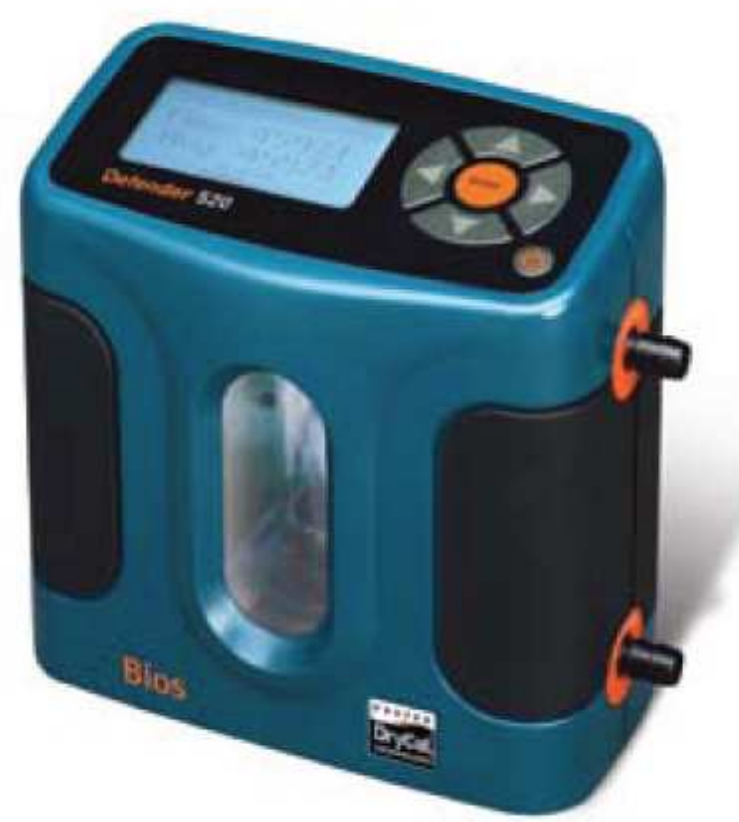

\begin{tabular}{|l|l|}
\hline Flow Ranges & $\begin{array}{l}\text { Low (L) } 5 \mathrm{~mL}-500 \mathrm{~mL} / \mathrm{min} \\
\text { Medlum (M) } 50 \mathrm{~mL}-5,000 \mathrm{~mL} / \mathrm{min} \\
\text { Hlgh (H) } 300 \mathrm{~mL}-30,000 \mathrm{~mL} / \mathrm{min}\end{array}$ \\
\hline Accuracy & $1 \%$ Volumetric \\
\hline Slze & $\begin{array}{l}\text { Small enough to fit easily in your hand; } \\
\text { slim enough to slide into a briefcase or tote }\end{array}$ \\
\hline Welght & $29 \mathrm{oz} / 820 \mathrm{~g}$ \\
\hline Dimensions $(\mathrm{H} \times \mathrm{W} \times \mathrm{D})$ & $5.5 \times 6 \times 3 \mathrm{in} / 140 \times 150 \times 75 \mathrm{~mm}$ \\
\hline
\end{tabular}

\begin{tabular}{|l|l|}
\hline User-Selectable Measurement Units \\
\hline Volumetrlc Flow & $\mathrm{mL} / \mathrm{min} \quad \mathrm{L} / \mathrm{min} \quad \mathrm{cc} / \mathrm{min} \quad \mathrm{cf} / \mathrm{min}$ \\
\hline Pressure (Defender 520 onlyl & $\mathrm{mmHg} \quad \mathrm{PSI} \quad \mathrm{kPa}$ \\
\hline Temperature (Defender 520 only) & ${ }^{\circ} \mathrm{C} \quad{ }^{\circ} \mathrm{F}$ \\
\hline
\end{tabular}




\section{Defender $\mathbf{5 0 0}$ Series Specifications}

\begin{tabular}{|c|c|}
\hline Approximate Time per Reading: & $1-15$ seconds \\
\hline Gas Compatibility: & $\begin{array}{l}\text { Use with non-corrosive, non-condensing, } \\
\text { non-combustible gases, less than } 70 \% \text { humidity }\end{array}$ \\
\hline Flow Modes: & Suction or Pressure \\
\hline Measurement Cell Style: & Integrated \\
\hline Temperature and Pressure Sensors: & $\begin{array}{l}\text { In the flow stream } \\
\text { Press. Accuracy: } 3.5 \mathrm{mmHg} \text { (typical), } 7.0 \mathrm{~mm} \text { (max); } \\
\text { Temp. Accuracy: } 0.8^{\circ} \mathrm{C} \text { (typical), } 1.3^{\circ} \mathrm{C} \text { (max) }\end{array}$ \\
\hline Reading Styles: & $\begin{array}{l}\text { Single (manual), Continuous or Burst, } \\
\text { with averaging function user-selectable } \\
\text { from } 1 \text { to } 100 \text { measurements }\end{array}$ \\
\hline AC Adapter/Charger: & $12 \mathrm{~V} \mathrm{DC},>250 \mathrm{ma}, 2.5 \mathrm{~mm}$, center positive \\
\hline Battery System: & $\begin{array}{l}\text { 6V rechargeable, sealed lead-acid, } \\
6-8 \text { hrs typical operation }\end{array}$ \\
\hline Battery Operational Time (5 cycles/min): & 3 hrs backlight on, 8 hrs backlight off \\
\hline Pressure and Suction Fittings: & 1/4" ID Hose Barb \\
\hline Warranty: & 1 year; battery 6 months \\
\hline Storage Temperature: & $0-70^{\circ} \mathrm{C}$ \\
\hline Ambient Humidity: & $0-70 \%$, non-condensing \\
\hline Operating Pressure (Absolute): & 15 PSI \\
\hline Display: & Backlit graphical LCD \\
\hline $\begin{array}{l}\text { Data Port } \\
\text { (for use with Optimizer software): }\end{array}$ & Serial (RS-232) \\
\hline $\begin{array}{l}\text { Data Cable } \\
\text { (for use with Optimizer software): }\end{array}$ & 1 meter (Defender Data Port to PC serial port) \\
\hline Protective Case: & Soft side or Pelican case available \\
\hline
\end{tabular}




\section{Appendix F}

\section{Experimental Data Collection Sheet}

\begin{tabular}{|c|c|c|c|c|c|c|c|}
\hline Paran & \multicolumn{2}{|c|}{ Present } & Temp, C & \multicolumn{2}{|c|}{ Pbar/Vel } & \multicolumn{2}{|c|}{ Time } \\
\hline TN & Manik & & EntryWall & BarmmHg & & GasOn & \\
\hline Date & ManBreath & & CoalWall & VPcl 1 & & BagOn & \\
\hline SubjectID & Table & & SamplWall & VPcl 2 & & & \\
\hline HoodFanHz & Clutter & & Floor & VductTran & & BagOff & \\
\hline WTrpm & Heated & & Ceiling & $\sim$ Vface & & GasOff: & \\
\hline HoodHeight & & Source & Air, $T d b$ & & Initials & & \\
\hline HoodWidth & PanToFace & & Air, T wb & InitTravser & & FatalError & \\
\hline CrossOrient & Freon, Ipm & & ManFace & Sampler & & MatchConfi & \\
\hline Intervention & $\mathrm{He}, \mathrm{Ipm}$ & & M. Torso & FTIR anal & & & \\
\hline Face Loc. & & & & & & & \\
\hline
\end{tabular}

\begin{tabular}{|c|c|c|c|c|c|}
\hline Location & Freon 134a & Residual & Time & RefNo & Comments \& Errors \\
\hline \multicolumn{6}{|l|}{ Ambient Left } \\
\hline \multicolumn{6}{|l|}{ AmbientRight } \\
\hline \multicolumn{6}{|l|}{ Downstream } \\
\hline \multicolumn{6}{|c|}{ Nose } \\
\hline \multicolumn{6}{|l|}{ Mouth } \\
\hline \multicolumn{6}{|c|}{ Duct } \\
\hline \multicolumn{6}{|l|}{ Other } \\
\hline
\end{tabular}




\section{Appendix G}

\section{Experimental Data Collection Software - Heavent ${ }^{\circledR}$ Measurement}

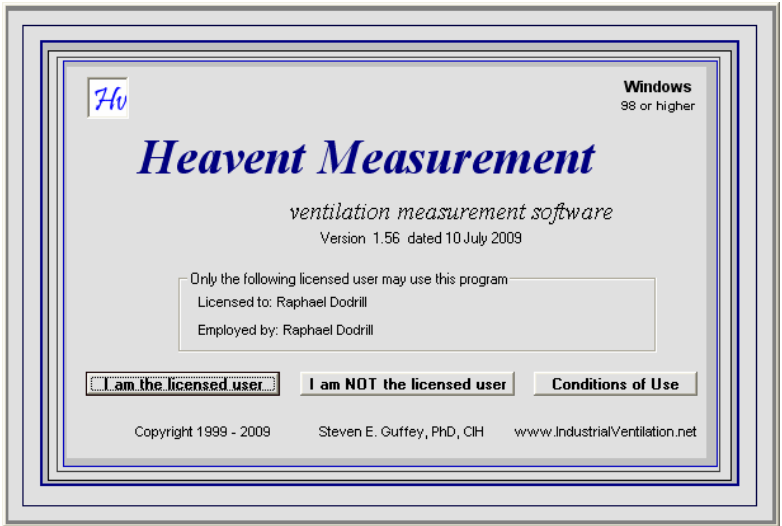

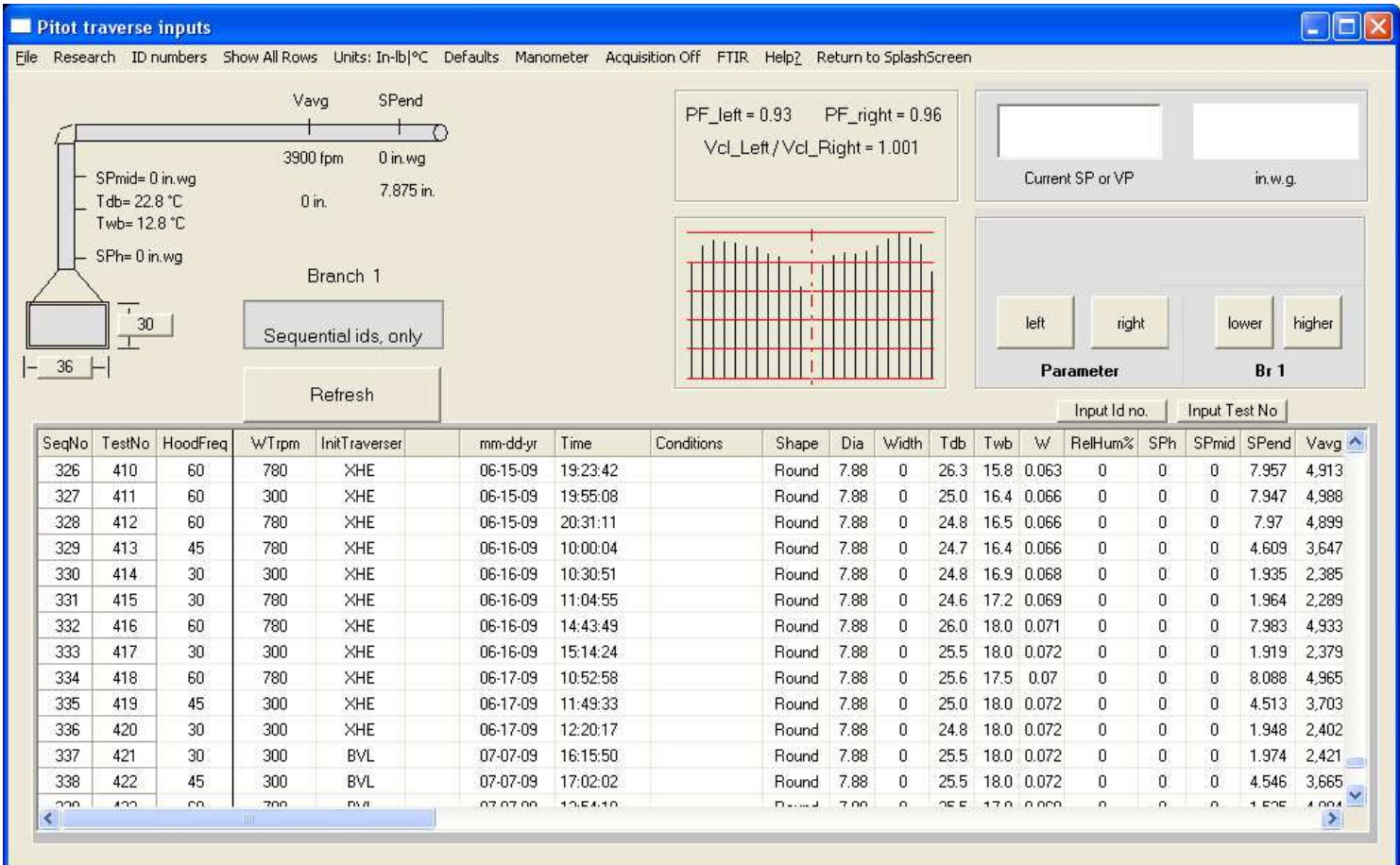




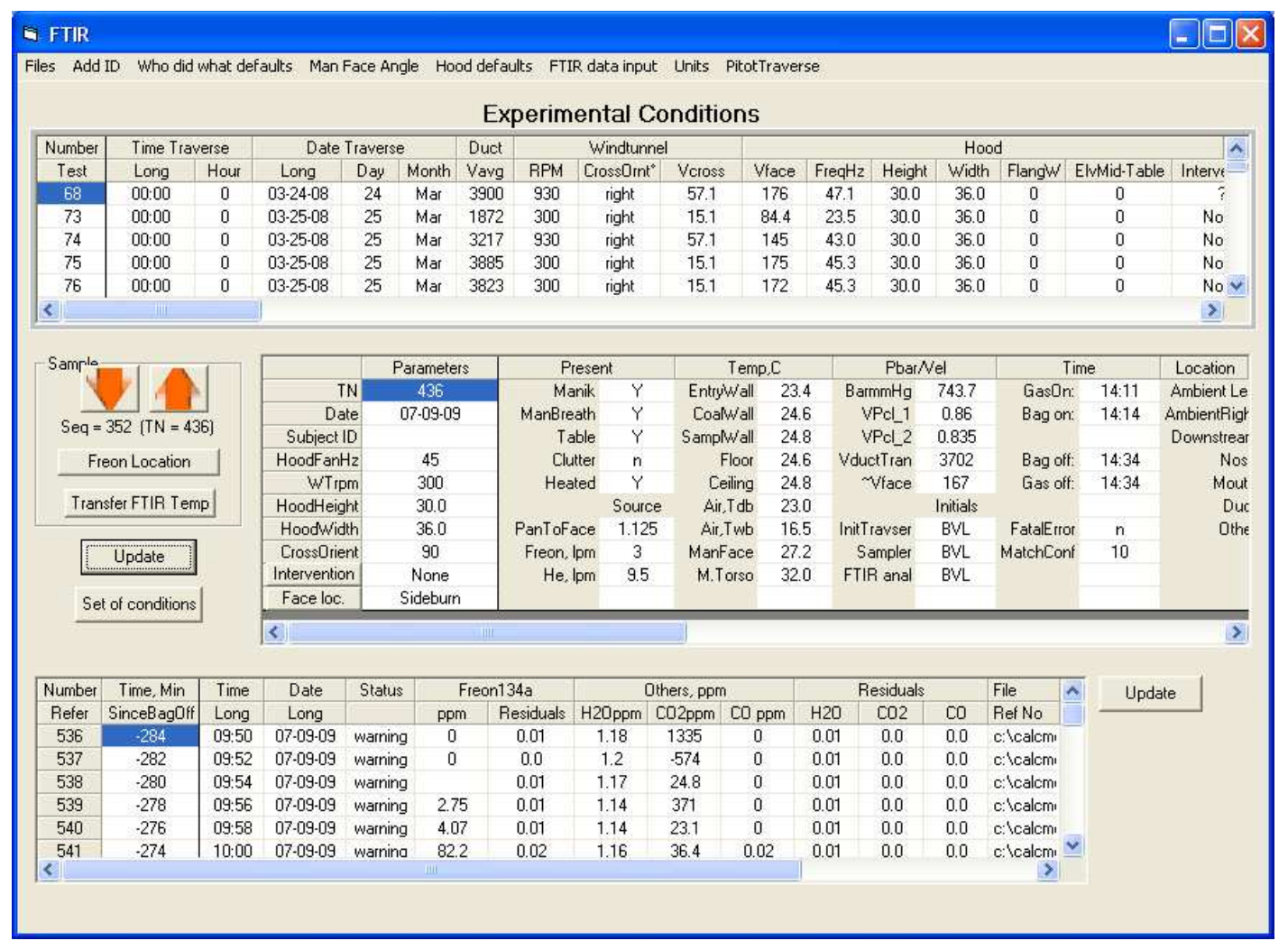




\section{Appendix H}

\section{All Experimental Data for Study I}

\begin{tabular}{|c|c|c|c|c|c|c|c|c|c|c|c|c|c|c|}
\hline $\begin{array}{l}-1 \\
\text { p } \\
\text { ż } \\
0\end{array}$ & 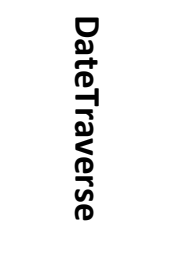 & 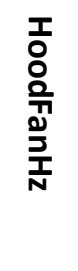 & $\begin{array}{l}\sum_{3}^{3} \\
\frac{7}{3} \\
3\end{array}$ & 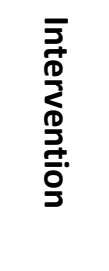 & 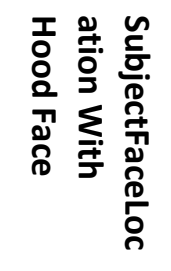 & $\begin{array}{l}\frac{T}{7} \\
0 \\
0 \\
0 \\
0 \\
0 \\
0 \\
0 \\
3\end{array}$ & 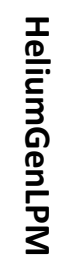 & 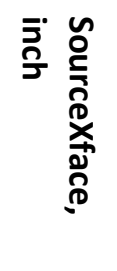 & $\begin{array}{l}\frac{8}{0} \\
3 \\
\frac{0}{0} \\
\frac{0}{5} \\
\frac{8}{0} \\
3\end{array}$ & 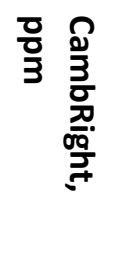 & $\begin{array}{l}\frac{2}{0} \\
\frac{0}{3} \\
\stackrel{0}{0} \\
\frac{0}{3} \\
3\end{array}$ & 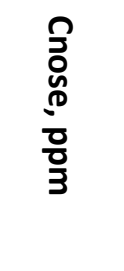 & $\begin{array}{l}\mathfrak{3} \\
3 \\
\frac{0}{5} \\
\stackrel{5}{5} \\
\frac{0}{0} \\
3\end{array}$ & $\begin{array}{l}\frac{2}{1} \\
\frac{1}{7} \\
\frac{0}{0} \\
\frac{0}{3}\end{array}$ \\
\hline 319 & 04-08-09 & 60 & 480 & None & Sideburn & 3 & 9.5 & 1.125 & 0 & 0.01 & 0.01 & 7.98 & 7.7 & 39.17 \\
\hline 320 & 04-08-09 & 30 & 300 & None & Sideburn & 3 & 9.5 & 1.125 & 0 & 0 & 0 & 34.02 & 34.64 & 79.77 \\
\hline 321 & 04-08-09 & 60 & 300 & None & Sideburn & 3 & 9.5 & 1.125 & 0.01 & 0.01 & 0 & 5.86 & 4.33 & 38.8 \\
\hline 322 & 04-08-09 & 30 & 480 & None & Sideburn & 3 & 9.5 & 1.125 & 0 & 0 & 0 & 18.23 & 20.69 & 79.66 \\
\hline 323 & 04-08-09 & 30 & 930 & None & Sideburn & 3 & 9.5 & 1.125 & 0.01 & 0 & 0 & 3.66 & 5.69 & 83.24 \\
\hline 324 & 04-08-09 & 60 & 780 & None & Sideburn & 3 & 9.5 & 1.125 & 0.01 & 0.01 & 0.01 & 2.71 & 2.12 & 39.72 \\
\hline 325 & 04-08-09 & 30 & 480 & None & Sideburn & 3 & 9.5 & 1.125 & 0.01 & 0.01 & 0.01 & 9.87 & 10.42 & 80.18 \\
\hline 326 & 04-08-09 & 30 & 930 & None & Sideburn & 3 & 9.5 & 1.125 & 0.01 & 0.01 & 0.01 & 4.41 & 6.78 & 83.45 \\
\hline 327 & 04-08-09 & 30 & 780 & None & Sideburn & 3 & 9.5 & 1.125 & 0.01 & 0.01 & 0 & 3.02 & 4.8 & 82.79 \\
\hline 328 & 04-09-09 & 30 & 630 & None & Sideburn & 3 & 9.5 & 1.125 & 0 & 0 & 0 & 3.56 & 4.37 & 79.86 \\
\hline 329 & 04-09-09 & 30 & 300 & None & Sideburn & 3 & 9.5 & 1.125 & 0 & 0 & 0 & 18.84 & 23.76 & 77.06 \\
\hline 330 & 04-09-09 & 60 & 930 & None & Sideburn & 3 & 9.5 & 1.125 & 0 & 0 & 0 & 1.76 & 1.81 & 39.74 \\
\hline 331 & 04-09-09 & 60 & 480 & None & Sideburn & 3 & 9.5 & 1.125 & 0 & -0.01 & 0 & 3.04 & 2.21 & 39.44 \\
\hline
\end{tabular}




\begin{tabular}{|c|c|c|c|c|c|c|c|c|c|c|c|c|c|c|}
\hline 332 & 04-09-09 & 60 & 930 & None & Sideburn & 3 & 9.5 & 1.125 & 0 & 0 & 0 & 1.75 & -0.196 & 39.68 \\
\hline 333 & 04-09-09 & 30 & 780 & None & Sideburn & 3 & 9.5 & 1.125 & 0 & 0 & 0 & 2.56 & 4.31 & 81.66 \\
\hline 334 & 04-09-09 & 30 & 630 & None & Sideburn & 3 & 9.5 & 1.125 & 0 & 0 & 0 & 4.06 & 5.9 & 80.46 \\
\hline 335 & 04-10-09 & 60 & 780 & None & Sideburn & 3 & 9.5 & 1.125 & 0 & 0 & 0 & 1.56 & 1.61 & 39.99 \\
\hline 336 & 04-10-09 & 60 & 300 & None & Sideburn & 3 & 9.5 & 1.125 & 0 & 0 & 0 & 7.79 & 4.98 & 39.56 \\
\hline 337 & 04-10-09 & 60 & 630 & None & Sideburn & 3 & 9.5 & 1.125 & 0 & 0 & 0 & 2.45 & 1.74 & 39.79 \\
\hline 338 & 04-10-09 & 60 & 630 & None & Sideburn & 3 & 9.5 & 1.125 & 0 & 0 & 0 & 2.19 & 1.51 & 39.7 \\
\hline 339 & 04-15-09 & 45 & 300 & None & Sideburn & 3 & 9.5 & 1.125 & -0.01 & -0.01 & -0.01 & 4.39 & 3.7 & 51.53 \\
\hline 340 & 04-15-09 & 45 & 780 & None & Sideburn & 3 & 9.5 & 1.125 & -0.01 & -0.01 & -0.01 & 2.71 & 2.86 & 53.57 \\
\hline 341 & 04-15-09 & 45 & 930 & None & Sideburn & 3 & 9.5 & 1.125 & -0.01 & -0.02 & -0.01 & 3.54 & 3.37 & 54.32 \\
\hline 342 & 04-16-09 & 45 & 630 & None & Sideburn & 3 & 9.5 & 1.125 & 0 & -0.01 & 0 & 2.87 & 2.94 & 53.1 \\
\hline 343 & 04-16-09 & 45 & 930 & None & Sideburn & 3 & 9.5 & 1.125 & 0 & 0 & 0 & 1.68 & 3.13 & 53.4 \\
\hline 345 & 04-17-09 & 45 & 480 & None & Sideburn & 3 & 9.5 & 1.125 & 0.01 & 0 & 0 & 4.18 & 3.22 & 52.58 \\
\hline 346 & 04-17-09 & 45 & 630 & None & Sideburn & 3 & 9.5 & 1.125 & 0 & -0.01 & 0 & 2.94 & 2.47 & 52.59 \\
\hline 347 & 04-17-09 & 45 & 300 & None & Sideburn & 3 & 9.5 & 1.125 & 0 & 0 & 0 & 9.74 & 3.92 & 51.92 \\
\hline 348 & 04-17-09 & 45 & 480 & None & Sideburn & 3 & 9.5 & 1.125 & 0 & 0 & 0 & 4.51 & 3.06 & 53.01 \\
\hline 349 & 04-17-09 & 45 & 780 & None & Sideburn & 3 & 9.5 & 1.125 & 0 & -0.01 & 0 & 3.2 & 3.48 & 53.97 \\
\hline 350 & 04-20-09 & 52.5 & 480 & None & Sideburn & 3 & 9.5 & 1.125 & 0 & 0 & 0 & 4.53 & 3.11 & 45.5 \\
\hline 351 & 04-20-09 & 37.5 & 930 & None & Sideburn & 3 & 9.5 & 1.125 & 0 & 0 & 0 & 4.51 & 5.29 & 64.68 \\
\hline 352 & 04-20-09 & 52.5 & 780 & None & Sideburn & 3 & 9.5 & 1.125 & -0.01 & 0 & -0.01 & 3.19 & 2.55 & 45.8 \\
\hline 353 & 04-21-09 & 52.5 & 300 & None & Sideburn & 3 & 9.5 & 1.125 & 0 & 0 & 0 & 5.29 & 3.71 & 45.03 \\
\hline 354 & 04-21-09 & 37.5 & 300 & None & Sideburn & 3 & 9.5 & 1.125 & -0.01 & -0.01 & 0 & 7.57 & 6.21 & 63.85 \\
\hline
\end{tabular}




\begin{tabular}{|c|c|c|c|c|c|c|c|c|c|c|c|c|c|c|}
\hline 355 & 04-21-09 & 37.5 & 780 & None & Sideburn & 3 & 9.5 & 1.125 & 0 & -0.01 & 0 & 5.5 & 6.5 & 64.72 \\
\hline 356 & 04-21-09 & 37.5 & 630 & None & Sideburn & 3 & 9.5 & 1.125 & 0 & 0 & -0.01 & 5.38 & 5.48 & 64.19 \\
\hline 357 & 04-22-09 & 52.5 & 780 & None & Sideburn & 3 & 9.5 & 1.125 & 0 & -0.08 & 0 & 3.23 & 2.75 & 45.93 \\
\hline 358 & $04-22-09$ & 52.5 & 630 & None & Sideburn & 3 & 9.5 & 1.125 & 0 & 0 & 0 & 3.22 & 2.37 & 45.21 \\
\hline 359 & 04-22-09 & 52.5 & 300 & None & Sideburn & 3 & 9.5 & 1.125 & 0 & 0 & 0 & 7.23 & 5.13 & 45.02 \\
\hline 360 & $04-22-09$ & 37.5 & 930 & None & Sideburn & 3 & 9.5 & 1.125 & 0 & -0.01 & -0.01 & 4.73 & 6.32 & 66.12 \\
\hline 361 & $04-22-09$ & 37.5 & 630 & None & Sideburn & 3 & 9.5 & 1.125 & 0 & 0 & 0 & 4.99 & 4.55 & 64.19 \\
\hline 362 & 04-22-09 & 37.5 & 480 & None & Sideburn & 3 & 9.5 & 1.125 & 0 & 0 & 0 & 7.31 & 6.31 & 62.99 \\
\hline 363 & 04-22-09 & 37.5 & 780 & None & Sideburn & 3 & 9.5 & 1.125 & 0 & -0.01 & 0 & 2.88 & 4.61 & 64.41 \\
\hline 364 & $04-22-09$ & 52.5 & 480 & None & Sideburn & 3 & 9.5 & 1.125 & 0 & 0 & 0 & 4.23 & 4.08 & 44.86 \\
\hline 365 & 04-23-09 & 52.5 & 630 & None & Sideburn & 3 & 9.5 & 1.125 & 0 & 0 & 0 & 4.13 & 3.35 & 45.47 \\
\hline 366 & 04-23-09 & 37.5 & 300 & None & Sideburn & 3 & 9.5 & 1.125 & 0 & 0 & 0 & 15.44 & 16.13 & 63.4 \\
\hline 367 & 04-23-09 & 37.5 & 480 & None & Sideburn & 3 & 9.5 & 1.125 & 0 & 0 & 0 & 6.93 & 5.62 & 64.05 \\
\hline 368 & 04-23-09 & 37.5 & 480 & None & Sideburn & 3 & 9.5 & 1.125 & 0 & 0 & 0 & 6.82 & 5.46 & 55.58 \\
\hline 369 & 04-29-09 & 52.5 & 930 & None & Sideburn & 3 & 9.5 & 1.125 & -0.01 & 2.54 & -0.01 & 3.84 & 3.6 & 47.76 \\
\hline 370 & 04-29-09 & 52.5 & 630 & None & Sideburn & 3 & 9.5 & 1.125 & -0.01 & 0 & -0.01 & 3.82 & 2.49 & 45.57 \\
\hline 371 & 04-29-09 & 52.5 & 930 & None & Sideburn & 3 & 9.5 & 1.125 & 0 & 0 & 0 & 4.02 & 3.84 & 46.11 \\
\hline 372 & 04-29-09 & 37.5 & 300 & None & Sideburn & 3 & 9.5 & 1.125 & 0 & 0 & -0.01 & 20.23 & 14.47 & 63.2 \\
\hline
\end{tabular}




\section{Appendix I}

\section{All Experimental Data for Study II}

\begin{tabular}{|c|c|c|c|c|c|c|c|c|c|c|c|c|}
\hline 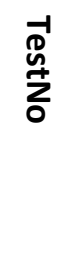 & 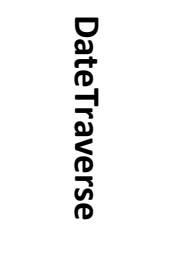 & 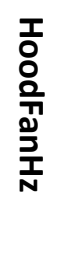 & $\underset{\substack{3 \\
3}}{\xi}$ & 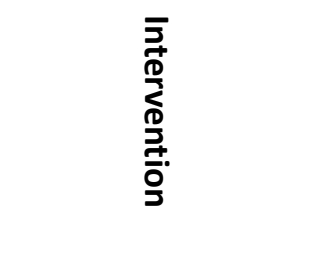 & 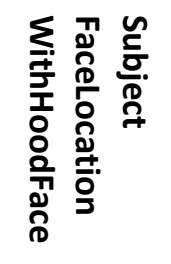 & $\begin{array}{l}\frac{8}{3} \\
\frac{8}{0} \\
\frac{0}{0} \\
\frac{9}{9} \\
\frac{0}{0} \\
3\end{array}$ & 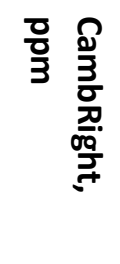 & $\begin{array}{l}2 \\
\frac{2}{0} \\
\vdots 3 \\
\vdots \\
\frac{0}{0} \\
3\end{array}$ & 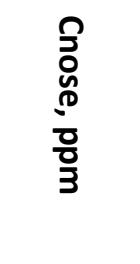 & $\begin{array}{l}\mathfrak{3} \\
3 \\
\frac{0}{5} \\
\stackrel{5}{5} \\
\frac{0}{0} \\
3\end{array}$ & $\begin{array}{l}2 \\
\frac{2}{2} \\
\frac{7}{2} \\
\text { 음 } \\
3\end{array}$ & 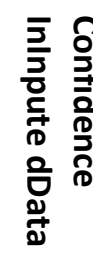 \\
\hline 378 & 05-21-09 & 30 & 300 & CowlTopSides12in & Sideburn & -0.01 & -0.01 & -0.01 & 82.96 & 213.74 & 75.17 & 10 \\
\hline 379 & 05-21-09 & 30 & 780 & CowlTopSides12in & Sideburn & -0.01 & -0.09 & -0.01 & 68.24 & 228.06 & 81.74 & 10 \\
\hline 380 & 05-21-09 & 45 & 780 & CowlTopSides12in & Sideburn & 0 & -0.01 & -0.01 & 95.74 & 183.34 & 54.63 & 10 \\
\hline 391 & $05-26-09$ & 30 & 780 & CowlTopSides12in & Sideburn & 0 & 0 & -0.01 & 333.48 & 582.98 & 81.48 & 10 \\
\hline 392 & 05-27-09 & 45 & 300 & CowlTopSides12in & Sideburn & -0.03 & 0 & -0.04 & 222.84 & 294.46 & 53.61 & 10 \\
\hline 393 & 06-01-09 & 60 & 300 & CowlTopSides12in & Sideburn & 0 & 0 & -0.02 & 172.26 & 205.18 & 34.33 & 10 \\
\hline 409 & 06-15-09 & 45 & 780 & CowlTopSides12in & Sideburn & -0.01 & 0 & -0.01 & 280.56 & 256.98 & 54.54 & 10 \\
\hline 410 & 06-15-09 & 60 & 780 & CowlTopSides12in & Sideburn & 0 & 0 & -0.01 & 179.98 & 135.84 & 40.52 & 10 \\
\hline 411 & 06-15-09 & 60 & 300 & CowlTopSides12in & Sideburn & 0 & 0 & -0.01 & 159.88 & 143.6 & 40.09 & 10 \\
\hline 418 & 06-17-09 & 60 & 780 & CowlTopSides12in & Sideburn & -0.01 & 0 & 0.6 & 174.84 & 151.91 & 40.37 & 10 \\
\hline 419 & 06-17-09 & 45 & 300 & CowlTopSides12in & Sideburn & -0.01 & 0 & -0.34 & 244.14 & 304.86 & 53.89 & 10 \\
\hline 420 & 06-17-09 & 30 & 300 & CowlTopSides12in & Sideburn & -0.03 & 0 & -0.01 & 534.09 & 689.78 & 80.46 & 10 \\
\hline 376 & 05-15-09 & 60 & 780 & FlangeBottom $12 \mathrm{in}$ & Sideburn & 0 & -0.01 & -0.01 & 15.1 & 25.6 & 34.5 & 10 \\
\hline
\end{tabular}




\begin{tabular}{|c|c|c|c|c|c|c|c|c|c|c|c|c|}
\hline 377 & $05-15-09$ & 30 & 300 & FlangeBottom 12in & Sideburn & -0.01 & 0 & -0.01 & 57 & 101 & 69.31 & 10 \\
\hline 381 & 05-21-09 & 45 & 780 & FlangeBottom 12in & Sideburn & -0.01 & -0.01 & -0.01 & 72.37 & 118.78 & 55.08 & 10 \\
\hline 382 & 05-21-09 & 60 & 300 & FlangeBottom 12in & Sideburn & -0.01 & -0.01 & -0.04 & 51.36 & 58.64 & 39.13 & 10 \\
\hline 383 & 05-21-09 & 45 & 300 & FlangeBottom 12in & Sideburn & -0.01 & 0 & -0.01 & 72.79 & 89.44 & 53.73 & 10 \\
\hline 384 & $05-22-09$ & 30 & 780 & FlangeBottom 12in & Sideburn & -0.01 & -0.01 & -0.01 & 55.35 & 165.33 & 82.22 & 10 \\
\hline 400 & $06-02-09$ & 45 & 300 & FlangeBottom 12in & Sideburn & -0.01 & 0 & -0.02 & 82.08 & 96.92 & 53.51 & 10 \\
\hline 401 & 06-02-09 & 45 & 780 & FlangeBottom $12 \mathrm{in}$ & Sideburn & -0.01 & 0 & -0.01 & 77.65 & 162.22 & 55.13 & 10 \\
\hline 402 & $06-02-09$ & 60 & 300 & FlangeBottom 12in & Sideburn & -0.01 & 0 & -0.01 & 53.96 & 58.94 & 39.88 & 10 \\
\hline 415 & $06-16-09$ & 30 & 780 & FlangeBottom 12in & Sideburn & -0.01 & 0 & -0.01 & 125.24 & 224.15 & 83.35 & 10 \\
\hline 416 & $06-16-09$ & 60 & 780 & FlangeBottom 12in & Sideburn & -0.01 & 0 & -0.01 & 76.32 & 115.65 & 40.88 & 10 \\
\hline 417 & $06-16-09$ & 30 & 300 & FlangeBottom 12in & Sideburn & 0 & 0 & -0.01 & 318.48 & 338.7 & 80.51 & 10 \\
\hline 388 & $05-25-09$ & 30 & 300 & FlangeTopSides12in & Sideburn & -0.01 & -0.01 & -0.01 & 189.9 & 169.95 & 78.85 & 10 \\
\hline 389 & 05-25-09 & 30 & 780 & FlangeTopSides12in & Sideburn & -0.01 & 0 & -0.01 & 123.51 & 246.94 & 82.22 & 10 \\
\hline 390 & $05-26-09$ & 45 & 780 & FlangeTopSides12in & Sideburn & -0.01 & 0 & 0 & 39.93 & 59.59 & 54.16 & 10 \\
\hline 394 & 06-01-09 & 45 & 300 & FlangeTopSides12in & Sideburn & -0.01 & 0 & -0.01 & 32.67 & 27.83 & 51.87 & 10 \\
\hline 395 & 06-01-09 & 30 & 780 & FlangeTopSides12in & Sideburn & -0.06 & 0 & -0.01 & 111.11 & 227.38 & 83.15 & 10 \\
\hline 396 & 06-01-09 & 60 & 780 & FlangeTopSides12in & Sideburn & -0.01 & 0 & -0.02 & 32.76 & 34.06 & 40.73 & 10 \\
\hline 403 & $06-02-09$ & 60 & 300 & FlangeTopSides12in & Sideburn & -0.01 & 0 & -0.03 & 39.27 & 32.71 & 40.15 & 10 \\
\hline 404 & 06-03-09 & 60 & 300 & FlangeTopSides12in & Sideburn & -0.01 & 0 & -0.01 & 30.6 & 24.04 & 39.55 & 10 \\
\hline 405 & 06-03-09 & 45 & 300 & FlangeTopSides12in & Sideburn & -0.03 & 0 & -0.01 & 39.96 & 33.71 & 53.32 & 10 \\
\hline 412 & $06-15-09$ & 60 & 780 & FlangeTopSides12in & Sideburn & -0.01 & 0 & -0.01 & 54 & 45.47 & 40.17 & 10 \\
\hline 413 & $06-16-09$ & 45 & 780 & FlangeTopSides12in & Sideburn & -0.01 & 0 & 0 & 62.54 & 52.46 & 54.15 & 10 \\
\hline
\end{tabular}




\begin{tabular}{ccccccccccccc}
\hline \hline 414 & $06-16-09$ & 30 & 300 & FlangeTopSides12in & Sideburn & -0.19 & 0 & -0.01 & 209.43 & 161.77 & 80.4 & 10 \\
373 & $05-14-09$ & 30 & 780 & None & Sideburn & -0.01 & -0.02 & -0.01 & 11.2 & 17.3 & 82.33 & 10 \\
374 & $05-14-09$ & 30 & 780 & None & Sideburn & 0 & -0.01 & -0.01 & 10.2 & 20.3 & 82.73 & 10 \\
375 & $05-14-09$ & 30 & 300 & None & Sideburn & -0.01 & -0.01 & -0.01 & 90 & 100 & 79.65 & 10 \\
385 & $05-22-09$ & 45 & 300 & None & Sideburn & -0.02 & -0.03 & -0.02 & 39.21 & 30.63 & 53.28 & 10 \\
386 & $05-24-09$ & 60 & 780 & None & Sideburn & 0 & 0 & -0.01 & 26.63 & 26.04 & 40.74 & 10 \\
387 & $05-24-09$ & 45 & 780 & None & Sideburn & -0.01 & -0.01 & -0.01 & 38.64 & 48.44 & 55.22 & 10 \\
397 & $06-01-09$ & 45 & 300 & None & Sideburn & -0.01 & 0 & -0.01 & 67.47 & 56.59 & 53.06 & 10 \\
398 & $06-02-09$ & 30 & 300 & None & Sideburn & -0.02 & 0 & -0.01 & 102.08 & 82.76 & 79.82 & 10 \\
399 & $06-02-09$ & 60 & 780 & None & Sideburn & 0 & 0 & -0.02 & 21.05 & 18.29 & 40.72 & 10 \\
406 & $06-03-09$ & 60 & 300 & None & Sideburn & -0.01 & 0 & -0.02 & 16.26 & 8.59 & 39.77 & 10 \\
407 & $06-15-09$ & 60 & 300 & None & Sideburn & 0 & 0 & -0.01 & 35.01 & 25.64 & 39.97 & 10 \\
408 & $06-15-09$ & 45 & 780 & None & Sideburn & 0 & 0 & -0.01 & 45.37 & 45.25 & 54.73 & 10 \\
\hline \hline
\end{tabular}




\section{Appendix J}

\section{Regression Analysis for Study I - Plain Hood Study}

Table J.1-a: Regression of Log $C_{\text {mouth }}$ with Hood Face Velocity $\left(V_{\text {face }}\right)$ at $V_{\text {cross }}=14 \mathrm{fpm}$

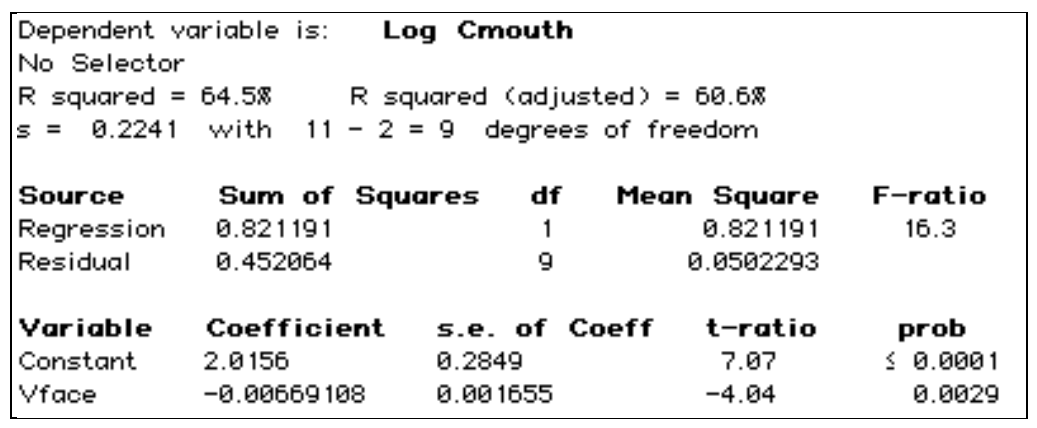

Table J.1-b: Regression of Log $C_{\text {mouth }}$ with Hood Face Velocity $\left(V_{\text {face }}\right)$ at $V_{\text {cross }}=26$ fpm

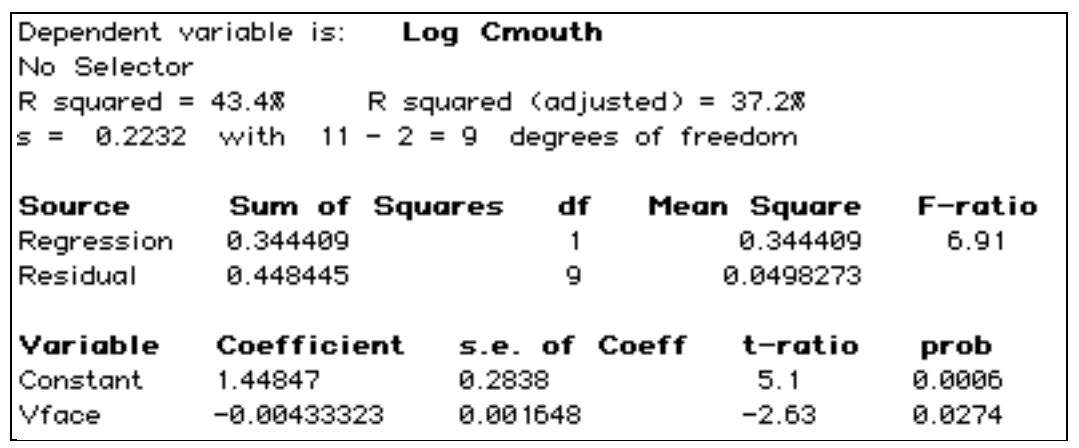

Table J.1-c: Regression of Log $C_{\text {mouth }}$ with Hood Face Velocity $\left(V_{\text {face }}\right)$ at $V_{\text {cross }}=36 \mathrm{fpm}$

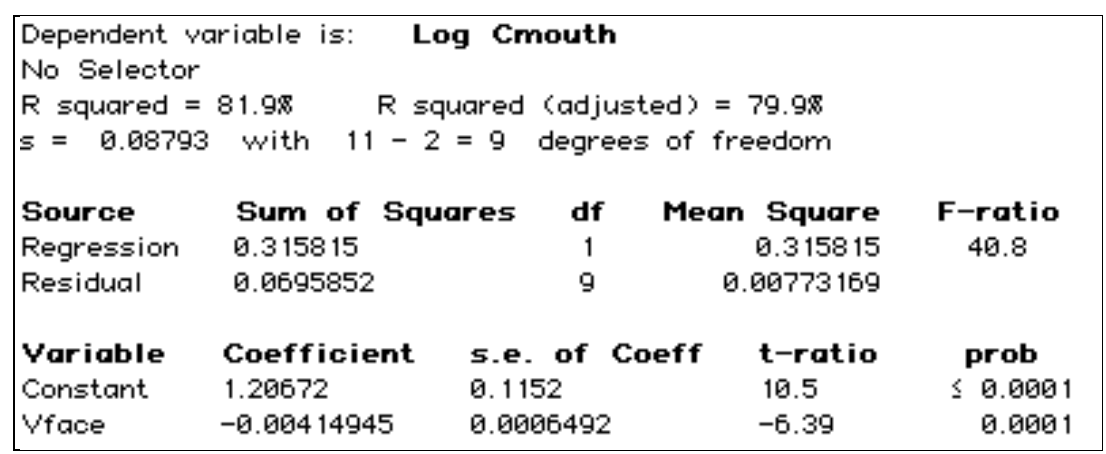


Table J.1-d: Regression of $\log C_{\text {mouth }}$ with Hood Face Velocity $\left(V_{\text {face }}\right)$ at $V_{\text {cross }}=46 \mathrm{fpm}$

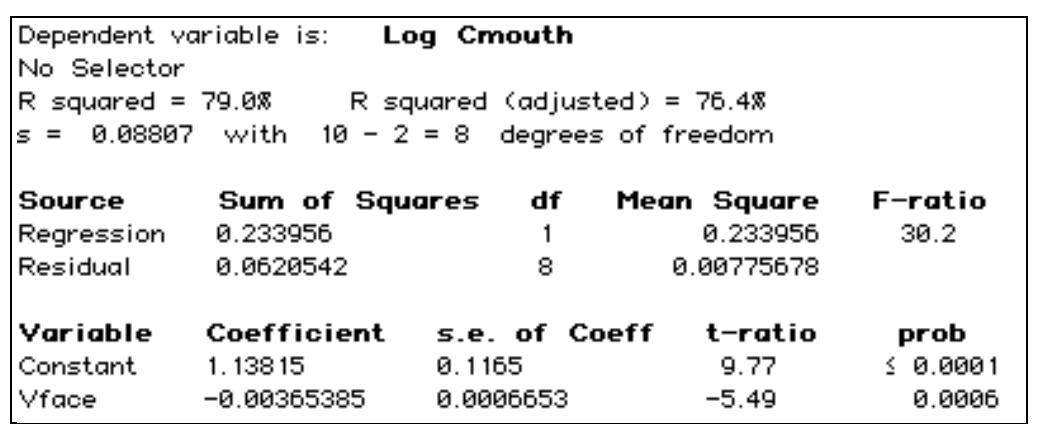

Table J.1-e: Regression of $\log C_{\text {mouth }}$ with Hood Face Velocity $\left(V_{\text {face }}\right)$ at $V_{\text {cross }}=57 \mathrm{fpm}$

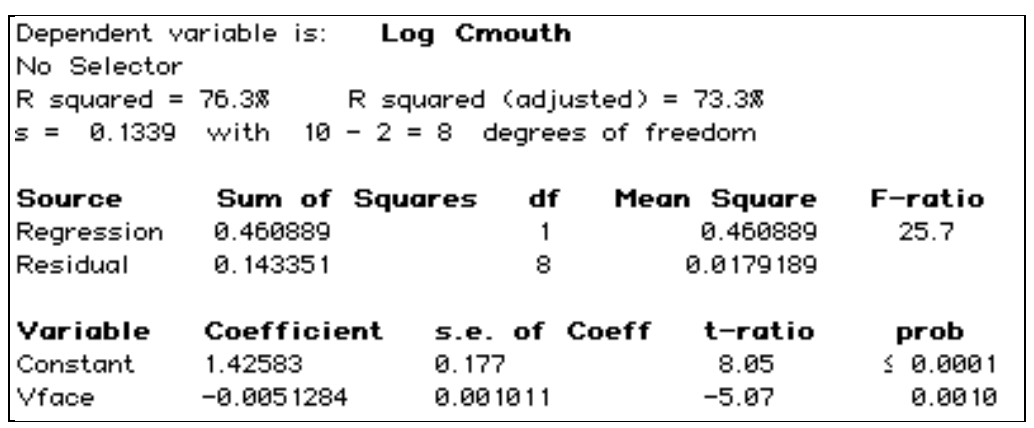


Table J.2-a: Regression of Log $C_{\text {mouth }}$ with Cross-draft Velocity $\left(V_{\text {cross }}\right)$ at $V_{\text {face }}=111 \mathrm{fpm}$

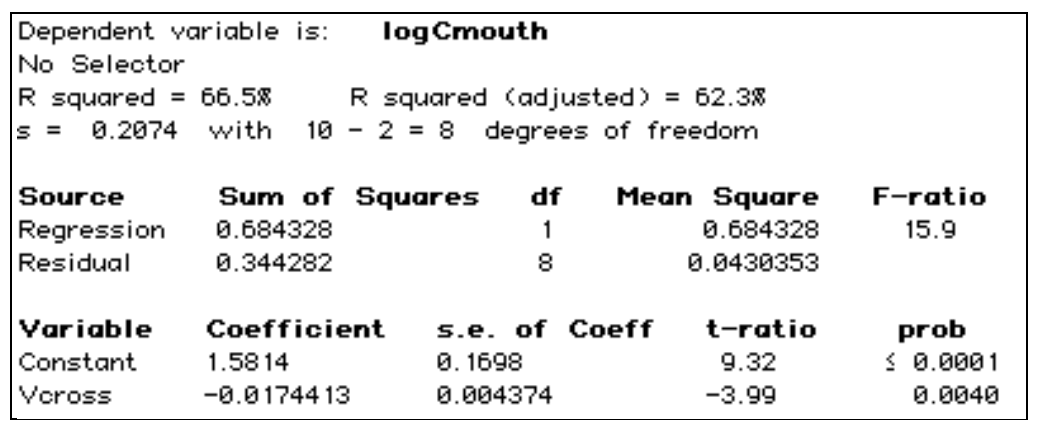

Table J.2-b: Regression of $\log C_{\text {mouth }}$ with Cross-draft Velocity $\left(V_{\text {cross }}\right)$ at $V_{\text {face }}=140 \mathrm{fpm}$

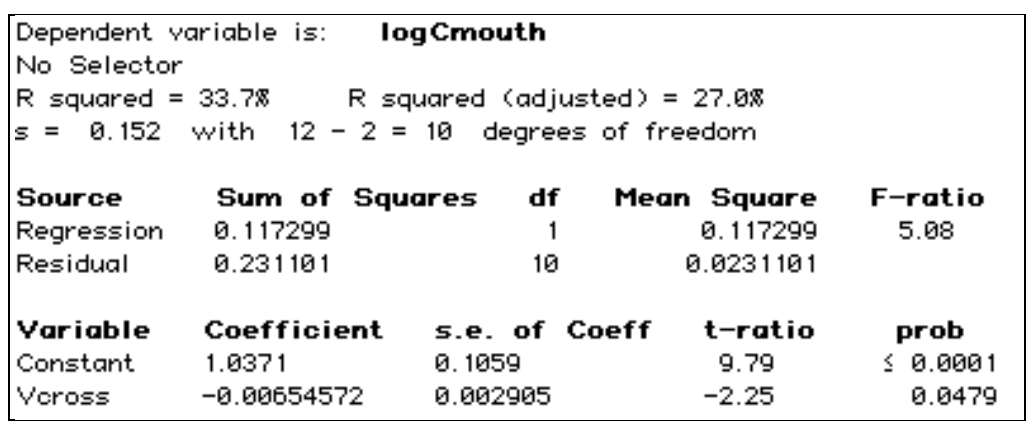

Table J.2-c: Regression of $\log C_{\text {mouth }}$ with Cross-draft Velocity $\left(V_{\text {cross }}\right)$ at $V_{\text {face }}=170 \mathrm{fpm}$

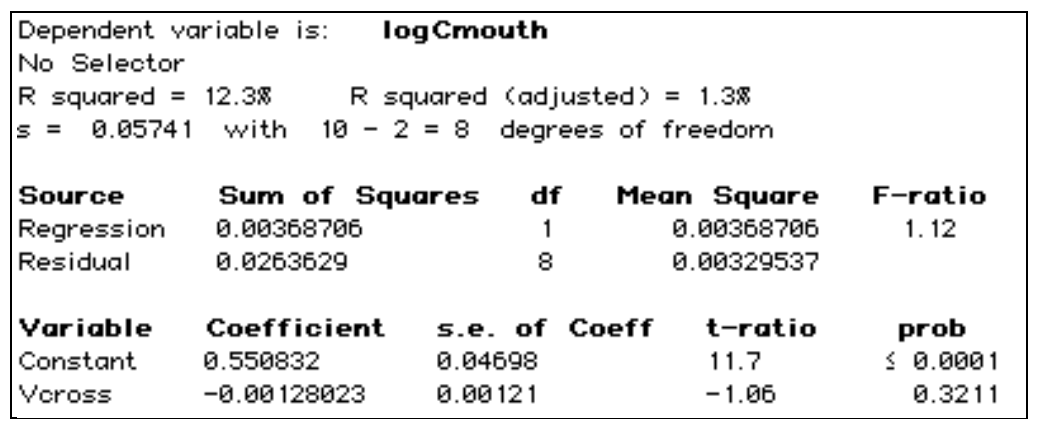


Table J.2-d: Regression of Log $C_{\text {mouth }}$ with Cross-draft Velocity $\left(V_{\text {cross }}\right)$ at $V_{\text {face }}=200 \mathrm{fpm}$

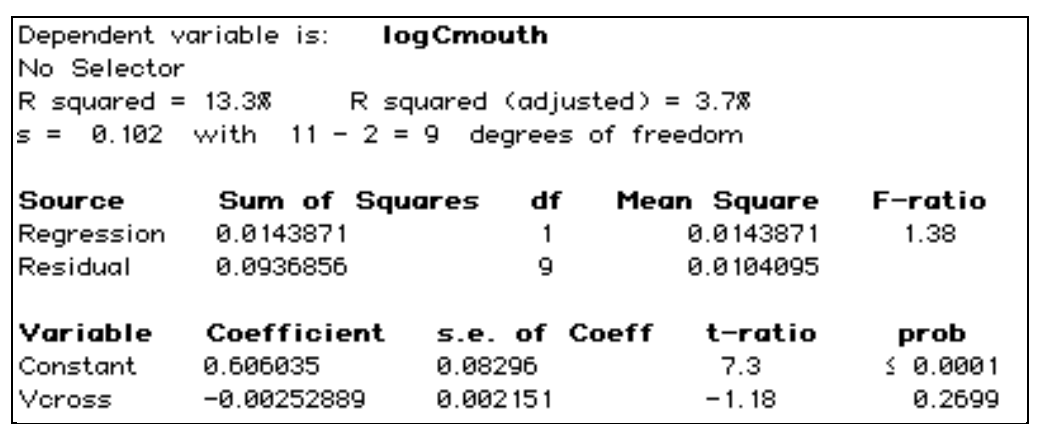

Table J.2-e: Regression of Log $\mathrm{C}_{\text {mouth }}$ with Cross-draft Velocity $\left(\mathrm{V}_{\text {cross }}\right)$ at $V_{\text {face }}=229 \mathrm{fpm}$

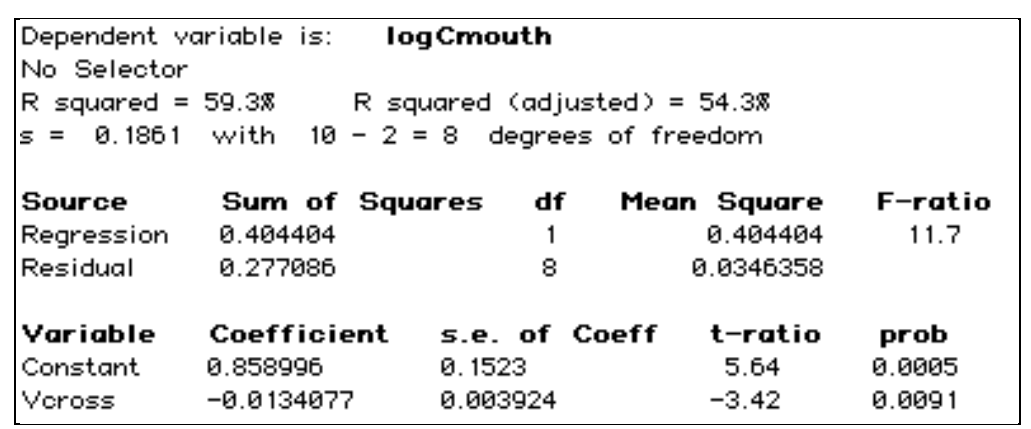

